by Giuliano F. Panzal,2, Leonardo Alvarez ${ }^{3}$, Abdelkrim Aoudia ${ }^{1,2}$, Abdelhakim Ayadi ${ }^{4}$, Hadj Benhallou ${ }^{4,5}$, Djillali Benouar $^{6}$, Zoltan Bus ${ }^{7}$, Yun-Tai Chen ${ }^{8}$, Carmen Cioflan ${ }^{9}$, Zhifeng Ding ${ }^{8}$, Attia El-Sayed ${ }^{10}$, Julio Garcia ${ }^{3}$, Bartolomeo Garofalo $^{11}$, Alexander Gorshkov ${ }^{12}$, Katalin Gribovszki ${ }^{13}$, Assia Harbi ${ }^{4}$, Panagiotis Hatzidimitriou ${ }^{14}$, Marijan Herak $^{15}$, Mihaela Kouteva ${ }^{16}$, Igor Kuznetzov ${ }^{12}$, Ivan Lokmer ${ }^{15}$, Said Maouche ${ }^{4}$, Gheorghe Marmureanu ${ }^{9}$, Margarita Matova $^{16}$, Maddalena Natale ${ }^{11}$, Concettina Nunziata ${ }^{11}$, Imtiyaz A. Parvez ${ }^{17,1}$, Ivanka Paskaleva ${ }^{16}$, Ramon Pico ${ }^{18}$, Mircea Radulian ${ }^{9}$, Fabio Romanelli ${ }^{2}$, Alexander Soloviev ${ }^{12}$, Peter Suhadolc ${ }^{2}$, Gyõzo Szeidovitz ${ }^{7}$, Petros Triantafyllidis $^{14}$, Franco Vaccari ${ }^{2}, 19$.

\title{
Realistic modeling of seismic input for megacities and large urban areas (the UNESCO/IUGS/IGCP project 414)
}

The project addressed the problem of pre-disaster orientation: hazard prediction, risk assessment, and hazard mapping, in connection with seismic activity and maninduced vibrations. The definition of realistic seismic input has been obtained from the computation of a wide set of time histories and spectral information, corresponding to possible seismotectonic scenarios for different source and structural models. The innovative modeling technique, that constitutes the common tool to the entire project, takes into account source, propagation and local site effects. This is done using first principles of physics about wave generation and propagation in complex media, and does not require to resort to convolutive approaches, that have been proven to be quite unreliable, mainly when dealing with complex geological structures, the most interesting from the practical point of view. In fact, several techniques that have been proposed to empirically estimate the site effects using observations convolved with theoretically computed signals corresponding to simplified models, supply reliable information about the site response to non-interfering seismic phases. They are not adequate in most of the real cases, when the seismic sequel is formed by several interfering waves. The availability of realistic numerical simulations enables us to reliably estimate the amplification effects even in complex geological structures, exploiting the available geotechnical, lithological, geophysical parameters, topography of the medium, tectonic, historical, palaeoseismological data, and seismotectonic models. The realistic modeling of the ground motion is a very important base of knowledge for the preparation of groundshaking scenarios that represent a valid and economic tool for the seismic microzonation. This knowledge can be very fruitfully used by civil engineers in the design of new seismoresistant constructions and in the reinforcement of the existing built environment, and, therefore, supply a par- ticularly powerful tool for the prevention aspects of Civil Defense. We present a selection of the main results obtained for the cities of Algiers, Beijing, Bucharest, Cairo, Debrecen, Delhi, Naples, Rome, Russe, Santiago de Cuba, Sofia, Thessaloniki and Zagreb.

\section{Introduction}

The UNESCO-IUGS-IGCP project 414 "Seismic Ground Motion in Large Urban Areas", started in 1997 and terminated in 2001, addressed the problem of pre-disaster orientation: hazard prediction, risk assessment, and hazard mapping, in connection with seismic activity and man-induced vibrations. The major scientific problem has been to handle realistic models on a very detailed level.

We can reduce loss of life and property damage by highly detailed specific prediction of seismic ground motion. With the knowledge of accurate, three-dimensional structures and probable, complex source mechanisms, the detailed ground motion at any site, or all sites of interest, can be determined. To map seismic ground motion we do not have to wait for earthquakes to occur in likely focal regions and then to measure ground motion with an extremely dense set of recording instruments; instead, with the knowledge above we can compute these seismograms from theoretical considerations. Thus, a complete database for all sites and predicted focal mechanisms can be constructed immediately; no delay is necessary while we wait for experimental evidence and recordings. This database would then, naturally, be updated continuously by comparison with incoming new experimental data.

The general plan (Panza et al., 1999a) included a group of Large Urban Areas and Megacities representative of a broad spectrum of seismic hazard severity, that require different efforts to reach a satisfactory level of preparedness. We have deliberately chosen objects not situated very close to known seismogenic zones. In fact the condition of being some tens of kilometers from the epicenter allowed us an optimum exploitation of the results of microzoning, and filled in a gap in preparedness, since, usually, most of the attention is focused on very near seismogenic zones.

An innovative modeling technique is the common tool to the entire project and, using first principles of physics about wave generation and propagation in complex media, takes into account source, propagation and local site effects. Therefore it is not necessary to resort to convolutive approaches, that have been proven to be quite unreliable, mainly when dealing with complex geological structures. These techniques supply reliable information about the site response to non-interfering seismic phases, but they are not ade- 
quate in most of the real cases when the seismic sequel is formed by several interfering waves (Panza et al., 2000).

The estimation of the seismic ground motion in a given urban area before the occurrence of a damaging earthquake requires the detailed knowledge of both the subsurface structure within the city and of the probable location and characteristics of seismic sources around it. Detailed numerical simulations play an important role in the computation of ground motion, especially in areas of complex geology, because they can provide realistic synthetic waveforms at places where no recordings are available. Synthetics are compared with observations wherever instrumental data are available, in order to validate and, when needed, to further improve the theoretical techniques.

\section{Method}

The mapping of the seismic ground motion due to the earthquakes originating in a given seismogenic zone can be made by measuring seismic signals with a dense set of recording instruments when a strong earthquake occurs or/and by computing theoretical signals, using the available information about tectonic and geological/geotechnical properties of the medium, where seismic waves propagate. Strong earthquakes are very rare phenomena and it is therefore very difficult (practically impossible in the near future) to prepare a sufficiently large database of recorded strong motion signals that could be analyzed in order to define generally valid ground parameters, to be used in seismic hazard estimations.

While waiting for the enlargement of the strong motion data set, a very useful approach to perform immediate microzonation is the development and use of modeling tools based, on one hand, on the theoretical knowledge of the physics of the seismic source and of wave propagation and, on the other hand, exploiting the rich database about the geotechnical, geological, tectonic, seismotectonic, historical information already available (e.g. see Field, 2000, Panza et al., 2000).

The initial stage of our work required the collection of all available data concerning the shallow geology, and the construction of cross-sections along which to model the ground motion. This work is by its nature multidisciplinary since information is requested from different disciplines, as seismology, history, archaeology, geology a)

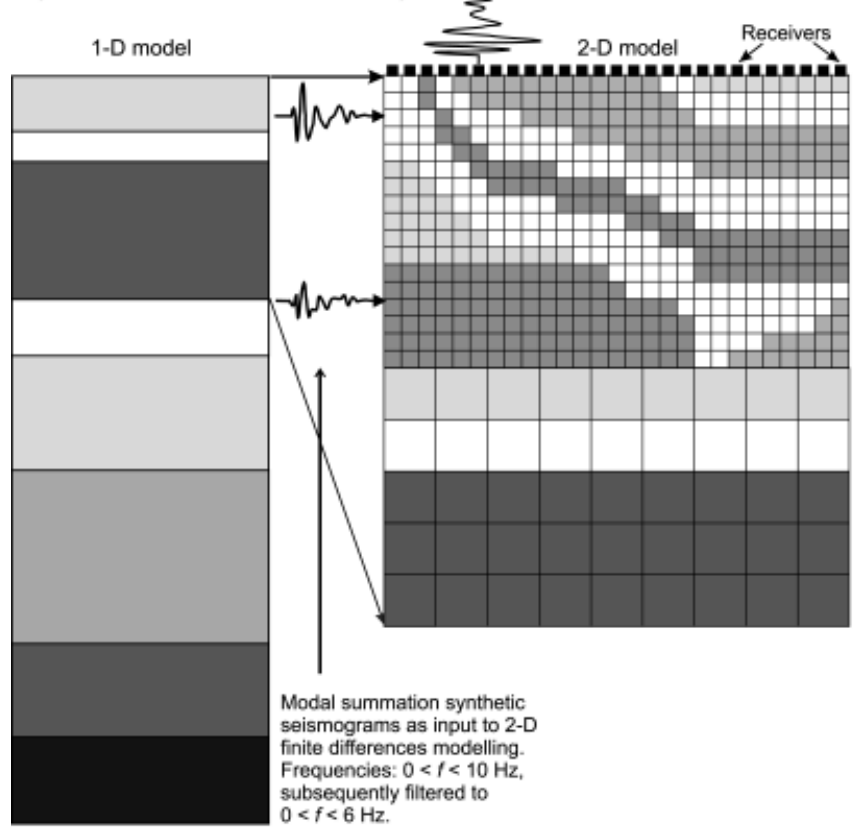

and geophysics to give engineers reliable building codes. The realistic modeling of ground motion requires, in fact, the simultaneous knowledge of the geotechnical, lithological, geophysical parameters and topography of the medium, on one side, and tectonic, historical, paleoseismological, seismotectonic models, on the other, for the best possible definition of the probable seismic source.

The computation of complete synthetic seismograms has been carried out by a hybrid method consisting of two parts: modal summation and finite differences modeling. The flow chart of the algorithm is given in Figure 1.

Modal summation technique for synthesizing realistic seismograms has its roots in the middle of the 20th century when Thomson (1950) and Haskell (1953) proposed a matrix method to efficiently compute the dispersion of surface waves in multilayered media. The method has been modified by many researchers during the second half of the century (e.g. Schwab and Knopoff, 1972; Florsch et al., 1991). The main problem in practice was the loss of precision when dealing with higher modes at high frequencies, which was solved by Schwab (1970) and Schwab et al. (1984). Introducing the seismic source via the formalism proposed by Ben-Menahem and Harkrider (1964), Panza (1985) gave an example of Rayleigh wave computation for frequencies up to $1 \mathrm{~Hz}$ for continental and oceanic models consisting of 70 layers and extending to depths of $1100 \mathrm{~km}$. The efficient Rayleigh wave computation for frequencies up to $10 \mathrm{~Hz}$ has been carried out by Panza and Suhadolc (1987). Florsch et al. (1991) gave the solution for Love and SH-waves. Although the modal summation offers an efficient way to obtain realistic estimates of ground motion, the assumption of horizontal isotropic layering is often inadequate. This is true in cases when the parameters used to define the properties of the media through which the seismic waves propagate vary rapidly at horizontal distances comparable to the wavelengths in question (laterally heterogeneous media). In such cases other numerical methods to solve the partial differential equations of motion - such as finite differences, finite elements, pseudospectral or boundary methods - are better suited for the job. The discussion on advantages and disadvantages of those methods are presented in Panza et al. (2000). The main drawback of those methods is that they are still very demanding regarding the processor power and memory, which limits the lengths of profiles along which the seismograms are c)

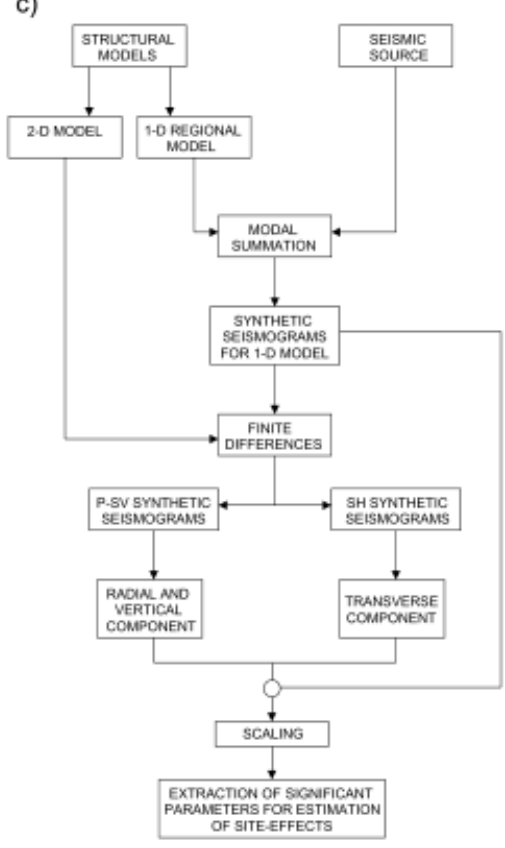
computed. The hybrid method as developed by Fäh et al. (1990), Fäh (1991; 1992) and Fäh et al. (1993a) combines the advantages of both approaches - the modal summation (Panza, 1985; Vaccari et al., 1989; Florsch et al., 1991; Romanelli et al., 1996) and finite differences (Alterman and Karal, 1968; Boore, 1972; Kelly et al., 1976; Virieux, 1984; 1986; Levander, 1988)

In the hybrid method, modal summation is initially applied along the bedrock (1D) model that represents the average path between the assumed source and the local, laterally heterogeneous (2D) structure beneath the area of interest. Double-couple point source of seismic waves is assumed, described by the strike and dip of the causative fault, its rake and the depth of focus. The Earth's model is defined as a

Figure 1. Schematic representation of the hybrid technique. The modal summation is applied considering stack of horizontal layers, each the bedrock model (a) to compute the input signals for the laterally varying part (b) where signals are of which is characterized by the propagated by finite differences numerical modeling to a set of sites on the surface. (c) Flow chart of the longitudinal and transversal algorithm. 
wave velocity within the layer, the density, thickness and the Q-factor controlling the anelastic attenuation. The seismograms are computed for frequencies up to $5-10 \mathrm{~Hz}$.

These signals are numerically propagated through the laterally varying local structure by the finite differences method. The finitedifferences grid is formed first, approximating the laterally varying model. A grid-step needs to be chosen obeying the empirical condition that at least 10 points per minimum wavelength are required. Prior to computations, a test is made by comparing computed synthetic accelerograms both by modal summation and by the hybrid method assuming the bedrock model along the whole length of the profile. If the outputs do not differ significantly (about less than 5\%), this indicates that the finite differences grid is properly set-up. The amount of discrepancy also gives us the order of numerical uncertainties involved. Synthetic seismograms of the vertical (VER), transversal (TRA) and radial (RAD) components of ground motion are computed at a predefined set of points at the surface. After scaling the signal's spectra to the assumed seismic moment by using the curves proposed by Gusev (1983) as reported in Aki (1987), the ratios of peak ground acceleration, PGA(2D)/PGA(1D), and the response spectra ratio, RSR, i.e. the response spectra computed (at $5 \%$ damping) from the signals synthesized along the laterally varying section normalized by the response spectra computed from the corresponding signals, synthesized for the bedrock reference regional model, are extracted from the computed seismograms. Other parameters of interest can be considered as well.

\section{Cities}

1. A large quantity of descriptions of earthquakes that have been felt in Rome is available (Molin et al., 1995). The realistic modeling of the seismic input gives a simple and natural explanation of the damage distribution observed as a consequence of the January 13, 1915 Fucino earthquake - one of the strongest events that have occurred in Italy during the last century (Intensity XI on the MCS scale). The well-documented distribution of damage in Rome, caused by the Fucino earthquake, is, in fact, successfully compared by Fäh et al. (1993b) with the results of a series of different numerical simulations, using PGA and Arias intensity, W. Since the correlation is good between PGA, W and the damage statistics, it has been possible to extend the zoning to the entire city of Rome, thus providing a basis for the prediction of the expected damage from future strong events.

The highest values of RSR are observed at the edges of the sedimentary basin of the Tiber, and strong amplifications are observed in the Tiber's river bed. This is caused by the large amplitudes and long duration of the ground motion due to (1) low impedance of the alluvial sediments, (2) resonance effects, and (3) excitation of local surface waves (Fäh et al., 1993b). A preliminary microzoning map has been produced by Vaccari et al. (1995). The microzonation map and the response spectra, corresponding to the three main seismogenic zones in Rome, are shown in Figure 2.

2. Zagreb, the capital and the largest city in Croatia, has nearly 1 million inhabitants, which is about $1 / 5$ of the country's population. Zagreb epicentral area is the most active one in the continental part of Croatia. The largest known earthquake in the area occurred in 1880 in Kasina, about $12 \mathrm{~km}$ to the NE from the center of the city. It was felt with the maximum intensity of VIII (MCS), and its magnitude is estimated to $M$ 6.0. Without direct strong motion observations, seismic zoning of the city area can only be accomplished by way of deterministic modeling of seismic input. Detailed modeling of ground motion has been performed along a profile running through the assumed epicenter and the very center of the city (Figure 3 ). In constructing the models describing the subsurface structures, all available information on the local geological and geotechnical conditions along the profile were taken into account.

The assumed source parameters are chosen to conservatively approximate the Kasina earthquake of $1880\left(h=5 \mathrm{~km} ; \mathrm{M}_{\mathrm{L}} \approx 6.0\right)$.
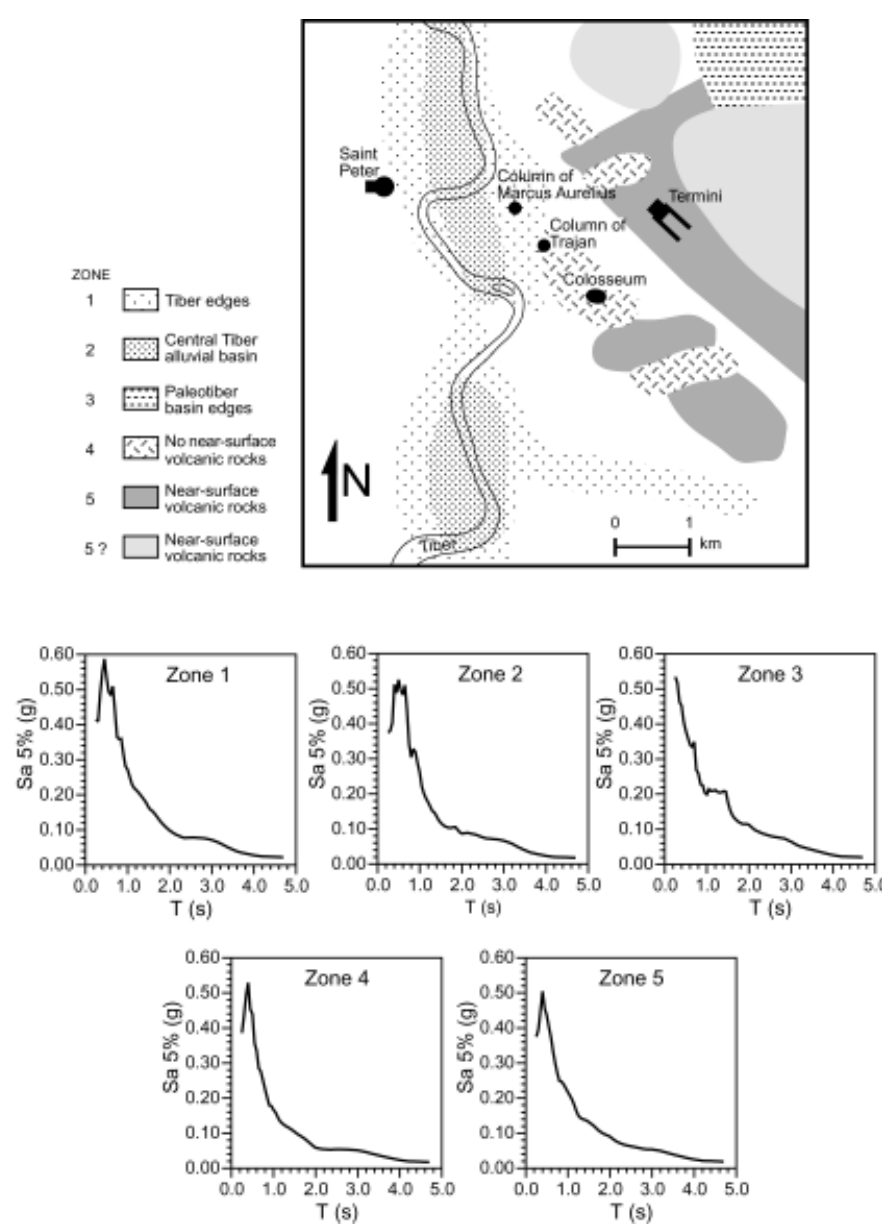

Figure 2. Microzonation map of Rome (top), based on the computation of realistic seismic ground motion due to three seismogenic zones around Rome: the Fucino area, the Alban Hills and the Carseolani Mountains. For the five zones identified in the map, the maximum absolute spectral acceleration (5\% damping) is given (bottom).

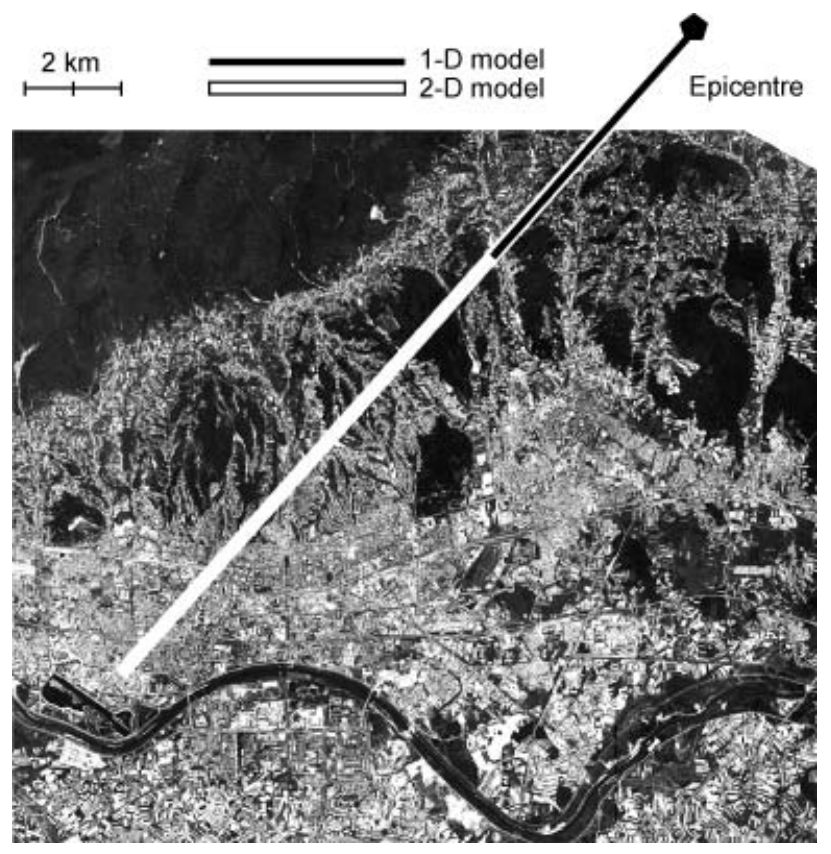

Figure 3. Satellite image of the Zagreb area, with the profile superimposed. 
The adopted causative fault is characterized by a strike of $60^{\circ}$, dip of $80^{\circ}$ and rake of $120^{\circ}$. For this pilot study a scaled point source is assumed. The computation of complete synthetic accelerograms (up to the frequencies of $6 \mathrm{~Hz}$ ) has been carried out by the hybrid method. The waveform is modeled by propagating the input signal (obtained by modal summation using the bedrock structure from Markusiić, et al., 2000) through the 2-D part of the model by a finite differences algorithm. The 2-D part (Figure 4, bottom) is $12 \mathrm{~km}$ long, $1.75 \mathrm{~km}$ deep, and consists of layers of silts, conglomerates, clays, sandstones and limestones in the NE part, while marls, sands, clays and recent alluvial deposits predominate in the SW part. The thickness of the thinnest alluvial layer considered is 10 meters. The active, steeply dipping fault which passes through the center of the city (along the main street, Ilica) is found at the epicentral distance of about $15 \mathrm{~km}$.
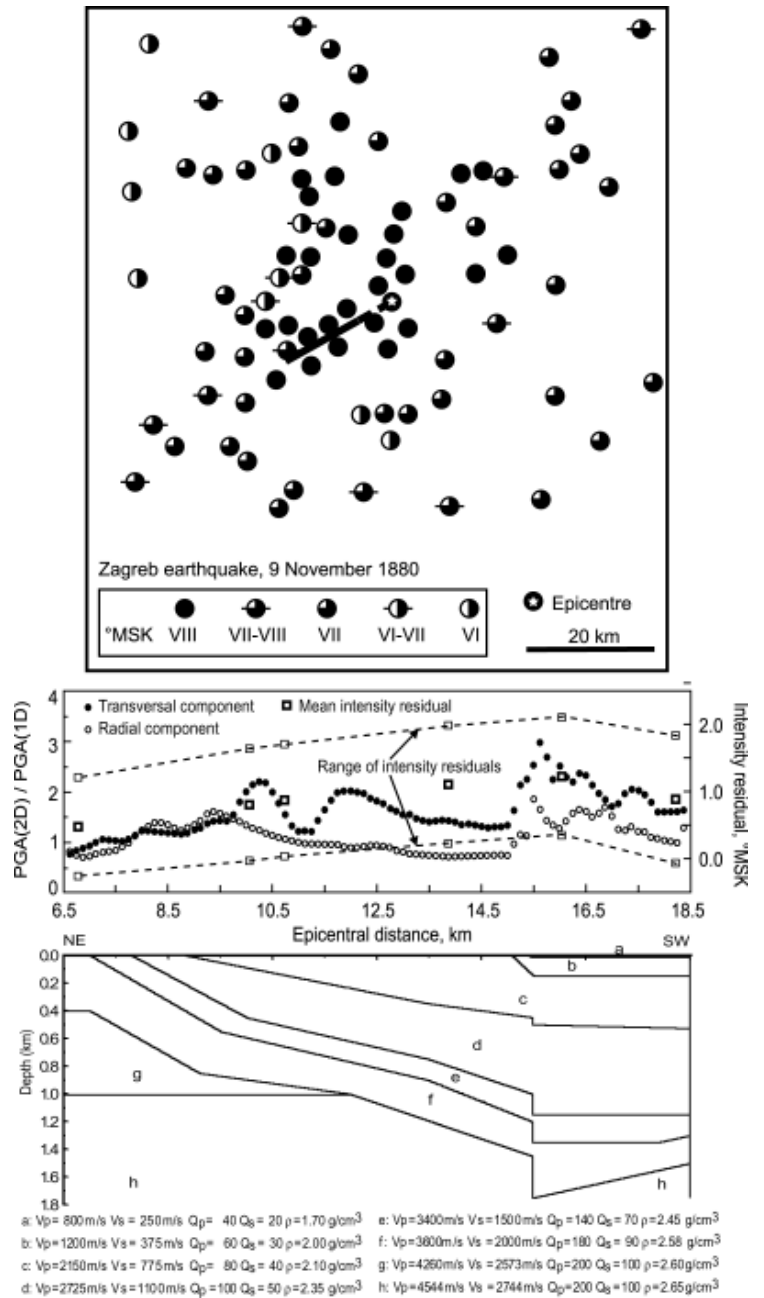

Figure 4. Top: A part of the intensity map of the 1880 Zagreb earthquake (Archives of the Department of Geophysics, Zagreb). The profile from Figure 3 is shown by dashed (1-D part) and solid line (2-D part). Middle: Horizontal PGA amplification (left scale, heavy and light) and intensity residuals (right scale, solid and empty squares). The residuals are computed relative to the expected intensities along the profile using the Sponheuer (1960) intensity attenuation relation $I=I_{0}-3 \log (R / h)-3 \mu \alpha(R-h)$. Here $I_{0}, R, h$ and $\alpha$ are epicentral intensity, hypocentral distance, source depth, and coefficient of macro-seismic attenuation, respectively, and $\mu=\log e$. The light squares connected by dashed lines mark the range of intensity residuals that are computed when all quantities are let to vary within the reasonable limits: $5 \mathrm{~km} \leq \mathrm{h}$ $\leq 10 \mathrm{~km}, I_{0}=8 \pm 0.25^{\circ} \mathrm{MSK}, 0.005 \mathrm{~km}^{-1} \geq \alpha \geq 0.0005 \mathrm{~km}^{-1}, I=I_{o b s}$ $\pm 0.25^{\circ} \mathrm{MSK}, I_{o b s}$ being the observed intensity as plotted on the map. Solid squares are mean residuals. Bottom: Laterally varying part (2-D) of the model along the profile as shown in Figure 3.
P-SV waves (radial and vertical components) and SH (transverse component) synthetic accelerograms are computed at 96 sites on the free surface along the $12 \mathrm{~km}$ long, laterally heterogeneous cross-section beneath the city. The reference seismic signals are calculated at the same positions, but using the bedrock model.

The obtained amplification profile, PGA(2D)/PGA(1D), of the horizontal motion is shown in Figure 4. For both components of motion peaks are found at sites near the fault (epicentral distance of about $15 \mathrm{~km}$ ). This computed amplification of PGA is consistent with the distribution of intensities reported for the 1880 earthquake (Figure 4) which exhibits a uniform band of intensity I = VIII (MSK) stretching from the epicenter southwestwards along the investigated profile. Figure 4 also shows intensity residuals (and their possible range, taking all associated uncertainties into account) along the profile trace, estimated relative to the isotropic macroseismic field, assuming valid the Sponheuer (1960) intensity attenuation law. Despite the low resolution, which is inherent to all analyses dealing with intensities, the residuals are seen to roughly follow the pattern of horizontal PGA amplification.

3. Debrecen is the second largest city of Hungary, after Budapest, with a population of about 300,000 people. It is located in the eastern part of the country not far from the Romanian border. The Êrmellék seismoactive region is the main quake source, which has to be taken into account for microzonation purposes. The macroseismic effects observed at the site of Debrecen in 1829 and 1834, when two devastating earthquakes occurred in the Êrmellék seismoactive region, correspond to MSK intensity between VI and VII (Figure 5). The tectonic lineament, so called "mobile zone", developed between the hill country of Szilágyság and the Great Hungarian Plain, as well as the Sárrét depression (Szeidovitz and Gribovszki, 2002). The continuation of this lineament in the Romanian territory is called Gálospetri graben. We assume that the aforementioned two earthquakes must have occurred in this deep graben.

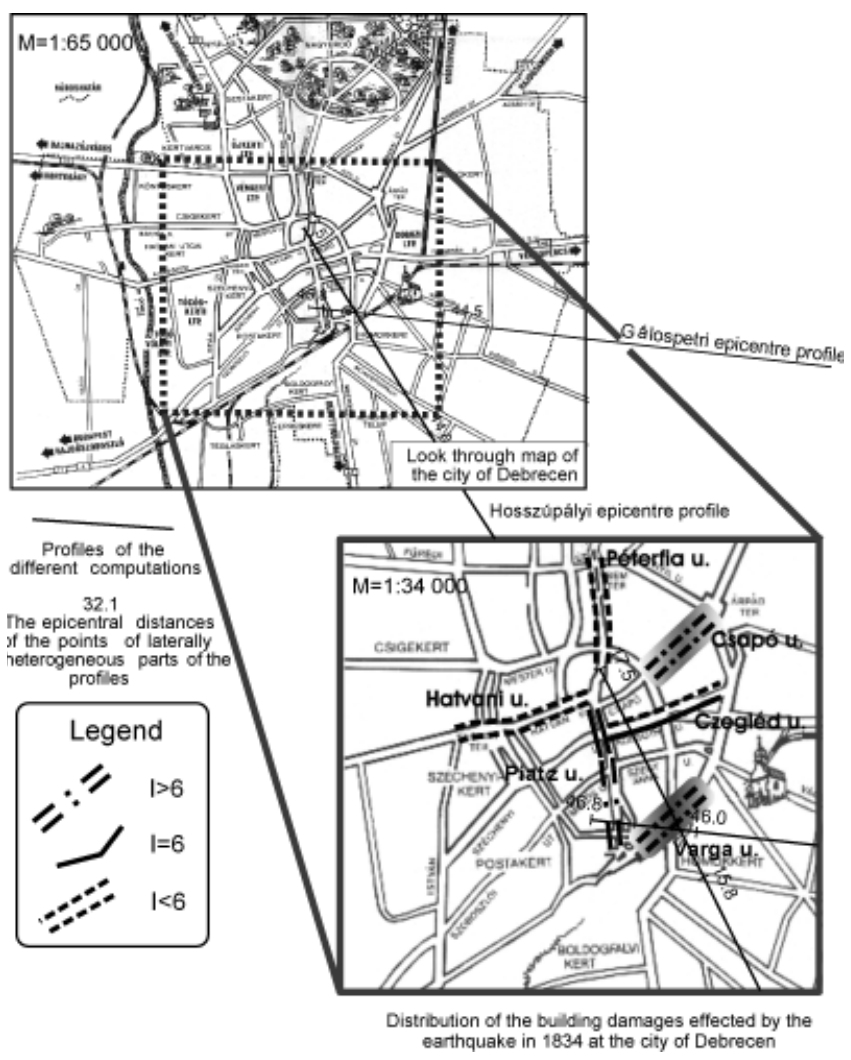

Figure 5. Map of the inner part of Debrecen with indication of the available intensity data.

The main task is to define a scenario corresponding to an earthquake of the same size as the destructive event that occurred on 15th of October 1834. From the analysis of the felt intensity (up to IX) it 
has been possible to estimate a magnitude ranging from 5.5 to 7.1 (Szeidovitz, 2000). The supposed parameters of the source mechanism are dip: $\delta=70^{\circ}$; rake: $\lambda=0^{\circ}$ (strike-slip); focal depth $=10 \mathrm{~km}$; $\mathrm{M}=6.0$. Keeping fixed the dip and rake, we have considered two sources, one coinciding with the original epicenter of the earthquake of 1834 (Gálospetri, strike-receiver angle of $15^{\circ}$, the other close to Hosszúpályi village (strike-receiver angle of $165^{\circ}$ ).

The laterally varying part of the model compiled on the basis of local geology, available geotechnical measurements, especially the knowledge of many shallow well loggings can be seen in Figures 6 and 7 .
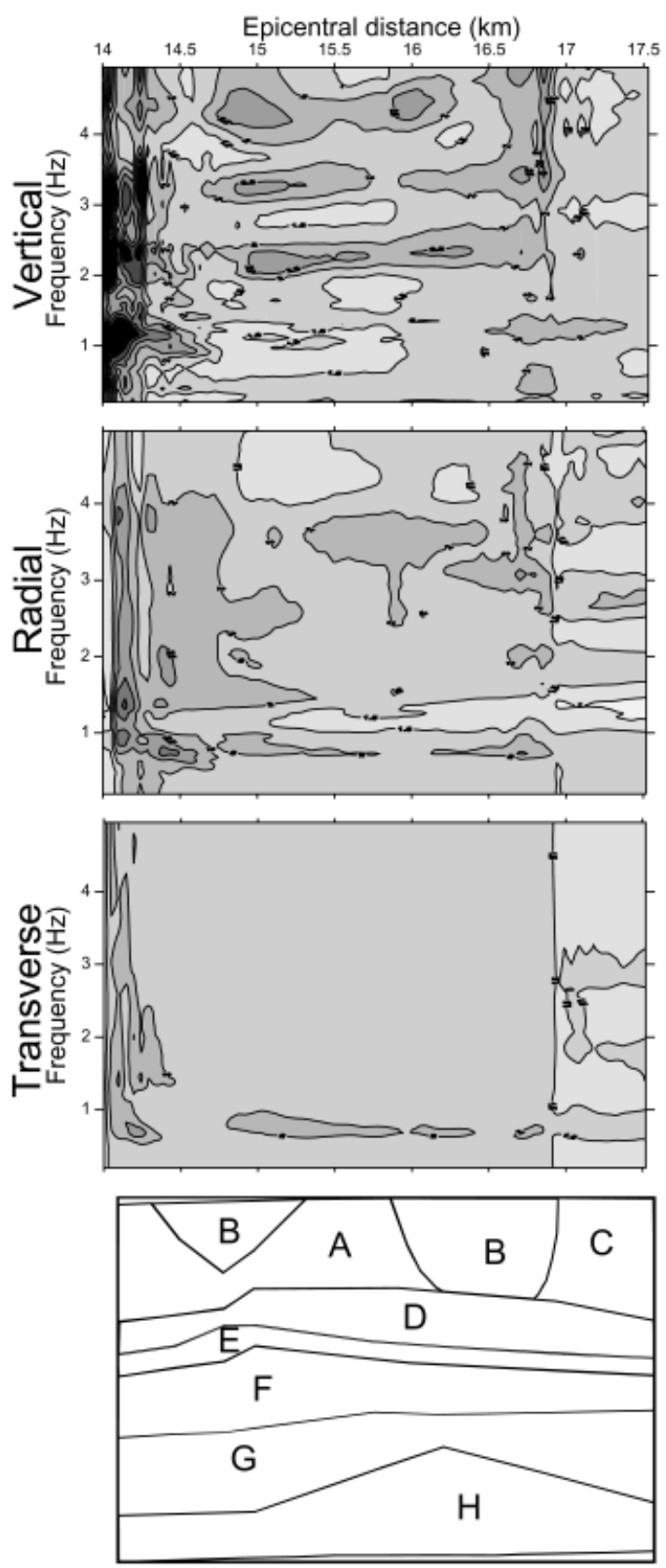

\begin{tabular}{|c|c|c|c|c|c|c|}
\hline & layers & 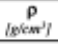 & 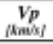 & $\underset{[\mathrm{kmos}]}{V_{\delta}}$ & $Q p$ & $Q_{s}$ \\
\hline & silty sand & 1.7 & 0.8 & 0.2 & 40 & \\
\hline $\begin{array}{l}\mathrm{C} \\
\mathrm{D}\end{array}$ & $\begin{array}{l}\text { sandyy clay } \\
\text { clay }\end{array}$ & $\begin{array}{l}1.6 \\
1.6\end{array}$ & 0.9 & 0.3 & $\begin{array}{l}40 \\
40\end{array}$ & $\frac{20}{20}$ \\
\hline E & sand, clayed sand & 1.8 & 1.2 & 0.4 & 40 & 20 \\
\hline $\mathbf{F}$ & clayed sand & 1.8 & 1.3 & 0.7 & 60 & 30 \\
\hline G & silty sand & 1.9 & 1.6 & 0.9 & 60 & 30 \\
\hline H & Upper Pannonian clay & y 2.0 & 2.1 & 1.2 & 80 & 40 \\
\hline
\end{tabular}

Figure 6. RSR (5\% damping) versus frequency (Epicenter Hosszúpályi).
When the epicenter is in Hosszúpályi, the length of the whole profile between the epicenter and the city of Debrecen is $17.5 \mathrm{~km}$ long, of which the heterogeneous (local model, section I) part is 3.5 $\mathrm{km}$ long. When the epicenter is in Gálospetri, the length of the whole profile between the epicenter and the city of Debrecen is $46.8 \mathrm{~km}$, of which the heterogeneous (local model, section II) part is $2.3 \mathrm{~km}$ long.

$\mathrm{P}-\mathrm{SV}$ (radial and vertical components) and SH (transversal component) synthetic displacement time series, velocity time series and accelerograms are computed along the local models, at 99 sites
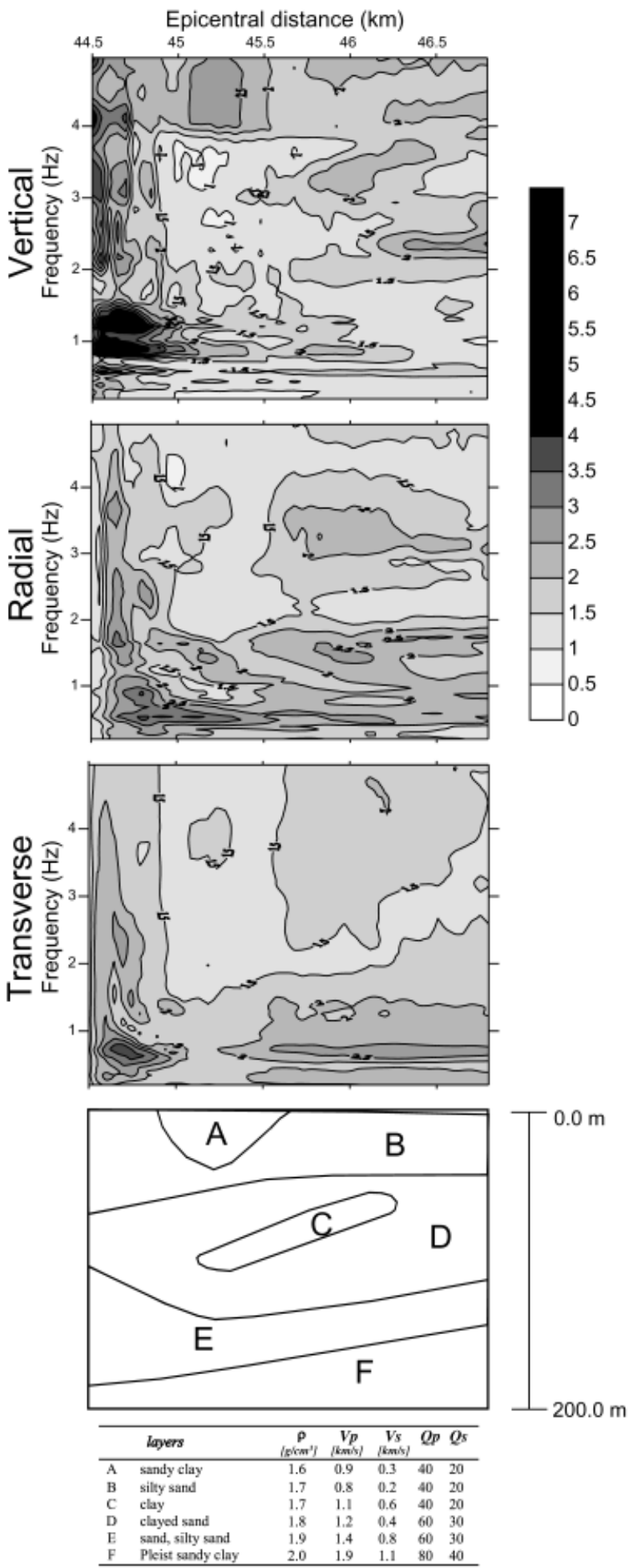

Figure 7. RSR (5\% damping) versus frequency (Epicenter Gálospetri). 
when the source is in Hosszúpályi and at 97 sites when the source is in Gálospetri. The RSR (5\% damping) along the profiles are shown in Figures 6 and 7. For both sources the RSR maximum values (2.5) are seen in the horizontal components, at the end of both profiles and for frequencies below $1 \mathrm{~Hz}$. This means that the multi-storey buildings at that part of Debrecen suffer a higher seismic hazard than the lower ones. Because of this, if an earthquake similar to the event of 1834 would occur in a residential or industrial area with tall buildings, it could cause much larger damage (larger macroseismic intensity) than the one caused by the 1834 event, which occurred when only single-storey buildings existed in Debrecen.

In the case of the Hosszúpályi epicenter, in the city center the trend of the RSR values is in good agreement with the observed decrease of the macroseismic intensity with increasing epicentral distance, from the 1834 Êrmellék earthquake epicenter. Accordingly to the relation proposed by Panza et al. (1999b), the design ground acceleration (DGA) values, between 0.097 and $0.090 \mathrm{~g}$, corresponding to Gálospetri epicenter, agree with the higher than VI (MSK) macroseismic intensity, which was established from the assessments of damages' records of the 1834 event.

4. The numerical synthesis of ground motion, that takes into account source, wave propagation path and local site geology, is particularly useful for the microzonation of Bucharest city, the capital of Romania. In fact there is a priori good knowledge on the location and focal mechanism of the seismic source affecting the city (Vrancea source), and a great amount of information about the geological and geotechnical properties at the site. The few instrumental data recorded in case of recent Vrancea earthquakes are very important to validate the synthetic computations.

In the case of Bucharest, the computations are made in a frequency range up to $1 \mathrm{~Hz}$, which, from the engineering point of view, concerns mainly the built environment characterized by long free periods. The synthetic seismic signals are computed for three recent, strong, intermediate-depth Vrancea earthquakes (August 30, 1986: $\mathrm{h}=133 \mathrm{~km}, \mathrm{Mw}=7.1$; May 30, 1990: $\mathrm{h}=74$ $\mathrm{km}, \mathrm{Mw}=6.9$ and May 31, 1990: $\mathrm{h}=87 \mathrm{~km}, \mathrm{Mw}=6.4)$ along three representative profiles crossing the Bucharest area (Figure 8 ). The RSR, for $5 \%$ damping, along the investigated profiles are shown in Figures 9, 10 and 11.

The analysis of the characteristics of the computed response spectra, in correlation with the geological features of the shallow structure, results in a preliminary seismic zonation of the city into

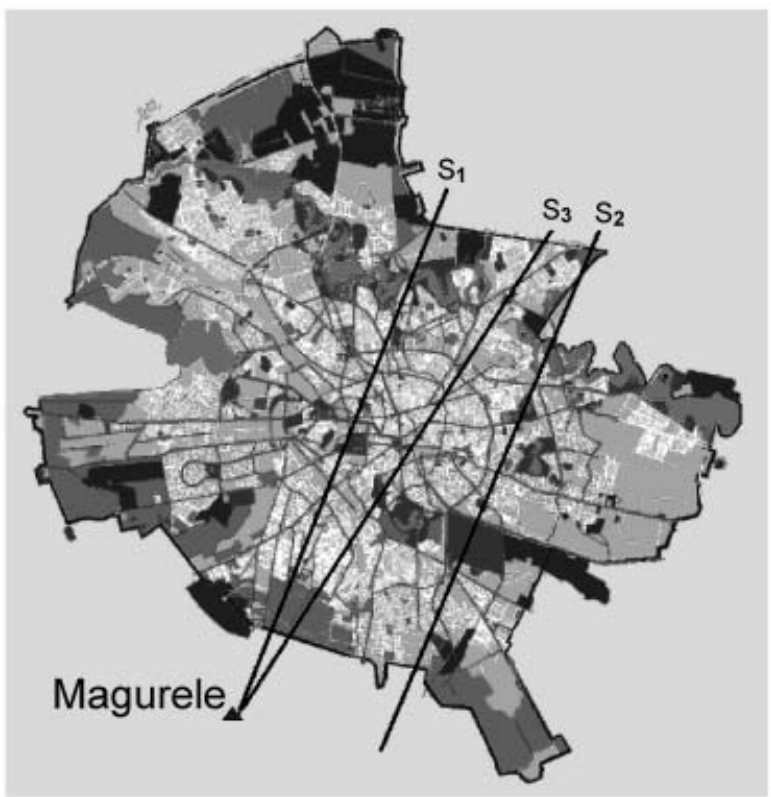

Figure 8. Map of Bucharest city with the positions of the profiles. The reference signal for calibration of the numerical computations is from Magurele seismic station.
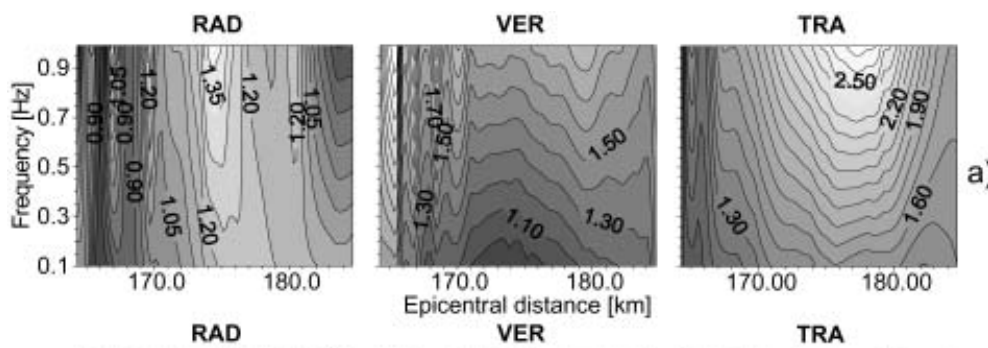

a)
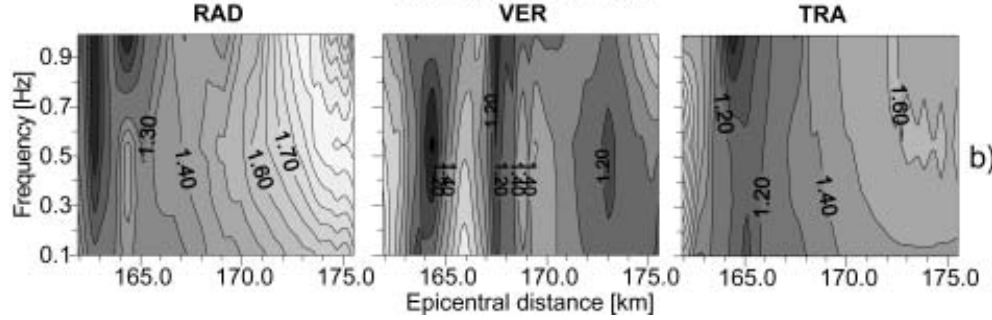

Figure 9. RSR versus frequency and epicentral distance for $S_{1}($ a) and $\mathrm{S}_{2}$ (b) profiles (Figure 8) in the case of May 30, 1990, displayed separately for the radial component (RAD), for the vertical component (VER) and for the transverse one (TRA).
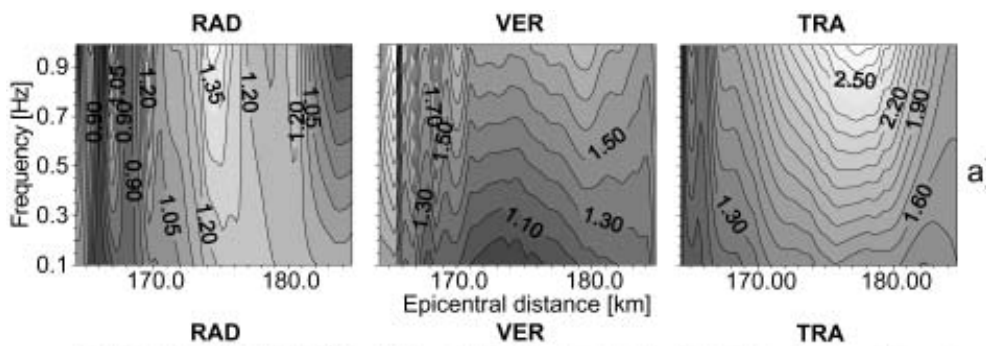

a)
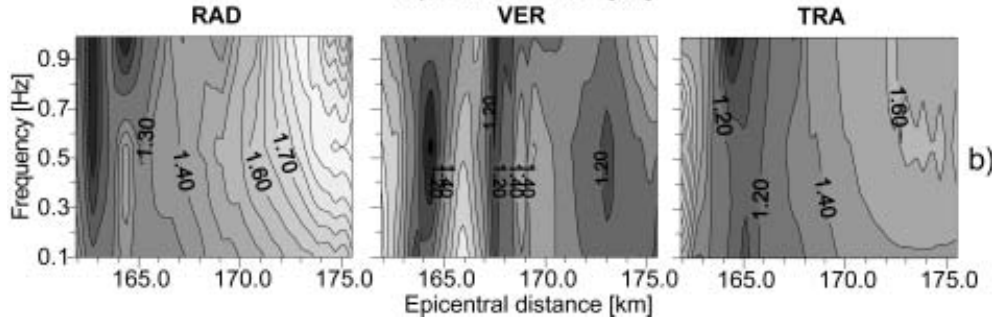

Figure 10. The RSR along $S_{3}$ (Figure 8) versus frequency and epicentral distance simulated for May 30, 1990 earthquake in the case of a structure with horizontal layers (a) and the case of the more realistic structure with tilted layers $(b)$.
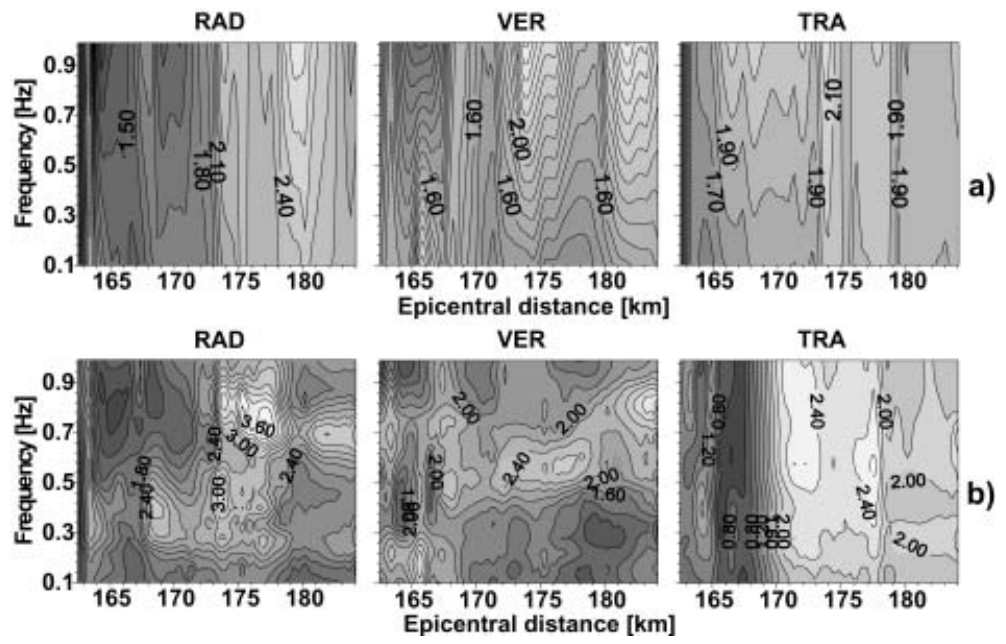

Figure 11. The RSR along $S_{2}$ (Figure 8) simulated for the August 30, 1986 (a) and May 31, 1990 (b) events. 
five zones (Figure 12). The pertinent, characteristic response spectra are given in Figure 13. They show a typical maximum response of about $0.2 \mathrm{~g}$ around $1.5 \mathrm{~s}$ period ( $0 \%$ damping) and the highest value $(0.3 \mathrm{~g})$ is obtained for the zone V. The RSR (5\% damping) for the zones defined in Figure 12 are given in Figure 14.

The site amplification estimated for different earthquakes, shows different amplification pattern for each ground motion component (transversal, radial, vertical) which all contribute signifi-

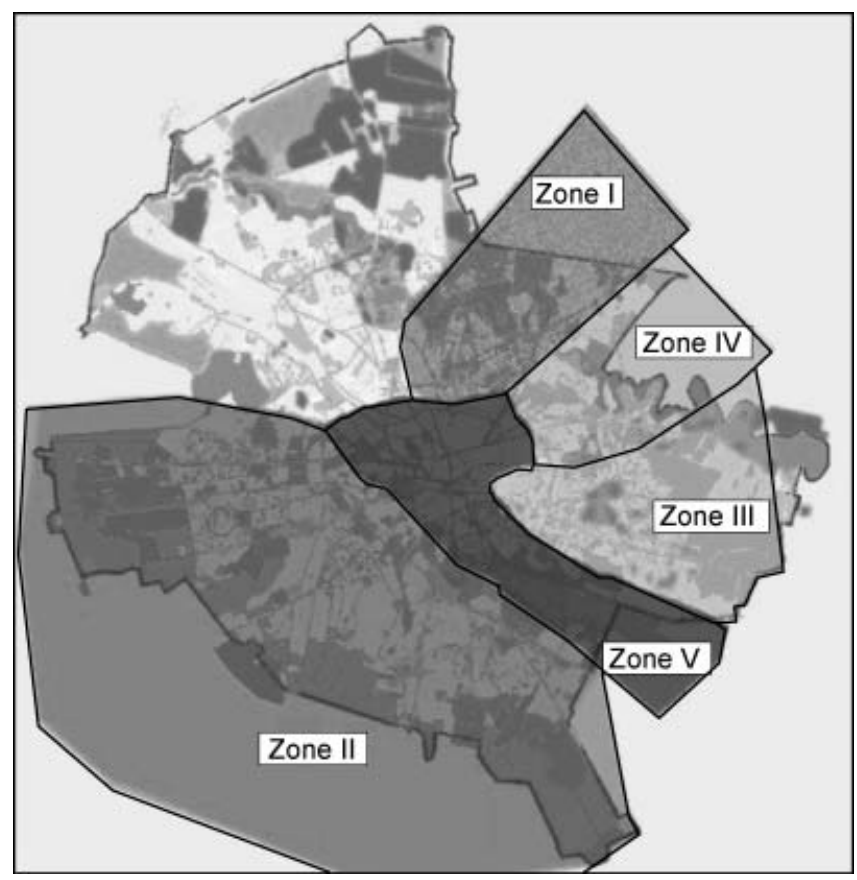

Figure 12. Preliminary seismic zonation map of Bucharest.

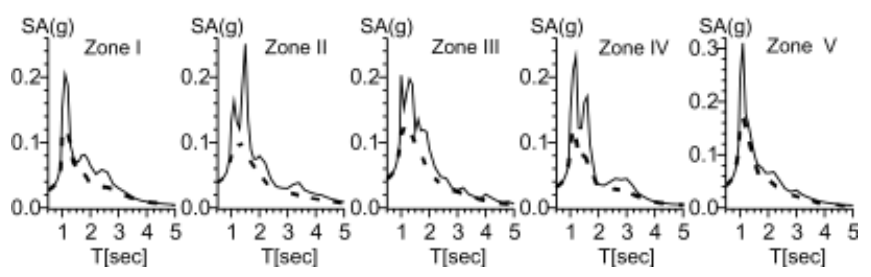

Figure 13. The response spectra, SA (g), (0\% damping — solid line; $5 \%$ damping - dashed line) corresponding to the zones defined in Figure 12.

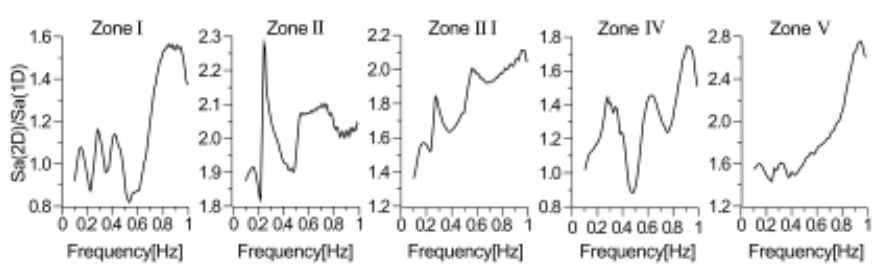

\section{Figure 14. RSR for 5\% damping for the zones defined in Figure} 12.

cantly to the seismic input. The frequency shift of the maximum RSR values along the same profile for different events (Figure 11) shows that the frequency content of the seismic ground motion changes with earthquake magnitude. From the modeling one may expect that, in Bucharest, the large magnitude Vrancea earthquakes induce seismic ground motion that peaks in the low frequency band $(<1 \mathrm{~Hz})$, since they are able to significantly excite soil layers with low modal frequency. On the other side, the $\mathrm{Mw}<7$ intermediatedepth events do not have such a capability and therefore induce seis- mic ground motion that peaks in a higher frequency band $(>1 \mathrm{~Hz})$. Observations of past strong earthquakes (1977, 1986 and both 1990 events) indicate that the modeling is in agreement, within the considered frequency limits, with the real soil response in Bucharest.

5 . The study of site effects and microzonation in a part of metropolitan Delhi city is based on a detailed modeling along two cross sections; North-South from the Inter State Bus Terminal (ISBT) to Sewanagar and East-West from Tilak Bridge to Punjabi Bagh (Figure 15).

A major event of intensity IX (MMI) occurred in Delhi on 15th July 1720 . This event caused large damage to property and innumerable people perished mainly in the old Delhi city. During recent

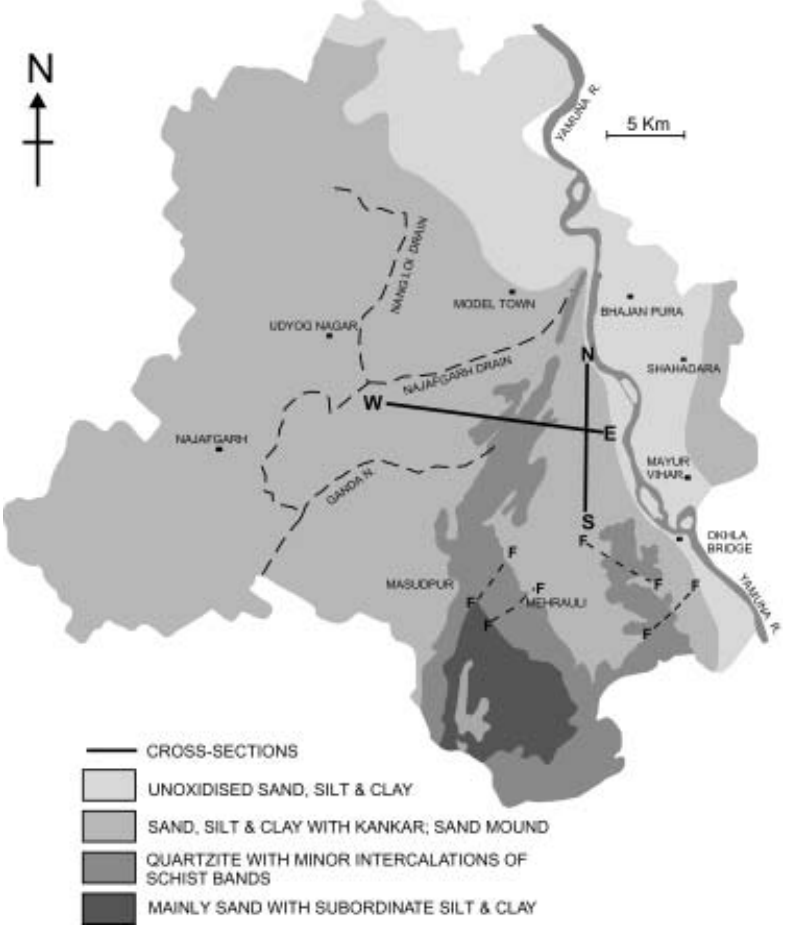

Figure 15. The geological map of Delhi and the position of NS and $E W$ profiles used in the modeling (modified after GSI, 1997).

times the most significant event was the shock of 27 August 1960 $(\mathrm{M}=6.0)$ having its epicenter between Delhi and Gurgaon (Iyengar, 2000). Full synthetic strong motion waveforms have been computed using the hybrid method for the earthquake source of July 15, 1720 (MMI=IX, M=7.4), along a NS cross-section, and the source of August 27, $1960(\mathrm{M}=6.0)$, along an EW cross-section. The RSR have been determined as well.

The synthetic seismograms (SH and P-SV waves) have been computed with the hybrid method for an array of 100 sites regularly spaced every 100 meters, along the NS cross section and every 140 meters, along the EW cross-section. The RSR, as a function of frequency and epicentral distance along the profile, up to a maximum frequency of $5 \mathrm{~Hz}$, is shown for the three components for NS and EW models in Figures 16 and 17, respectively. In Figure 16, for the NS cross-section, the amplification reaches the largest values for frequencies above $2.8 \mathrm{~Hz}$, and the maximum is above 6 . For the vertical and radial components, the maximum amplification is in the range of less then 4 to less than 6 , at frequencies of 4.7 and $2.8 \mathrm{~Hz}$, respectively. The RSR values in Figure 17 for the EW model reach up to about 8 in the transverse component at a frequency of $3.9 \mathrm{~Hz}$, whereas in the vertical component, the RSR is above 4 at a much higher frequency of $4.9 \mathrm{~Hz}$. One of the sources used is at a distance of $10 \mathrm{~km}$ with magnitude 7.4, whereas the other is at a distance of 45 $\mathrm{km}$, with magnitude 6.0. Nevertheless the RSR, in both cases, reach the value of 7.0. All this indicates that, due to the local effects, one may expect local macroseismic intensity increments of about two units, with respect to the average value observed in the area (Panza et al., 1999b). 


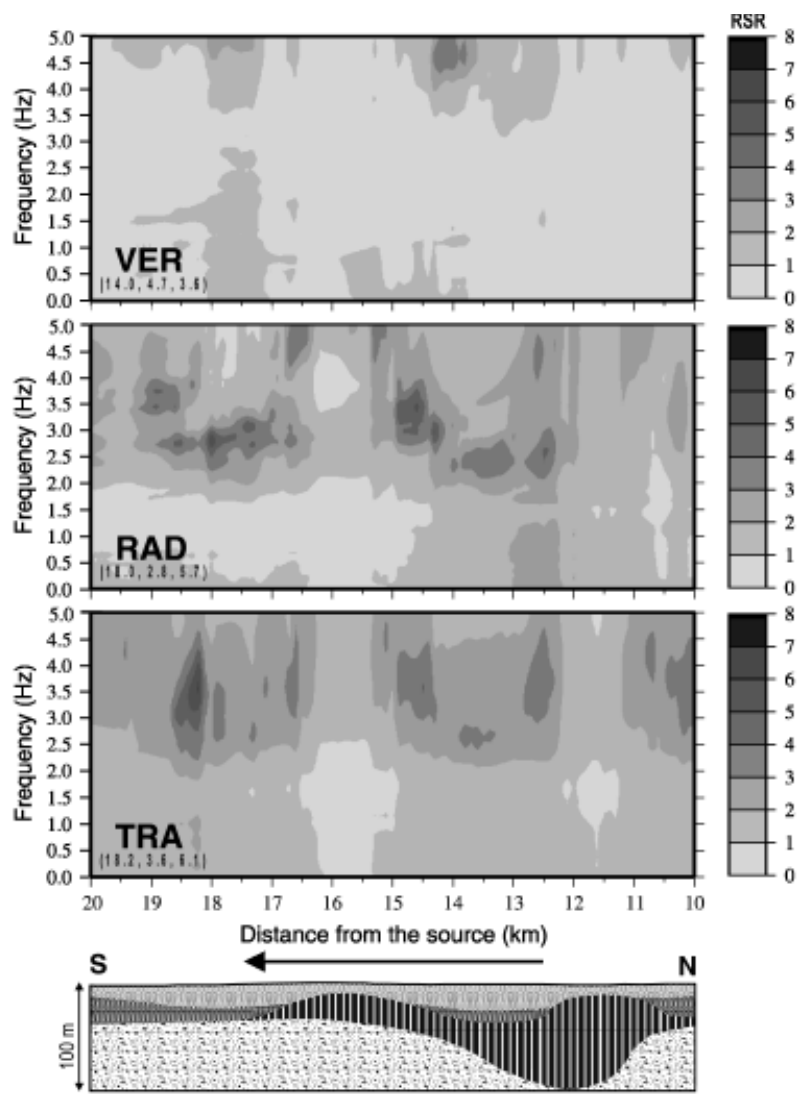

Figure 16. The NS cross-section and the corresponding plots of $R S R$ versus frequency. The numbers in brackets represent distance, frequency and RSR at maximum amplification, respectively.

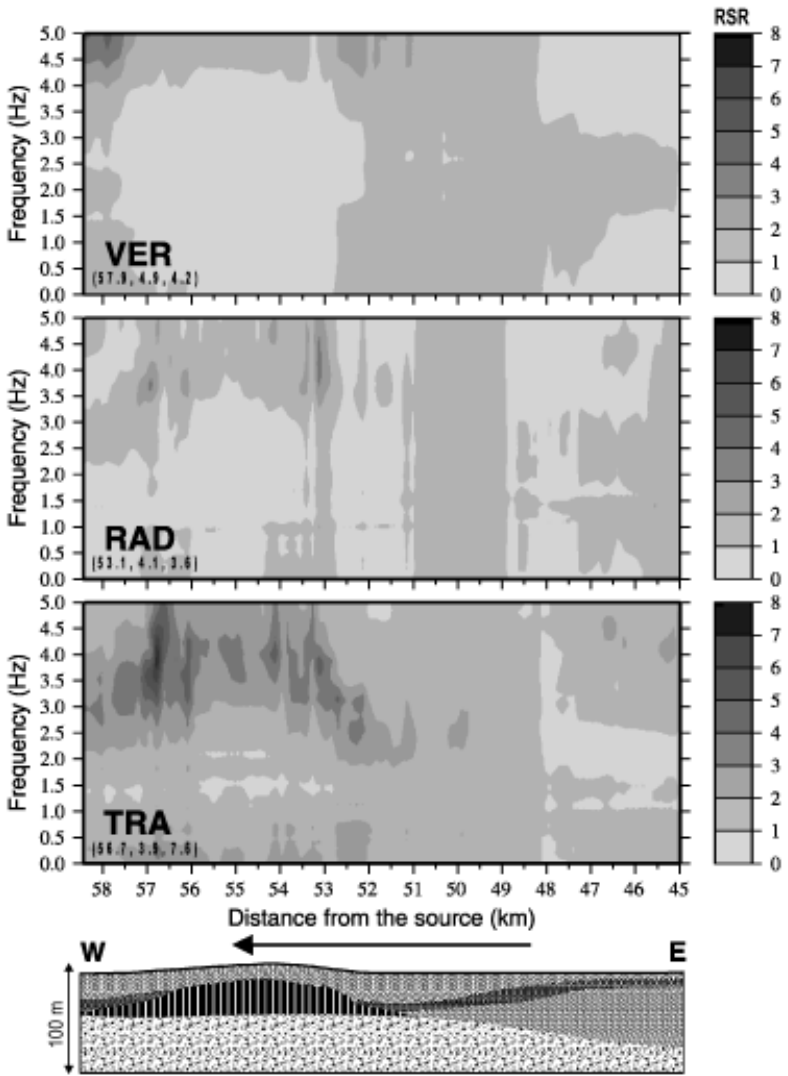

Figure 17. The EW cross-section and the corresponding plots of RSR versus frequency. The numbers in brackets represent distance, frequency and RSR at maximum amplification, respectively.
6. The database of 3-D geophysical structures for Beijing City has been built up to model the seismic ground motion in the City, caused by the 1976 Tangshan and the 1998 Zhangbei earthquakes. The two selected large earthquakes lie to the southeast and the northwest of the City, respectively, and they can be considered representative of the most dangerous seismogenic areas around Beijing. The research area is defined by the latitude from $39.8^{\circ} \mathrm{N}$ to $40.1^{\circ} \mathrm{N}$ and the longitude from $116.2^{\circ} \mathrm{E}$ to $116.6^{\circ} \mathrm{E}$. The data from local dense drilling wells and geological survey results (Gao and Ma, 1993) are used to define the distribution of the Quaternary and Tertiary sediment properties and thickness. There are two abnormally thick Quaternary sediment zones near the city, one at its north-western margin, the other in the north-eastern suburbs. In the latter the thickness reaches $0.8 \mathrm{~km}$. The parameters in the database constructed to study the seismic ground motion in Beijing city, include the density, the seismic velocities of $\mathrm{P}$ - and $\mathrm{S}$-waves, and the attenuation parameter $\mathrm{Q}$ values for the different sedimentary units (Quaternary, Late Tertiary and Early Tertiary). The density values are obtained from local geophysical surveys and gravity inversion results (Group of results of deep geophysical prospecting, 1986). The S-wave velocity is derived from shallow seismic exploration and drilling well data.

The synthetic modeling has been tested against the available macroseismic data (Sun et al., 1998) and records (Ding et al., 2002a). The three component broadband synthetic seismograms along 5 profiles crossing the city area have been calculated, with the maximum frequency of $4 \mathrm{~Hz}$. The ground motion in this frequency band is effective for various buildings existing inside the research area. Three profiles, TS02, TS03, TS04, point towards to the epicenter of the 1976 Tangshan earthquake, and two profiles, ZB05 and ZB06, point towards the epicenter of the 1998 Zhangbei earthquake (Figure 18).

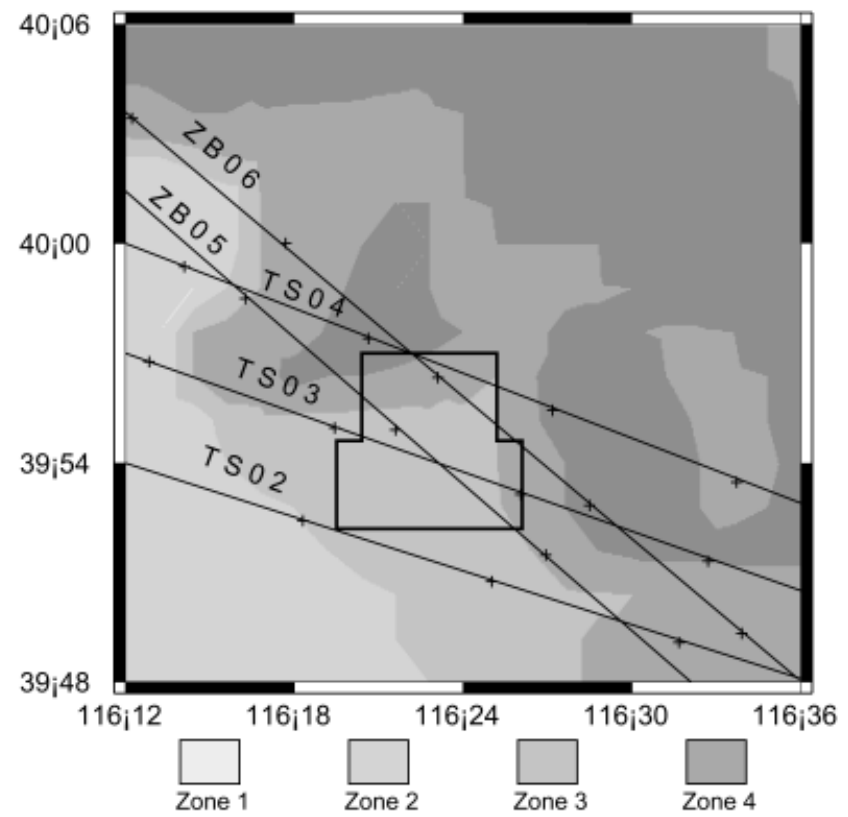

Figure 18. Positioning of the studied profiles and different site effect zones in Beijing City.

The 1976 Tangshan earthquake caused damage in Beijing City. In most of the City the observed macroseismic intensity is VI, on the China Seismic Intensity (CSI) Table (Xie, 1957), which is quite close to the MSK scale, but an abnormal intensity was observed in the northwest part of the town with the value of VII (CSI). The source parameters of the earthquake, used in our computation, are given by Ding et al. (2002a). The seismic ground motion for the 1976 Tangshan earthquake is modeled along the three profiles, TS02, TS03 and TS04, shown in Figure 18.

In Figure 19 the RSR are plotted versus epicentral distance and frequency. They reach the largest values where the thick Quaternary sediments are found (at about $170 \mathrm{~km}$ ) and at the frequency of 1-2 
$\mathrm{Hz}$, which is the fundamental resonant frequency of the soil there For the transverse component, which is the dominant one, the RSR for a set of selected sites is shown in Figure 20, to illustrate the variation of the dominant frequency along the profile.

In January 10, 1998, an earthquake occurred in Zhangbei County, which is located to the north-west of Beijing City, at a distance of about $200 \mathrm{~km}$. The profiles ZB05 and ZB06 are oriented

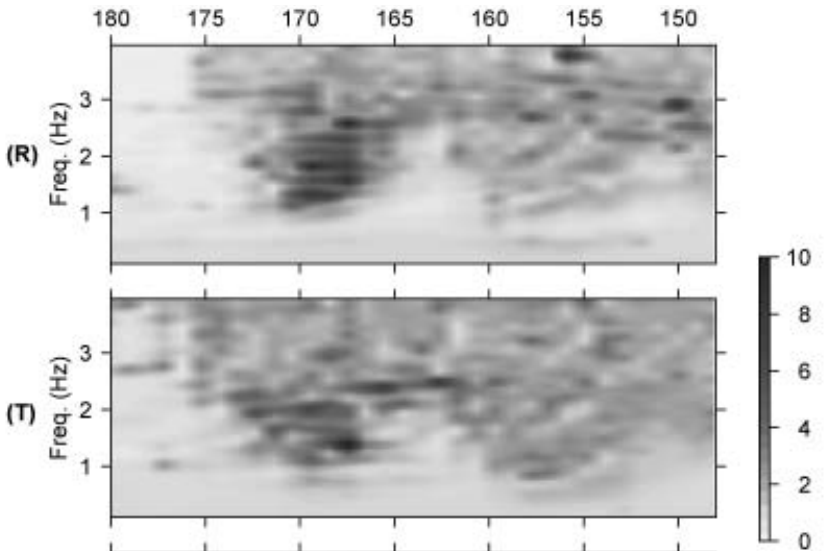

(Z)
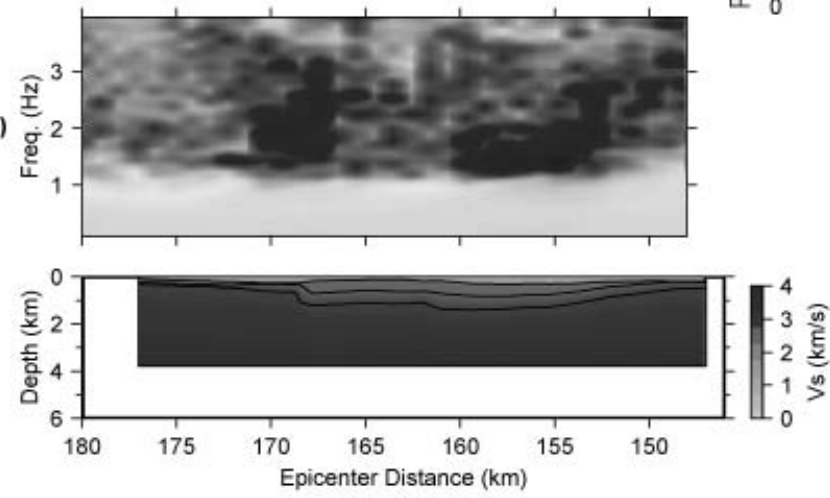

Figure 19. RSR versus frequency and distance along Profile TSO4, $(R=R A D ; T=T R A ; Z=V E R)$.
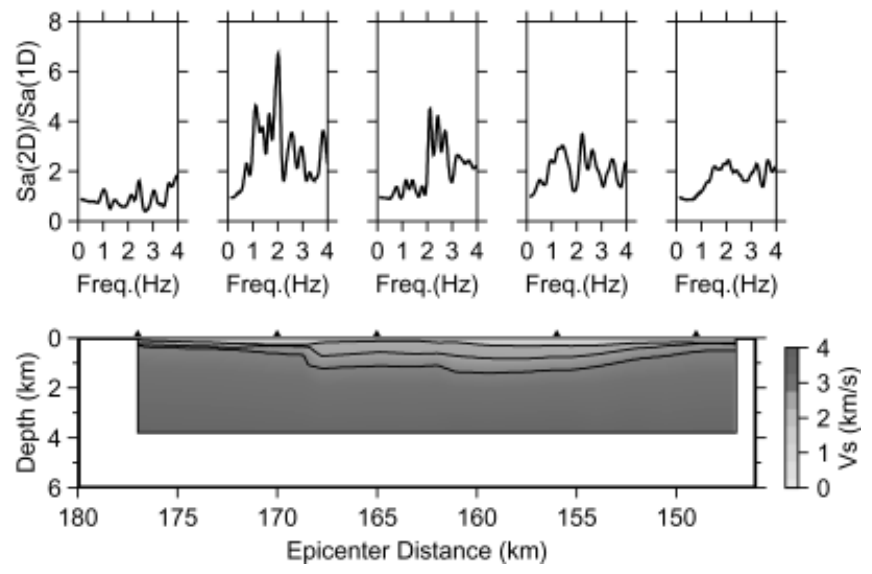

Figure 20. RSR of SH-waves at selected sites along Profile

from the epicenter to the points $\left(39.8^{\circ} \mathrm{N}, 116.535^{\circ} \mathrm{E}\right)$ and $\left(39.8^{\circ} \mathrm{N}\right.$, $\left.116.6^{\circ} \mathrm{E}\right)$, respectively. Along ZB05, the RSR peak at $215 \mathrm{~km}$ is found mainly at high frequencies, from 1.7 to $3 \mathrm{~Hz}$ (Figure 21). This is the fundamental resonant frequency for the thick Quaternary sediments there. For other places with thinner Quaternary sediments, the dominant frequency is greater than $2.5 \mathrm{~Hz}$.

Two thick Quaternary sediment zones lie on the ZB06 profile at about $215 \mathrm{~km}$ and $232 \mathrm{~km}$. Figure 22 shows the synthetic 3-compo- nent seismograms along the profile: the amplification of the seismic waves is controlled by the thickness of the Quaternary sediments. The modeling of the seismic ground motion, for both the Tangshan and the Zhangbei earthquakes shows that the thick Quaternary sedimentary cover amplifies the peak values and increases the duration of the seismic ground motion in the north-western part of the City. Therefore the thickness of the Quaternary sediments in Beijing City is the key factor that controls the local ground effects, and, as it can be seen from Figure 18, four zones are defined on the base of the different thickness of the Quaternary sediments (Ding et al., 2002b). The response spectra computed for each zone (Figure 23 and 24) indicate that peak spectral values as high as $0.1 \mathrm{~g}$ are compatible with past seismicity and can be well exceeded if an event similar to the 1697 Sanhe-Pinggu occurs.

7. Based on the historical record, the largest macroseismic intensity experienced in Naples is VIII on the MCS scale. The 1980, Irpinia earthquake $\left(\mathrm{M}_{\mathrm{S}}=6.9, \mathrm{M}_{\mathrm{L}}=6.5\right)$, located about $90 \mathrm{~km}$ from Naples, is representative of a strong shaking in Naples since it
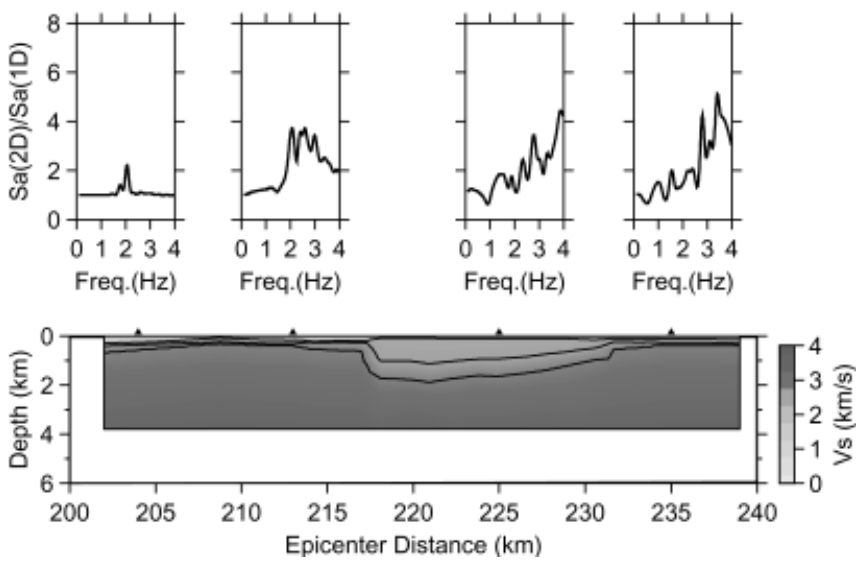

Figure 21. RSR of SH-waves at selected sites along the profile ZBO5.
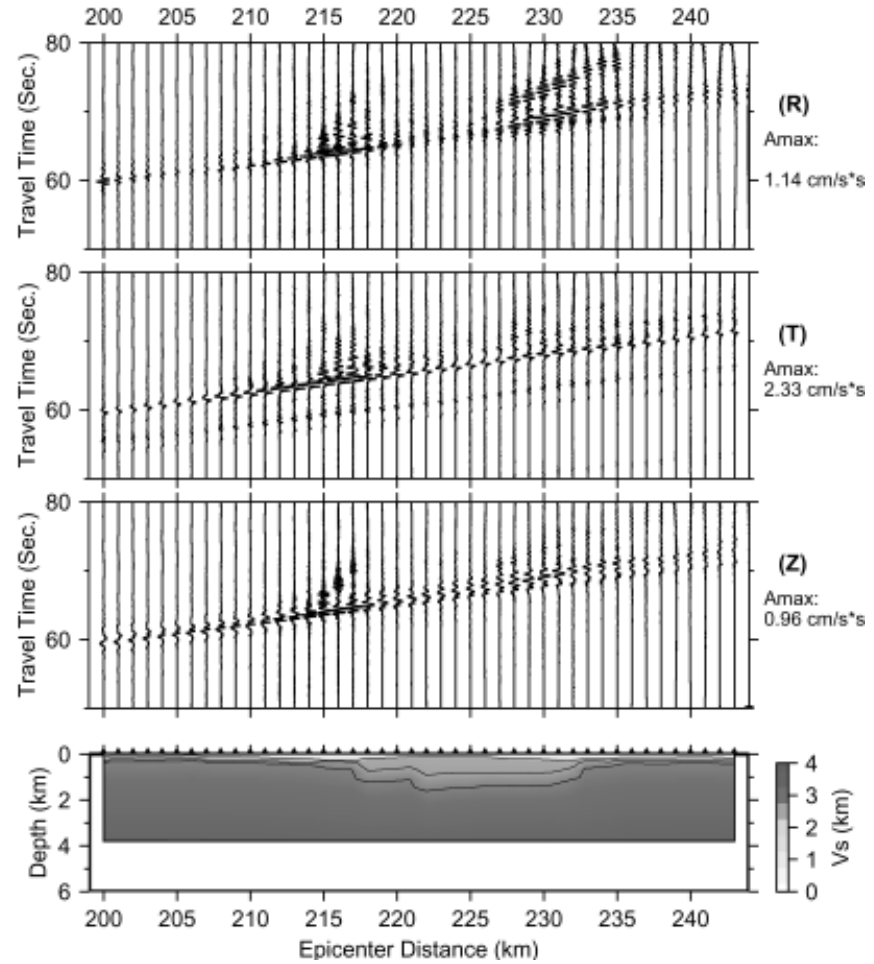

Figure 22. The structural model and the synthetic seismograms along the profile $Z B 06, R=R A D, T=T R A, Z=V E R$. 


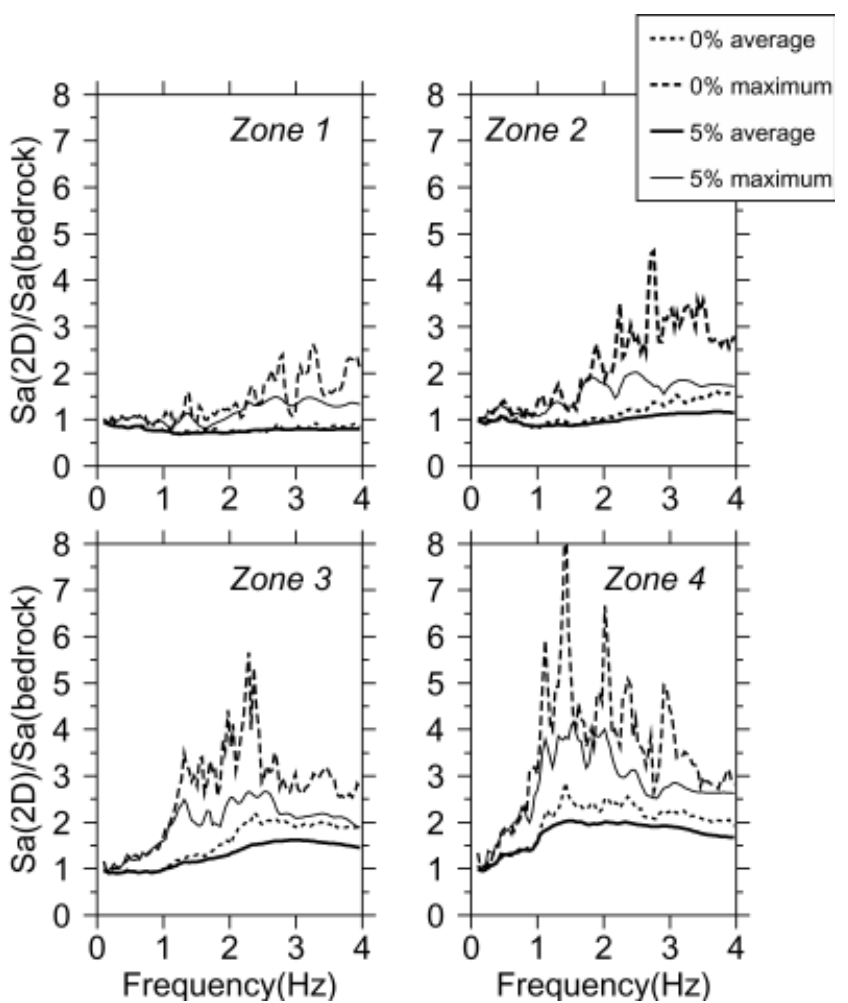

Figure 23. Maximum and average RSR for the four zones (for $0 \%$ and $5 \%$ damping).
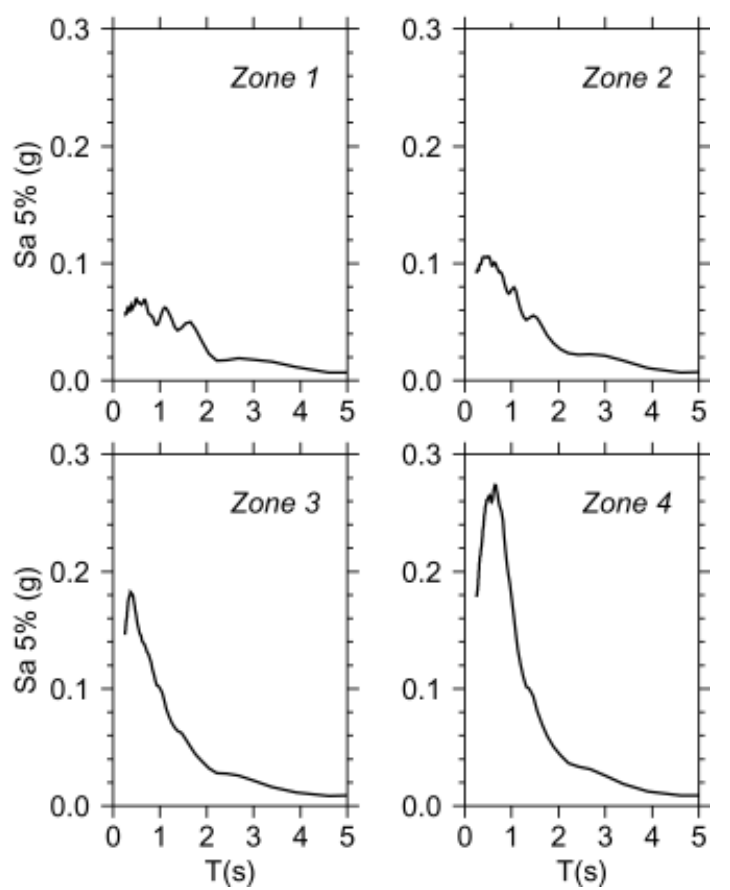

Figure 24. Absolute spectral acceleration (5\% damping) for the four zones.

caused intensity VII on the MSK scale, roughly equivalent to intensity VIII (MCS) (Decanini et al., 1995). For the first time, an earthquake was recorded by a strong motion instrument about $10 \mathrm{~km}$ away from Naples. The recorded acceleograms were utilized to make comparison between observed and simulated ground accelerations. For this purpose, synthetic seismograms have been computed with the mode summation technique (Panza, 1985; Florsch et al., 1991) and a reasonable agreement has been obtained with recorded accelerograms.
This validation at hand and the availability of detailed geological and geotechnical information about the local soil conditions has allowed us to compute quite realistic ground motion at Naples using the hybrid approach.

The geological setting of Naples is mainly characterized by pyroclastic materials, soil (pozzolana) and rock (tuff), from Campi Flegrei many eruptive centers and Vesuvio, that often underwent morphological changes in the past due to the influence of the meteoric and marine agents and to the urban settlement. The Neapolitan volcaniclastic soils are classified as ranging between sandy silt and silty sand. The compact tuff horizon represents the Neapolitan seismic bedrock $\left(\mathrm{V}_{\mathrm{S}}>750 \mathrm{~m} / \mathrm{s}\right)$.

Taking into account the stratigraphies, 6 homogeneous zones have been recognized in Naples (Figure 25). Zones 1 and 2 are characterized by a cover of recent pyroclastic products on a Neapolitan Yellow Tuff (NYT) deep horizon $(>80 \mathrm{~m})$, and the shallow one $(<15$ $\mathrm{m})$, respectively. Zone 3 is characterized by a tuff horizon consisting of ancient Vesuvian tuff in the eastern part and of campanian ignimbrite in the northern part. In the recent past, zone 4 was under the sea level. As a consequence, the representative stratigraphic soil column has a cover of sands on the NYT horizon, which is at depths greater than $40 \mathrm{~m}$. Zone 5 comprehends the historical center of Naples, and is peculiar for the presence of several cavities in the tuff formation. It is characterized by a cover of man-made ground, up to $20 \mathrm{~m}$ of thickness, on the NYT horizon. Zone 6 was a marsh recently drained. The sub-soil, affected by significant lateral variations, is mainly formed by man-made ground, alluvial soils (ashes, sands, peat), NYT tuff and marine sands.

A synthesis of the literature on the shear wave velocity measurements carried out at the Campi Flegrei-Neapolitan soils and tuffs (Nunziata et al., 1999a) has evidenced the wide scattering of VS and recognized the primary influencing factors in the vertical pressure,

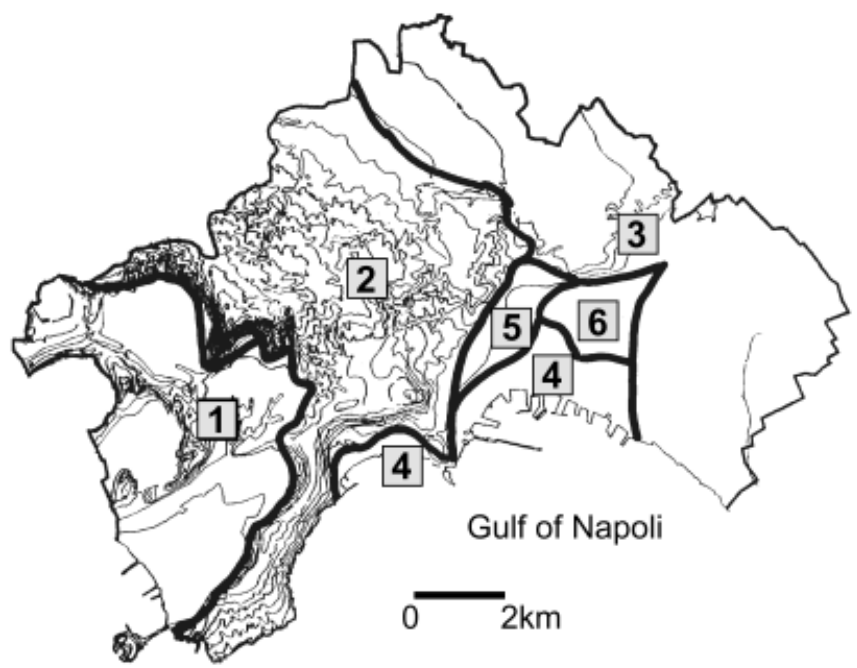

Figure 25. Map of the seismo-stratigraphic zones of Naples.

mostly for the incoherent deposits: the textural characteristics, and the different hardening degrees. In the last years, detailed VS velocity profiles with depth have been obtained in representative lithostratigraphic sites of Naples by using Rayleigh surface waves recorded in refraction seismic surveys (Nunziata et al., 1999b). The shear wave velocity distribution with depth is obtained by the non-linear hedgehog inversion method (Valyus et al., 1968; Panza, 1981), from the group velocity dispersion curves measured employing the FTAN method on single channels (Levshin et al., 1992). The good agreement with cross-hole measurements, has evidenced that the dispersion of group velocity is a powerful tool in engineering geophysics as only one receiver is needed

Ground motion of the SH wave component has been computed for each zone by considering cross- and down-hole or FTAN measurements of $V_{S}$. In absence of $V_{S}$ profiles, a parametric study has been conducted by considering minimum and maximum values of 
the $V_{S}$ ranges individuated for the different formations. Spectral amplifications of 2-3 have been computed at 1-3 Hz. Average and maximum response spectra have been obtained by assuming a 5\% damping, but a $2 \%$ damping has been assumed at the zones 4 and 5 because of the present masonry buildings (Figure 26). It turns out that in the center of Naples, zones 4 and 5 (see Figure 26), the response spectra are almost the same, despite the presence of cavities within the tuff horizon and the sands. Maximum peak accelerations have been computed at about $2 \mathrm{~Hz}$, which is very close to the eigenfrequencies of the existing and most damaged buildings by the 1980 Irpinia earthquake (Nunziata and Panza, 2002). Similar spectra were obtained for the zones 1, 2 and 3, while significant accelerations are observed at frequencies lower than $2 \mathrm{~Hz}$ in the zone 6 . It is clear that inside a specific zone some variability of the ground motion exists, and the shown spectra represent averages (Figure 26). This is particularly true for the zone 6 because of the lateral heterogeneities due to the presence of peat levels (Nunziata et al., 2000).

Finally, moderate transverse component peak ground accelerations of $0.04-0.10 \mathrm{~g}$ have been estimated at Naples. Taking into account the correlation obtained for the Italian territory between synthetic peak ground accelerations (PGA) on one side, and intensity on the other (Panza et al., 1999b), the estimated macroseismic intensities (MCS) are in the range VII-VIII, in agreement with the observed values.

8. Most of the cities in northern Algeria are in earthquake prone zones. Historically, the capital Algiers and its surroundings has been affected by earthquakes located in 3 clearly defined zones: Cheliff zone, Cherchell zone and Blida zone (Figure 27). The reduction of
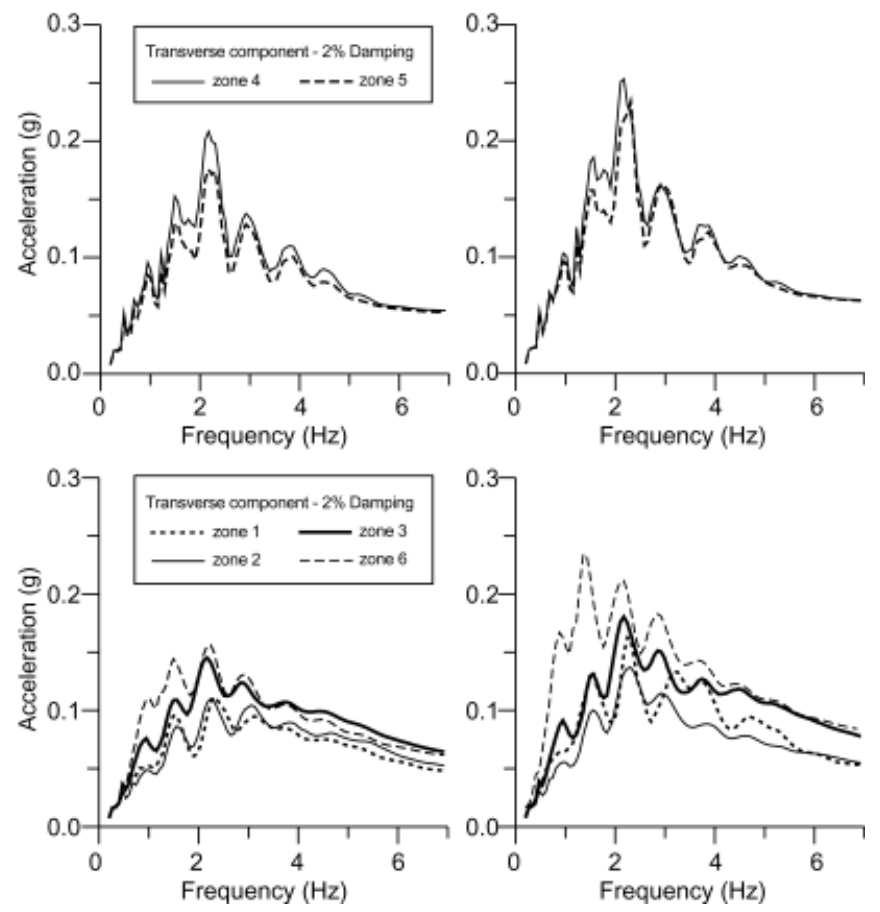

Figure 26. Average (left column) and maximum (right column) response spectra for the 1980 earthquake in the 6 zones (shown in Figure 25) of Naples.

seismic risk requires a detailed microzonation of the urban areas and this must be preceded by a realistic seismic hazard assessment. For this purpose the tectonics and seismic potential in Algiers area $\left[36^{\circ} \mathrm{N}-37.75^{\circ} \mathrm{N}, 2^{\circ} \mathrm{E}-4^{\circ} \mathrm{E}\right]$ are analyzed. Due to the heterogeneity in the quality and quantity of the macroseismic information and of the instrumental data sources, the earthquake catalogue is subdivided into three time windows: (1) before 1830, that corresponds to the pre-colonization era and whose seismicity is not considered, since the retrieved macroseismic information is not sufficiently consistent for a careful and deep study of these earthquakes; (2) the 1830-1900

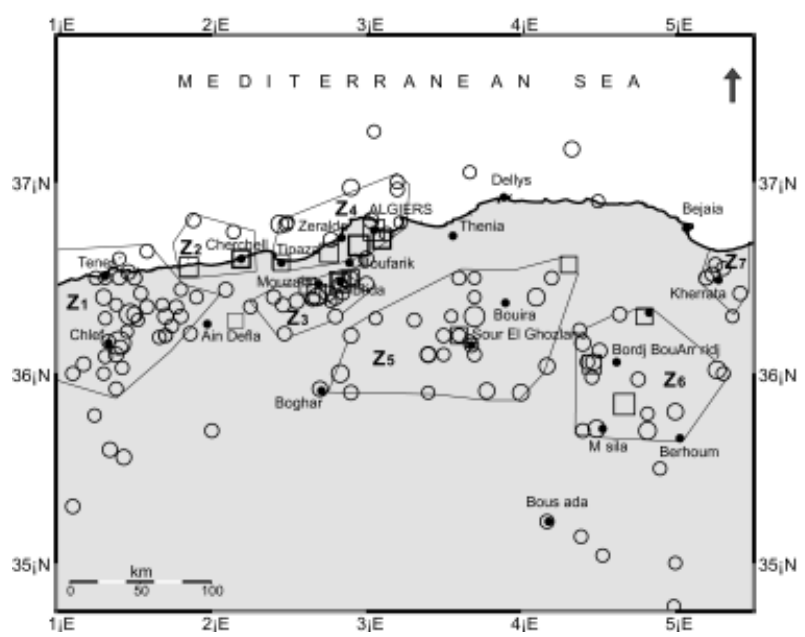

Figure 27. Seismogenic zones in central Algeria, $Z_{1}$ : Cheliff zone, $Z_{2}$ : Cherchell zone, $Z_{3}$ : Blida zone, $Z_{4}$ : Algiers Sahel zone, $Z_{5}$ : Sour El Ghozlane zone, $Z_{6}:$ M'sila zone, $Z_{7}$ : Kherrata zone. This figure represents the seismicity of magnitude $M \geq 4.0$ from 1900 to 1990 (earthquake data are from Benouar, 1993).

period, during which the proliferation of local newspapers contributed largely to the survival of macroseismic information and enabled us to confirm a total of 130 seismic events from 1833 to 1899; (3) the post-1900 period, which has been quite well investigated by Benouar (1993), Mokrane et al. (1994) and Sebai, (1997). The seismic events mentioned in Hee (1950) and in Grandjean (1954) omitted by the aforementioned authors have also been merged into the catalogue after verification and careful analysis. This catalogue has been updated until 2000 using ISC, USGS/NEIC and CRAAG data files. Figure 28 represents the seismicity of the considered zone from 1839 to 2000 . It can be noticed that the high-

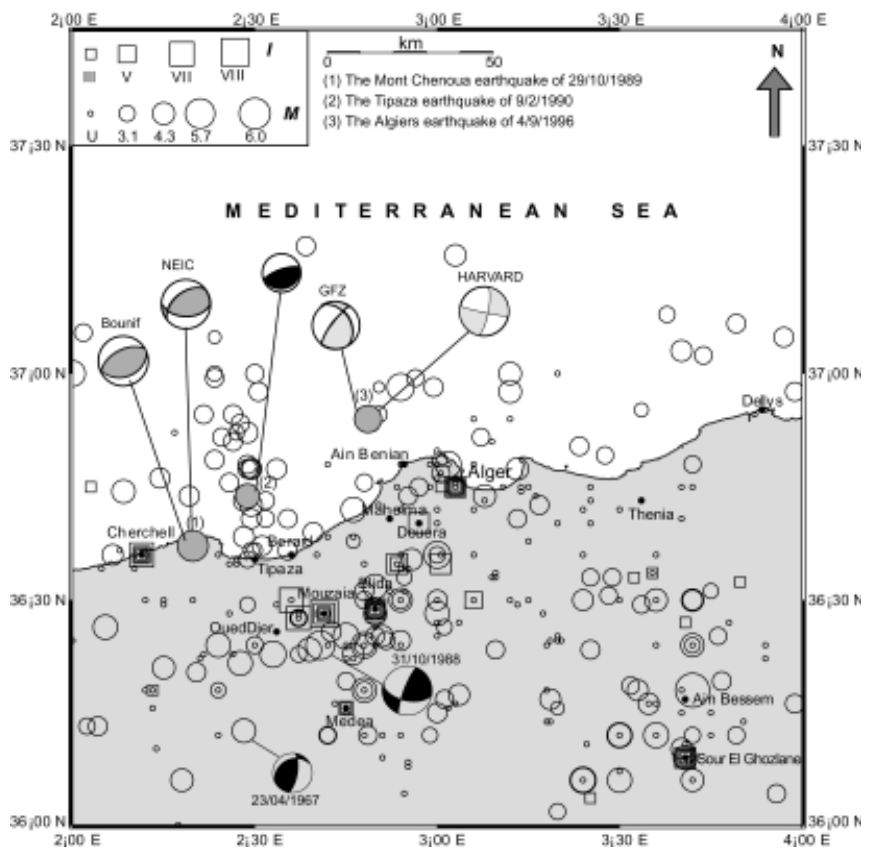

Figure 28. The spatial distribution of earthquakes (only main seismic events of the updated catalogue) from 1839 to 2000 (square: pre 1900 period, circle: post 1900 period, u for unknown magnitude). Focal mechanism solution of the earthquake of 23/4/1967 is from Girardin et al., 1977, those of 31/10/1988 and 9/2/1990 are Harvard CMT solutions. The different fault plane solutions drawn in gray correspond respectively to the Mont Chenoua earthquake of 29/10/1989 (in dark gray) and the Algiers earthquake of 4/9/1996 (in light gray). 
est seismic activity is situated to the west of Algiers where the strongest events occurred (Chenoua earthquake of 29/10/1989, $\mathrm{Ms}=5.7$; Algiers earthquake of 4/9/1996, Ms=5.3). The focal mechanisms suggest that reverse faulting is the predominant mode of seismic deformation in the Algiers area.

Various studies enabled the insight into the seismotectonic framework of the region. Seismological studies of the most recent earthquakes that affected the Algiers area (Mont-Chenoua earthquake of 29/10/1989, Tipaza earthquake of $9 / 2 / 1990$ and Algiers earthquake of 4/9/1996) as well as geological studies (field observation, morphological analysis, analysis of aerial and satellite photographs, digital elevation models, study of the marine terraces and of the hydrographic network etc.) allowed the identification of the tectonic features responsible for the seismic activity. The most important are the activities of the Sahel of Algiers, a fold structure 70 $\mathrm{km}$ long (from Tipaza to Algiers), inclined to the south with an average topographic height of $200 \mathrm{~m}$ (Meghraoui, 1988) and that of the 6 $\mathrm{km}$ long Mahelma structure affecting the quaternary terraces and trending in the NE-SW direction (Figure 29) (Maouche and Haddoum, 2001). The studies conducted after the Algiers earthquake of 4/9/1996 (Maouche et al., 1998; Sebai, 1997; Maouche, 2001) high-

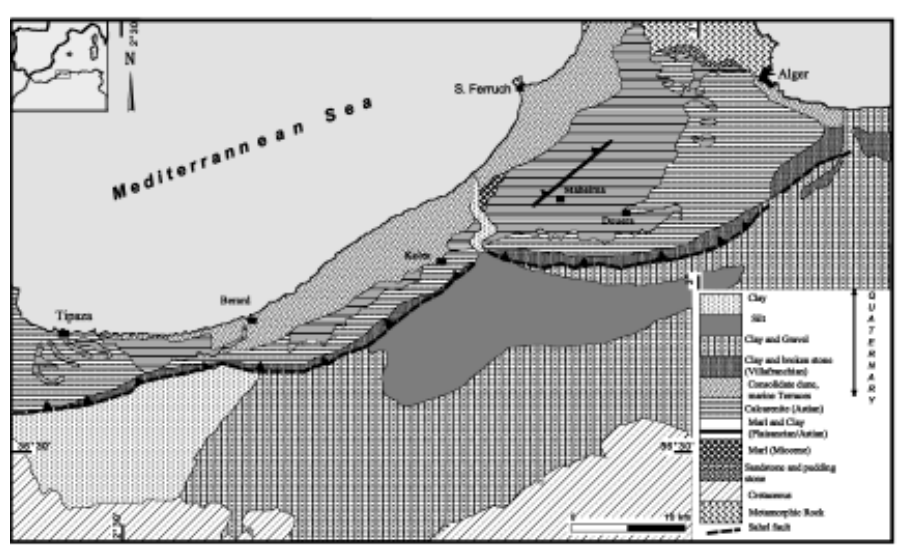

Figure 29. Synthetic geological map showing the Plio-Quaternary deposits at the Algiers Sahel, dashed line represents the reverse blind fault of the Sahel anticline (from Maouche and Haddoum, 2001).

light another structural feature in the Sahel of Algiers corresponding to the presence of a tectonic element on the Ain Benian margin and parallel to the coastline.

Earthquakes in the Algiers area can have destructive effects despite their relatively low magnitudes. In fact, the seismicity in Algiers area is shallow and the geological setting is characterized by marly, sandy or marine sedimentary materials which make this zone very sensitive even to a moderate seismic input. The historical seismicity of the Algiers Sahel prior to 1830 is still under review but preliminary results suggest that much of the damage was concentrated in the coastal localities. Two types of seismotectonic sources are suggested in this zone: (1) blind reverse faulting evidenced by morphological indications as deformed terraces and a dense drainage pattern; (2) marine faults to be identified by reflection profiles analysis and which could have been the source of the last destructive earthquake in Algiers (4/9/1996). Accordingly to historical records, Algiers area has been affected by earthquakes located in 3 clearly defined zones, Cheliff $\left(Z_{1}\right)$, Cherchell $\left(Z_{2}\right)$ and Blida $\left(Z_{3}\right)$ in Figure 27 , which increased the vulnerability of the elements at risk in the city. The findings highlight the great interest to be taken in the detailed and timely assessment of the seismic hazard of Algiers and its surroundings, that is made possible by the realistic modeling of the scenario seismic input.

As the urbanization rapidly continues, Algiers is faced with the challenge of developing in a way that should be environmentally, socially and economically sustainable. Natural disaster mitigation constitutes a necessity for urban inhabitants, an obligation for governments and a strategic resource for investment promoters. The microzonation of Algiers will be completed in the framework of the UNESCO/IUGS/IGCP project 457 "Seismic Hazard and Risk Assessment in North Africa (SHRANA)" (D. Benouar, Leader, Algeria; G. F. Panza, Co-leader, Italy; A. El-Sayed, Co-leader, Egypt; T. Benaissa, Co-leader, Morocco; M'Hamed, Co-leader, Tunisia; S. Abdennur, Co-leader, Libya.

9. The location of Cairo, at the tip of the Nile delta, and the dense population (now 15 million inhabitants), made it a city of a long and relatively well documented history. These documents are preserved in a variety of sources, varying from written documents, papyri to archaeological evidences, provided by the temples and monuments themselves. In total, about 60 earthquakes are reported as felt and/or damaging in Cairo (Ambraseys et al., 1994). Based on the reported damage, Cairo-Faiyoum represents the most vulnerable area to small local (1847 and 1992) and large distant (1926 and 1995) earthquakes. At least $80 \%$ of the reported damage in CairoFaiyoum area has been caused by remote earthquakes that are located as far as the Hellenic Arc (e.g., event of 1926, Ms=7.4). From the distribution of damage it seems that the Nile Canyon responds in an abnormal way to the propagated seismic waves.

The source parameters of the October 12, 1992 Cairo earthquake (El-Sayed et al., 1999) and the accumulated crustal information (Said, 1981; Barazangi et al., 1996) gave us a good opportunity to verify the effect of the Nile graben sediments (Figure 30) on the propagation of seismic waves (Fäh et al., 1994; Panza et al., 2000). This verification is carried out by computing synthetic seismograms (radial, vertical and transverse components) at 97 sites for reference bedrock model and local, laterally heterogeneous model (for maximum frequency of $7 \mathrm{~Hz}$ ).

The largest amplification is observed mainly at low frequencies (Figure 31). For SH waves, the largest amplification (a factor of 6) occurs in the frequency band from 1 to $2 \mathrm{~Hz}$. At the edges of the local model, this band expands to higher frequencies. The pattern of the spectral amplification is quite different in the case of radial and vertical components of Rayleigh waves. In the vertical component, the amplification is stronger (a factor of 13) and occurs for frequencies between 1.5 and $4.5 \mathrm{~Hz}$. The high amplification values for the verti-

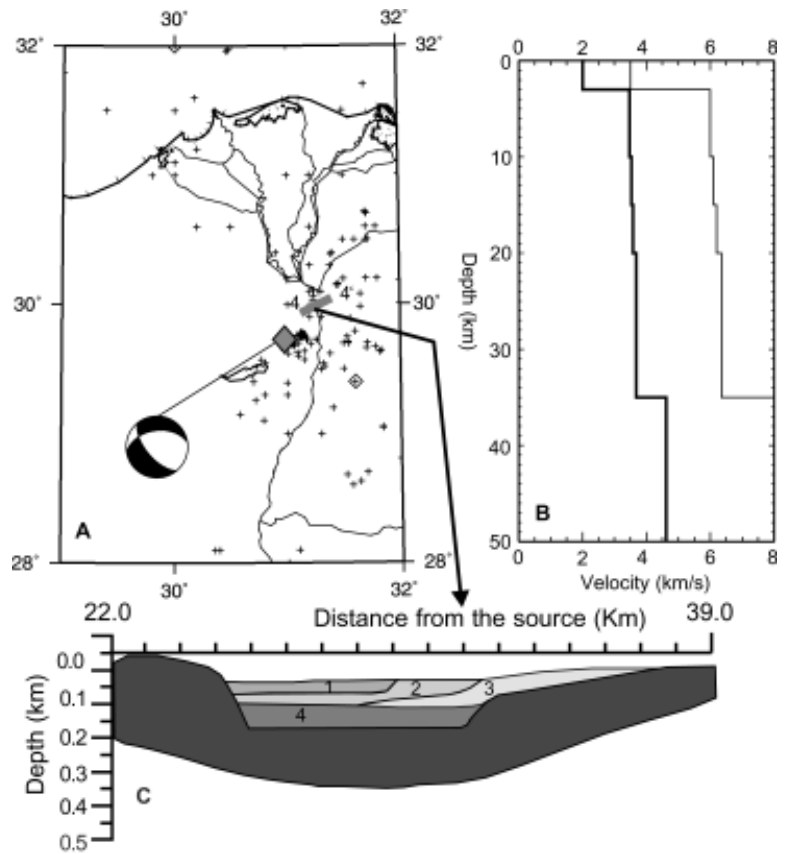

Figure 30. (A) Distribution of earthquake epicenters around the Cairo-Faiyoum area. The beach ball represents the focal mechanism of the October 12, 1992 earthquake; (B) Crustal model (VP and VS) adopted for the path from the source to the local model; (C) the local model for the profile 4-4' (Said, 1981). 
cal component at short periods clearly points out the importance of considering, for engineering purposes, vertical as well as horizontal components of motion. The most complicated pattern for the spectral amplification is observed in the case of the radial component of Rayleigh waves. As shown in Figure 31, the maximum amplification, about 7, is quite spread in space and frequency. For distant sources, the amplification becomes stronger at lower frequencies (Figure 31). The amplification of seismic waves at low frequencies is certainly relevant to understand and interpret the damage caused by distant earthquakes, like those of the Hellenic Arc (1994) and Aqaba (1995).

The October 12, 1992 and June 26, 1926 earthquakes supply good data to verify our modeling for local and distant earthquakes, respectively. In the case of the 1992 local event, the most severe damage was reported for the regions (such as El-Aiyat, El-Beeadaa and Al-Akwan, Giza districts) where thick sediments are present and the water table is shallow (JICA, 1993). For example at Berwash village, accordingly to our modeling the area of maximum spectral amplification, $30 \%$ of houses collapsed, 50\% suffered serious damage and $10 \%$ suffered light damage (JICA, 1993). On the other side of the valley, in Cairo city, the reported damage is smaller than that reported in Giza (Elgamal et al., 1993). In general, the areas of severe damage reported by JICA (1993) and Elgamal et al. (1993) correspond to the areas of maximum spectral amplification obtained with our modeling along the cross section.

The distribution of damage due to the 1926 distant event is another example that supports our calculations. The epicentral distance from Cairo is about $700 \mathrm{~km}$, therefore energy peaks were observed at frequencies of 1-2 Hz (El-Sayed et al., 2000). Nevertheless, it harmed a wide range of building in the Cairo-Faiyoum area. Areas of maximum damage are those settlements located above the
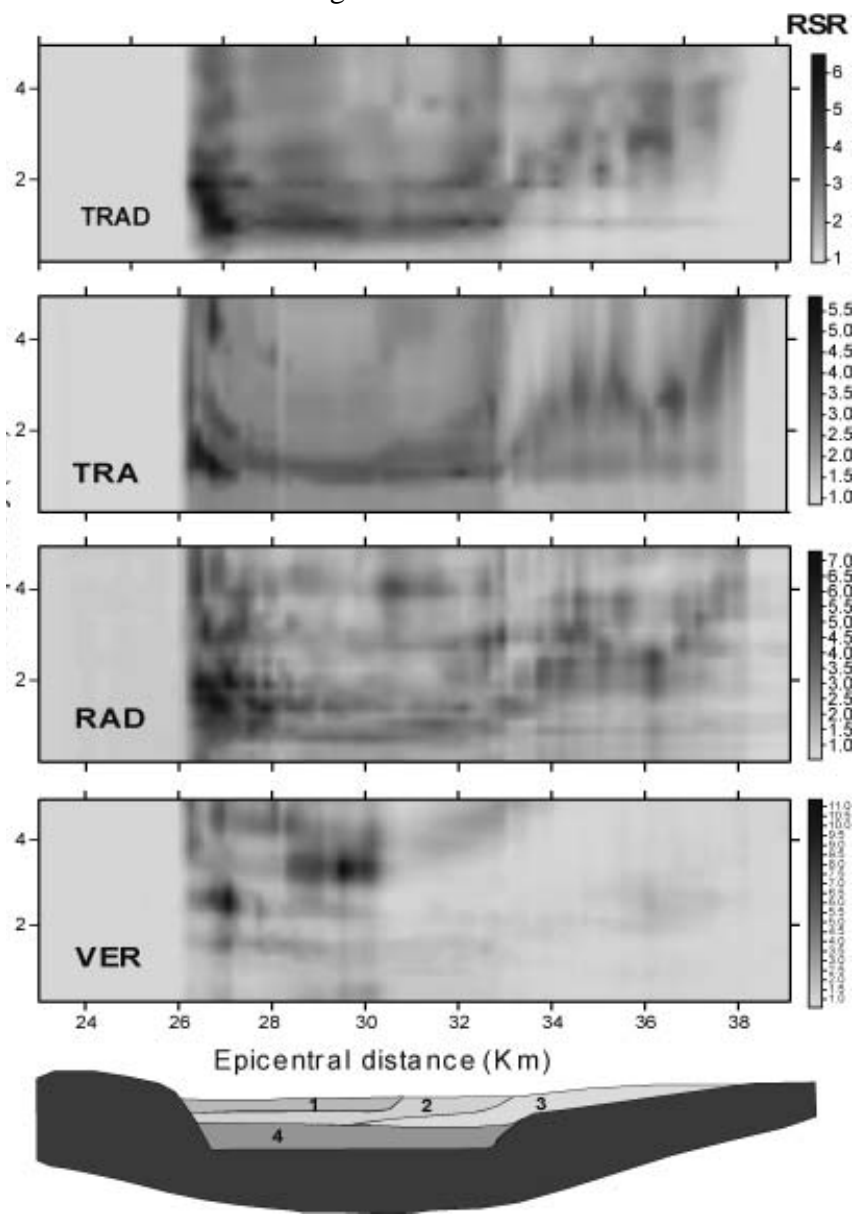

Figure 31. The cross section and the corresponding RSR versus frequency for VER, RAD and TRA. TRAD is the response spectra ratio assuming an epicentral distance of $150 \mathrm{~km}$.
Nile Canyon filling sediments. This again confirms that the Nile Canyon sediments strongly amplify the propagated seismic waves, even at the low frequencies that are usually generated by distant earthquakes like the events of 1996 (Cyprus) and of 1997 (Aqaba).

10. Santiago de Cuba basin is characterized, from the geological point of view, by rocks, and stiff and unconsolidated sediments of different age, origin and lithological composition. As a primary basis for our study we used the geological map of Medina et al. (1999), complemented with tectonic data provided by Arango (1996) and Pérez and García (1997). A compilation of the structural parameters, geotechnical information, and geological geometry of the subsoil in Santiago de Cuba was constructed in the form of a database containing data from more than 600 boreholes. The analysis of these data, together with the consideration of the intervals of variation of the physical-mechanical properties of the rocks present in the geological map, permitted us to simplify and generalize the map of Medina et al. (1999), defining only 6 kinds of soils in the study region. These soils correspond to sands and sandstones of Quaternary formations, clays, sands and magmatic intrusions from Neogene formations, calcareous rocks and limestones from Neogene and Quaternary formations, as well as volcano-clastic rocks, tuffs, tuffites and agglomerates of El Cobre formation of the Paleogene Volcanic Arc. Additionally, significant lenses of gravely alluvium (gravels, sands and clays with calcareous composition) are present at depth in different parts of the basin. For studying the influence of the sedimentary basin structure on the seismic input, four profiles were selected across the basin. Ground motion has been investigated in 49 sites distributed along all considered profiles with a spacing of $900 \mathrm{~m}$. In Figure 32 we present the simplified geologic-tectonic scheme together with the profiles traces and investigated sites.

Synthetic SH-waves seismograms have been calculated by the hybrid approach (modal summation for the path source-profile and finite differences for the profile) for a maximum frequency of $1 \mathrm{~Hz}$ (Alvarez et al., 2001). The regional structural model, used for the modal summation part, was constructed using the contribution of Arriaza (1998), who reinterpreted the results of Bobenko et al. (1980), while for depths ranging from 30 to $150 \mathrm{~km}$ the results of the P-waves tomography study of Van der Hilst (1990) and of the gravimetric study of Orihuela and Cuevas (1993) have been considered. For depths greater than $150 \mathrm{~km}$, the oceanic model of Harkrider

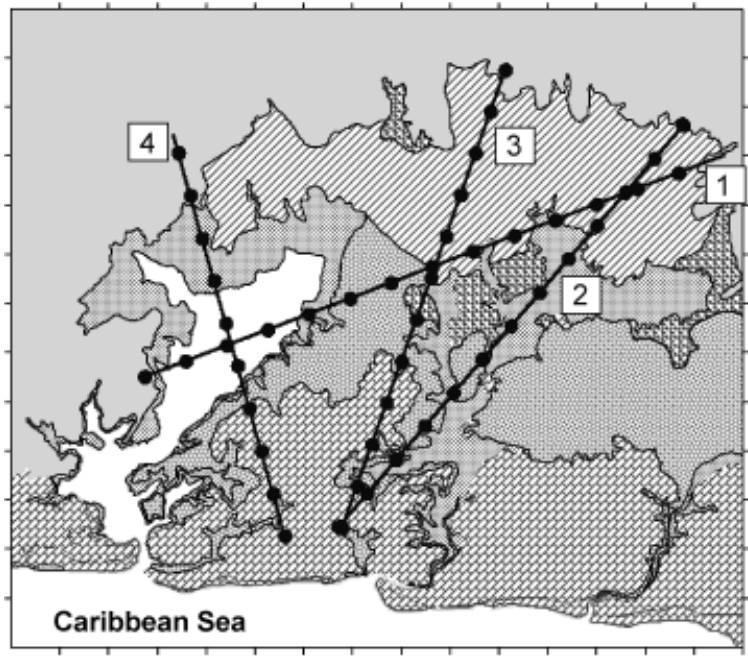

Figure 32. Simplified geological scheme of Santiago de Cuba basin (modified from Medina et al., 1999), 1-sand and sandstones (Ouaternary formations), 2-clays (Neogene), 3-marls (Neogene), 4-magmatic intrusions, 5-calcareous rocks and limestones (Neogene and Quaternary formations), 6 - rocks from El Cobre formation (Paleogene Volcanic Arc); the ticks on the frame of the figure are $1 \mathrm{Km}$ apart, the left-low corner has coordinates $19.954^{\circ} \mathrm{N}$ and $75.897^{\circ} \mathrm{W}$. With thick lines are plotted the 4 analyzed profiles, and with solid circles the sites in which synthetic seismograms are calculated. 
(1970) is added. The corresponding cross sections for depths $<50 \mathrm{~m}$ have been prepared using borehole data from a band $0.25 \mathrm{~km}$ wide at both sides of each profile trace. More distant boreholes have been used for larger depths, up to $210 \mathrm{~m}$. The cross sections show smooth transitions through the different zones and sharp ones when crossing the fault present in the study area. The data on the mechanical properties (P- and S-waves velocities and quality factors) of the strata (see caption to Figure 33) were taken from the literature (Pavlov, 1984, Ishihara, 1993, Berge, 1999), as no direct measurements are available. The density is supported by laboratory measurements data, present in the mentioned database. The grid used in the finite difference calculations was selected with dimension, at the surface, $\Delta \mathrm{x}=\Delta \mathrm{z}=0.015 \mathrm{~km}$, in agreement with the detail given in the sections. The sources are placed on the Oriente transform fault system, at $30 \mathrm{Km}$ of depth, and at a distance of $25 \mathrm{~km}$ from the coast, in the main seismogenetic zone that affects the region, where the expected strong earthquakes are likely to be located. For each site we calculate displacement, velocity and acceleration seismograms for a point source with seismic moment $\mathrm{Mo}=1.0 \times 10^{13} \mathrm{~N}-\mathrm{m}$, focal depth $\mathrm{h}=30 \mathrm{~km}$, and focal mechanism: dip $=21^{\circ}$, azimuth $=302^{\circ}$ and rake $=21^{\circ}$. Figure 33 presents the regional structure and the four cross sections.

RSR has been determined for each site and it turns out to be larger and more variable for frequencies greater than $0.4 \mathrm{~Hz}$. At the end of profile 2 a clear resonance effect is present, characterized by very high values, that correspond, in the time domain, to long wave trains. The RSR data for each site are sampled at $0.05 \mathrm{~Hz}$ from 0.39 to $0.99 \mathrm{~Hz}$ for a total of 13 points, at each site. These data are pro-
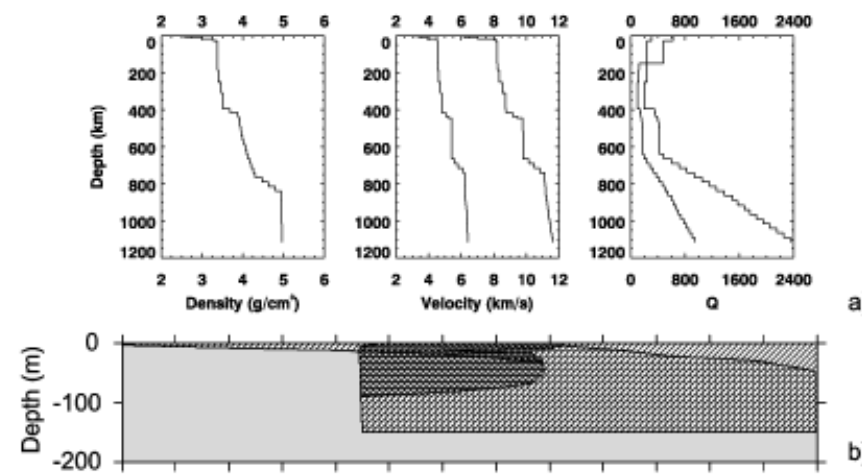

a)

b)
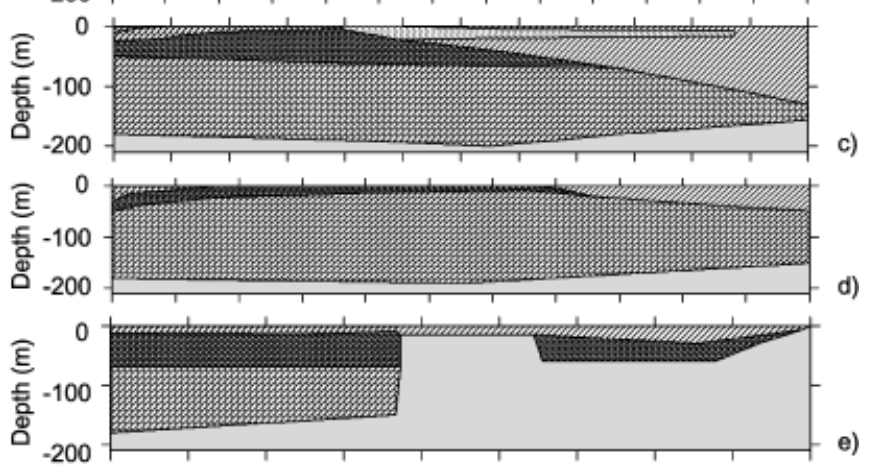

d)

\begin{tabular}{|c|c|c|c|c|c|}
\hline No. & Brief Description & $V_{p}$ & Vs & $\rho$ & $Q p$ \\
\hline 1 & Sands & 1.2 & 0.35 & 1.8 & 100 \\
\hline 2 & Clays & 0.8 & 0.3 & 1.6 & 100 \\
\hline 3 & Marls & 1.3 & 0.6 & 2.0 & 150 \\
\hline 4 & Calcareous soils & 0.9 & 0.5 & 1.8 & 150 \\
\hline 5 & Calcareous rocks & 2.5 & 1.4 & 2.3 & 200 \\
\hline 6 & Igneous rocks & 2.4 & 0.8 & 2.1 & 350 \\
\hline
\end{tabular}

Figure 33. Structural data used for the calculations. a) Physical properties of the regional structure; b-e) Cross-sections for profiles 1-4, horizontal ticks corresponds to site positions; $f$ ) Legend for $(b-e)$. cessed, for the classification in compact sets, with a non-supervised logical-combinatorial algorithm included in PROGNOSIS system (Ruiz et al., 1992). The methodology is described by Pico (1999). For the zoning, a sort of correspondence between surface geology and RSR level was sought. The classification process results in the identification of three groups with different level of RSR: high, intermediate and low. Consequently, the microzoning of the basin is made in terms of these three groups. The boundaries between zones follow, whenever possible, the boundaries between the different elements of the geological map (slightly smoothed). For the zones not crossed by the profiles we took into account the results obtained in similar (by structure in depth) zones crossed by them. The microzoning scheme is shown in Figure 34a, where the small sub-zone, corresponding to the sites where the resonance effect has been identified, is delimited by a thick dashed line. The average RSR curves for each zone are shown in Figure 34b.

The RSR patterns show the influence of the different geological features. There is a 'regular' behavior, characterized by very small RSR values at small frequencies, followed by a smooth monotonous RSR increment from about $0.4 \mathrm{~Hz}$, until $0.9 \mathrm{~Hz}$, where the relative maximum is reached, and a small decrease until $1 \mathrm{~Hz}$. An exception occurs at the end of profile 2, where the RSR pattern shows the appearance of very large amplitudes in the range $0.6-0.8 \mathrm{~Hz}$, in the form of a narrow peak, followed by a sharp decrease towards $1 \mathrm{~Hz}$. In this part there is a thick clay layer, but before reaching it the waves travel through a structure where a relatively big lens of sands, of the small San Juan river basin, is embedded into the clays. It results in a

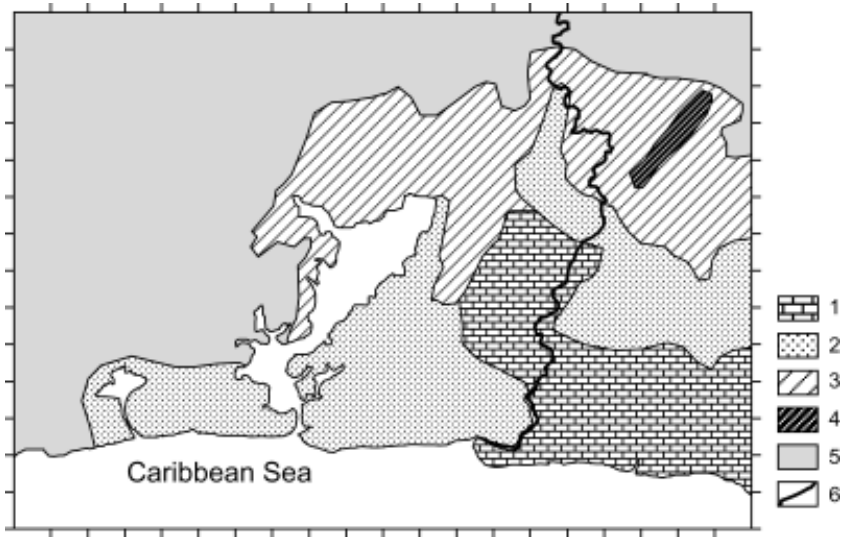

Figure 34a. Microzoning of Santiago de Cuba basin: 1-low RSR level, 2-intermediate RSR level, 3-high RSR level, 4-subzone of zone 3, where resonance effect was identified, 5-zone of El Cobre formation, not included in the analysis, 6-San Juan river; the ticks on the frame of the figure are $1 \mathrm{~km}$ apart, the lower left corner has coordinates $19.945^{\circ} \mathrm{N}$ and $75.945^{\circ} \mathrm{W}$.level.

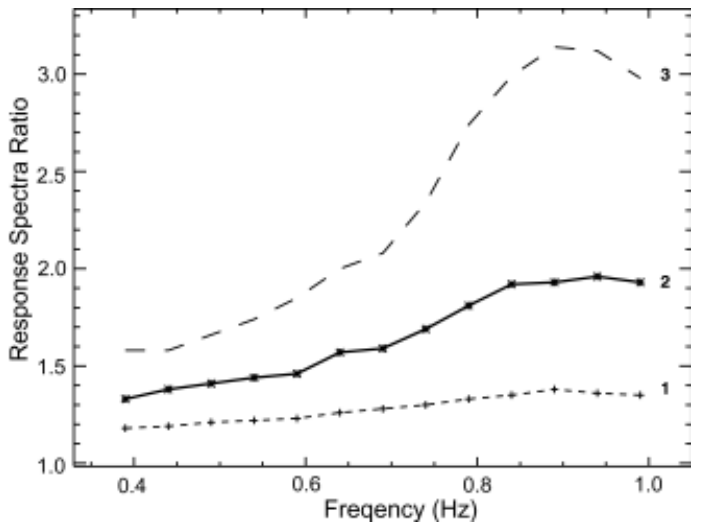

Figure 34b. Average RSR curves versus frequency for each zone of the microzoning scheme: 1-low RSR level, 2-intermediate RSR level, 3-high RSR level. 
cumulative increase of waves amplitude and duration, which remains after the sand lens is passed.

The synthetic signals have been scaled to $\mathrm{M}_{\mathrm{S}} \boldsymbol{z}_{\mathrm{z}}$ the most probable strong earthquake, and to $M_{S} \&$ the maximum possible earthquake. From these scaled signals the maximum ground motion displacement, velocity and acceleration are obtained, while the values of the design ground acceleration (DGA) are computed by scaling acceleration seismograms with the design response spectra for the soils S1, S2 and S3 of the Cuban building code (Norma Cubana, 1999).

11. The detailed geotechnical information used in the Thessaloniki area is coming from a series of tests and extended geophysical prospects (cross-hole and down-hole measurements, surface wave inversions) carried out within the whole urban area by the Laboratory of Soil Mechanics and Foundation Engineering of Aristotle University of Thessaloniki. The known geometry and the dynamic properties of the soil (density, body wave velocities and quality factors) that were used resulted from various studies of this area (Pitilakis et al., 1992; Anastasiadis, 1994; Raptakis, 1995). All information have been elaborated in order to construct seven 2D cross sections, each along a profile with different orientation (Figure 35), covering most of the city area. The layering for the seven cross sections is shown in Figure 36, and each layer dynamic properties, as well as the focal mechanisms of the double-couple point sources that were used to excite the seismic wavefield impingent on the cross-sections are discussed in detail by Triantafyllidis et al. (2002a; 2002b).

Figure 37 shows RSR with 5\% damping for all components of motion along three of the studied profiles. The white spots that appear at some profiles indicate amplifications that are slightly higher than the maximum value specified on the gray scale of each section.

In the first graph of Figure 37, the high amplification zones (up to epicentral distance of $92 \mathrm{~km}$ ) outline the interface between bedrock and basin boundaries of section A3, especially for the horizontal components. At the basin's center, between sites TYF and POL

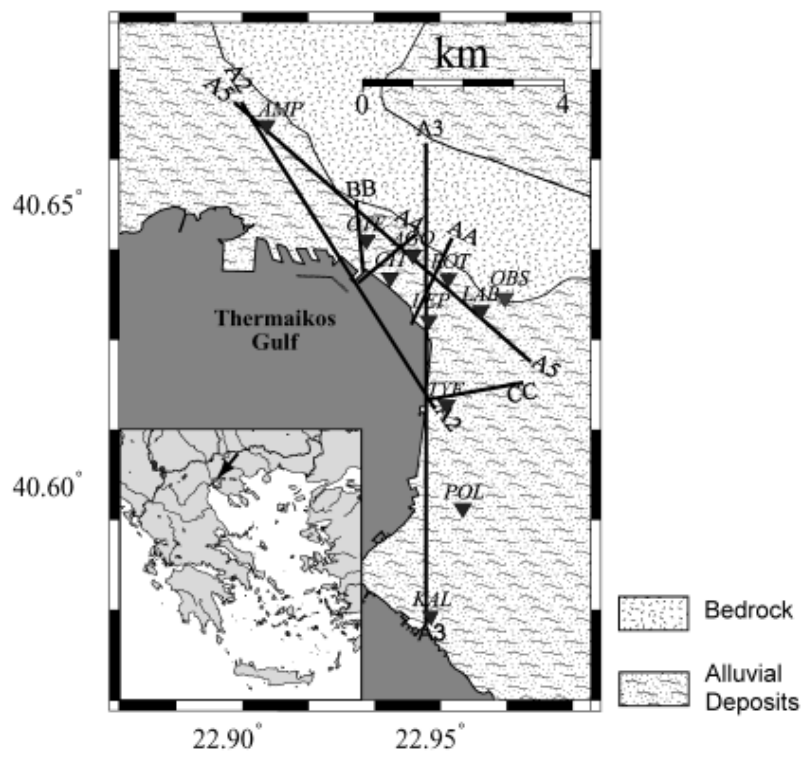

Figure 35. Map of the urban area around Thessaloniki, giving in details the length and the orientation of cross sections along which the seismic response was estimated with the hybrid method.

(93 to $95 \mathrm{~km}$ ) a zone of increased amplification appears at different frequencies for each component. These high amplifications at high frequencies in the vertical component can be attributed to local surface waves, which are trapped in the layers close to the surface.

The spectral amplifications along section A4 have a very similar frequency variation in space and the level is approximately the same for all three components (Figure 37). It is evident from the figure that the amplification of spectral acceleration occurs at different
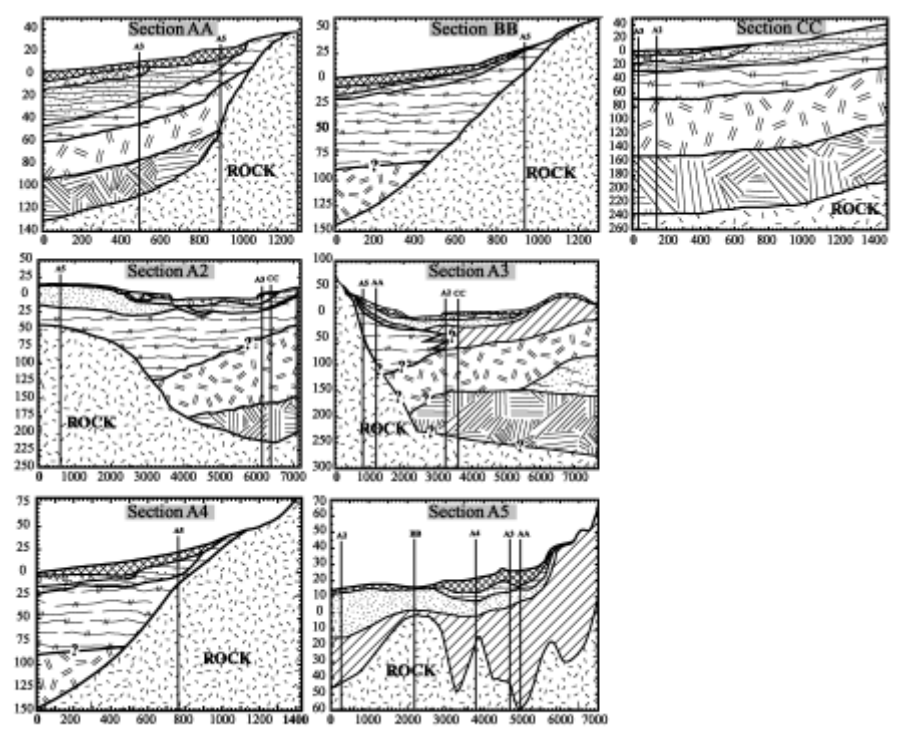

Figure 36. The seven 2-D geological profiles along which the seismic response was estimated with the hybrid method. The question marks on sections $B B, A 2, A 3$, and A4 denote the lack of absolute accuracy of boundaries position. The vertical lines indicate the intersection points between the considered profiles. Axes units are in meters.

frequencies for the sites CIT and AGO. Combining this observation with the extent of damage in the area around CIT during the earthquake of June 20,1978, the importance of estimating spectral amplifications for earthquake engineering purposes is evident. The knowledge of site response in relation to the complete frequency content of a specific design earthquake is therefore the only reliable image of seismic hazard useful for engineers.

The last graph of Figure 37 shows the variation of RSR along section A5. The bedrock configuration is clearly evidenced at distances 25.5 to $26.5 \mathrm{~km}$ from the source by low values of amplification at low frequencies for both horizontal components, with essentially no amplification on the vertical component. Along the points where the total width of the sedimentary layers increases (from 26.5 $\mathrm{km}$ on), the horizontal components appear to be strongly amplified between 1 and $2 \mathrm{~Hz}$. On the contrary, the vertical component shows in general low amplifications that vanish at higher frequencies. This is probably due to the presence of the clay layer below the superficial alluvial deposits, which amplifies the vertical component of the surface waves giving high amplifications only at frequencies greater than $4.5 \mathrm{~Hz}$.

The results confirm that the geometry and depth of the rock basement are important factors that can significantly affect the seismic amplification of a certain site (see section A5 in Figure 37). In cases where the rock basement is located at shallow depths under the surface, the big differences of impedance between the surface layers and the basement generate edge effects (see section A3 in Figure 37). It has also been observed that the thin low-velocity surface layers generate resonance and entrap local surface waves, thereby creating increased amplifications (generally between 1 and $4 \mathrm{~Hz}$ ) for the horizontal components, whereas the vertical component is only amplified at higher (over $5 \mathrm{~Hz}$ ) frequencies. This phenomenon is particularly evident in sections A3 and A5 (Figure 37).

The proposed 2D models based on the geotechnical and geophysical investigations explain quite well the main amplification features in the area of interest. Such detail in the knowledge of the subsurface structure can be, therefore, considered as sufficient, within the considered frequency range, to reliably estimate for engineering purposes the ground motion shaking effects within a city, given a scenario earthquake.

The obtained theoretical ground response estimates have been validated by Triantafyllidis et al. (2002b), who compared them with 

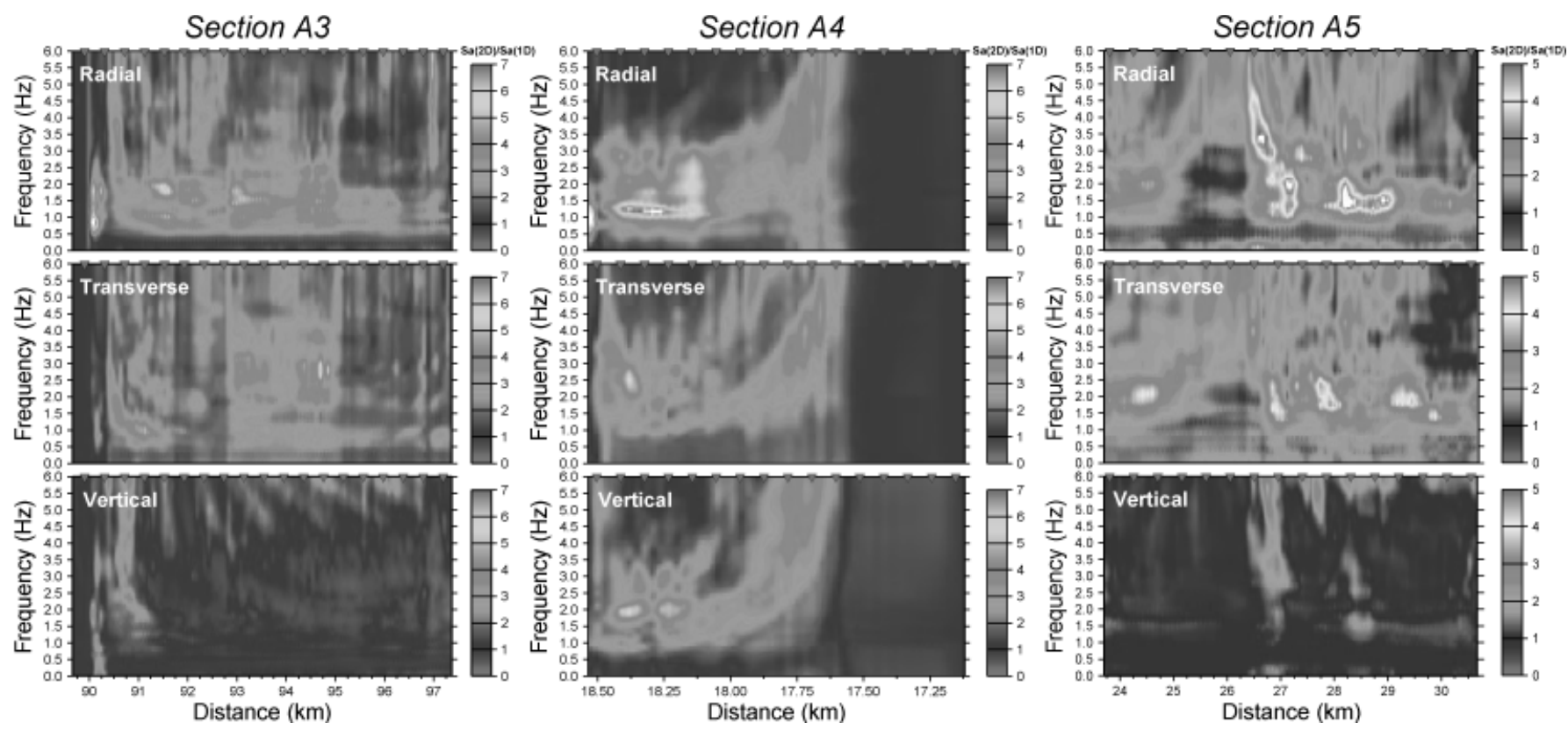

Figure 37. Representation of the RSR versus frequency, along sections A3, A4 and A5 (spectra computed with 5\% damping) for all three components.

the ones obtained from the experimental method of SSR at different sites within Thessaloniki (Triantafyllidis et al., 1999). In such comparisons it is of course possible to have some discordances between theoretical and experimental estimations of site effects. This is mainly due to two reasons: a) unavailability of a sufficiently detailed knowledge of the large number of parameters that characterize the input model and $b$ ) the neglecting of possible $3 \mathrm{D}$ effects.

In order to make the results applicable for antiseismic planning and the mitigation of seismic hazard, with emphasis on big urban areas such as the city of Thessaloniki, the next step (Panza et al., 2000) is to use such results to construct microzoning maps for each "scenario" earthquake. In fact, the site response at a given locality obtained from two "scenario" earthquakes can be different, as demonstrated by several authors (e.g. Romanelli and Vaccari, 1999; Field et al., 2000; Panza et al., 2000; Moldoveanu and Panza, 1999, Moldoveanu et al., 2000; Panza et al., 2002, Triantafyllidis et al., 2002c, Herak et al., 2002). In particular Triantafyllidis et al. (2002c) have compared the ground response in terms of spectral ratios at the intersection points between various sections in the city of Thessaloniki. Since the local geological model under an intersection point is common to both profiles, the differences in the obtained results can only be due to the different excitation of the incoming wavefield and the differences of propagation along the 2-D profiles. Such a comparison checks in the most reliable way the response of each intersection point to different earthquake "scenarios".

The results obtained by Triantafyllidis et al. (2002c) are shown in Figure 38, where the solid lines represent the mean ground amplification (using the spectral ratios calculated with hybrid method along the two or three intersecting profiles), at the nine intersection points of these profiles. Shaded areas show the variation zone of the mean spectral ratios plus/minus one standard deviation. Light shaded bands are the areas where the average of the horizontal components (radial and transverse) variates (thick line), while the dark shaded area is the corresponding zone for the vertical mean ratio (thin line). At the broader area limited by points A5-A3-AA, the smoothing of the average ground response (Figure 38d) is even more obvious and the standard deviation zone is even wider, especially for the vertical component, particularly at low frequencies (below $2 \mathrm{~Hz}$ ).

In the figure one can observe for the same location (e.g. three close-by intersection points of profiles A5-A3 (a), A5-AA (b), and A3-AA (c)) differences both in the spectral shape as well as in the amplification level and in the frequency where the maximum amplifi- cation occurs. These differences are obvious in both components, horizontal and vertical. Since the regional 1-D velocity model underneath the whole area is the same, the effects of the propagation path up to the target area are minimized. Hence, the main factor giving rise to the observed differences is the variability of the seismic wavefield generating sources (mechanism and distance) used for the simulations. At the broader area limited by points A5-A3-AA, the smoothing of the average ground response (Figure 38d) is even more obvious and the standard deviation zone is even wider, especially for the vertical component, particularly at low frequencies (below $2.5 \mathrm{~Hz}$ ).

12. The seismic hazard in Sofia region is related to local destructive earthquakes with intensity up to IX (MSK), like the one of 1858 (Bonchev et al., 1982; Christoskov et al., 1989), and with the impact of more distant sources, which have caused macroseismic effects with intensity up to VII in the city. The seismicity of the
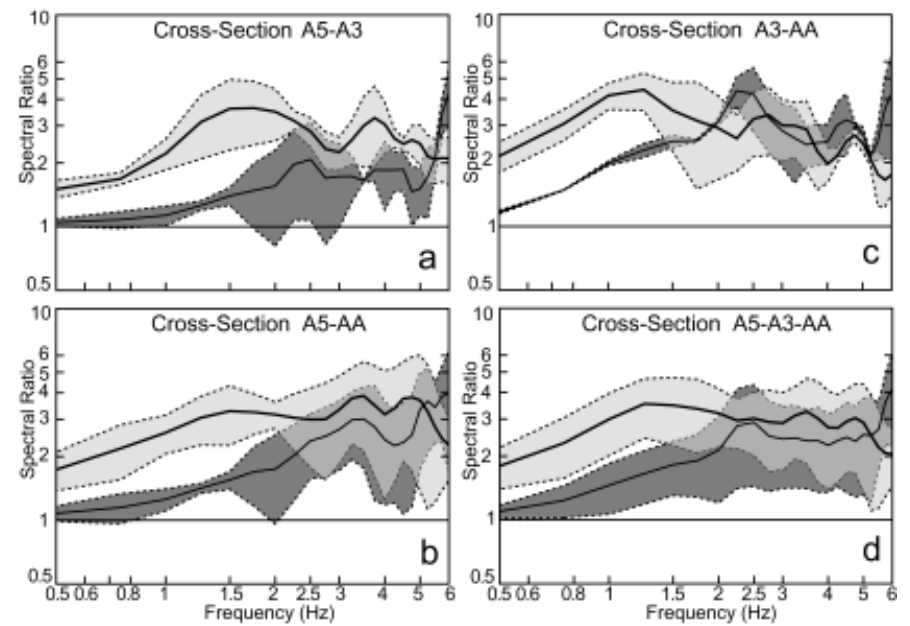

Figure 38. Means of spectral amplification calculated at the common points of the cross sections (solid lines). Shaded areas show the variation range plus/minus one standard deviation of the average of horizontal (light area) and vertical (dark area) mean amplification. Figure $38 a, 38 b$ and $38 c$ describe the variability of the ground motion response at each intersection point. Intersection points A3-A5, A3-AA and A5-AA are very close together (see Figure 35) so Figure 38d estimates the overall variability of ground response within a very small area in the city. 
region is mainly shallow. The epicentral map for earthquakes with magnitude $\mathrm{M}$ in the range 4.0-7.0, within the Sofia graben and the adjacent horsts, is shown in Figure 39. The strong and moderate earthquake epicenters are concentrated along the faults, and also on the fault crossing joints, mainly in the central and the southern parts of the Sofia graben. The epicentral map of earthquakes with magnitude $\mathrm{M}<4.0$ for the period $1996-1999$ is shown in Figure 40. The weak earthquake epicenters are located along the faults as well as in the horsts to the north, east and south of the Sofia graben. The shallow earthquakes occur mainly at depths of up to $10 \mathrm{~km}$ (Figure 39 and 40). The earthquake hypocenters localized at depths of $11-30$ $\mathrm{km}$ are concentrated near the Vitosha fault and in the vicinity of its crossings with the Chepintsi and the Vladaya faults (Matova, 2001).

The seismic hazard maps of the Circum - Panonian Region constructed by Panza and Vaccari (2000) show that Sofia could suffer macroseismic intensity up to X (MSK - 76) (Medvedev, 1977). According to the information available (Petkov and Christoskov, 1964), the macroseismic intensity at Sofia varies within 2 degrees

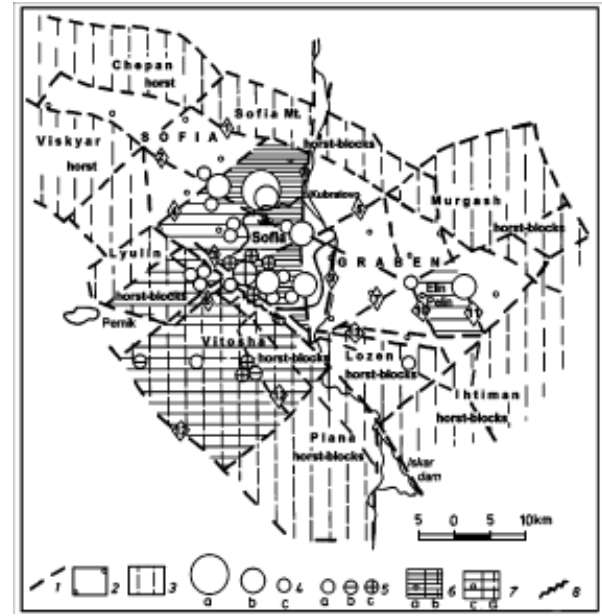

Figure 39. Seismic events with magnitude $M$ in the range from 4.0 to 7.0. 1 -faults: $a$ - block boundary, $b$ - sector of the Vitosha fault zone activated during the 1858 Sofia earthquake (M $=6.5$ 7.0); 2 - block of the Sofia graben; 3 - block of the adjacent horsts; 4 - epicenters of earthquake with magnitude: $a-M=6.0$ - 7.0, $b-M=5.0-5.9, c-M=4.0-4.9 ; 5-$ depths of earthquakes hypocenters: $a-$ up to $10 \mathrm{~km}, \mathrm{~b}-11-20 \mathrm{~km} ; \mathrm{c}-21-30 \mathrm{~km} ; 6-$ block of relatively high concentration of epicenters: $a$ - of high concentration and $b$ - of moderate one.

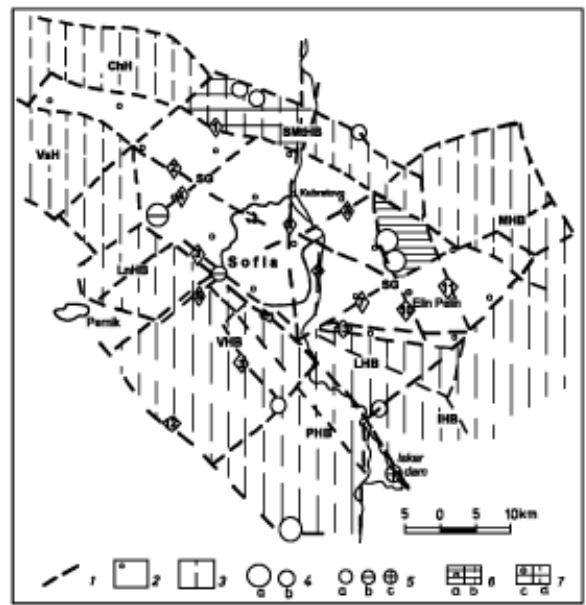

Figure 40. Weak earthquakes in the blocks of the Sofia graben and the adjacent horsts in the 1996 - 1999 period. 1 - fault, 2 graben block, 3 - horst block, 4 - earthquake epicenters: $a-M=$ 3.0 - 3.6, $b-M=2.5-2.9 ; 5-$ depth of earthquake hypocenters: $a$ - up to $10 \mathrm{~km}, \mathrm{~b}-11-20 \mathrm{~km}, \mathrm{c}-21-31 \mathrm{~km}$.
(MSK). The maximum intensity (MSK) I = IX is expected in the south-eastern central part of the town. If coseismic effects are considered as well (e.g. land-sliding, liquefaction) the macroseismic intensity distribution within the investigated territory changes visibly, particularly in the south-western part of the region but the variation is still $\Delta \mathrm{I}=2$.

A preliminary analysis of the site response in the Sofia region has been performed on the base of the elastic vibration periods of the site using the data obtained from 14 boreholes, reaching depth up to $600 \mathrm{~m}$. Three models with different depths have been used to perform these analyses. Models $\mathbf{M}_{30}$ (30 m deep) and $\mathrm{M}_{50}$ (50m deep) are based on the Eurocode 8 soil classification. Model $\mathrm{M}_{\&}$, that reaches the depth of the bedrock (shear velocity $V_{S}>750 \mathrm{~m} / \mathrm{s}$ ) has been compiled following the soil classification provided in the Bulgarian Code'87. The soil has been discretized into a finite element mesh of one-dimensional shear elements. Viscous damping and lumped mass system used in the computations yielded plain distributions of the first four free periods. The results for the fundamental free period for models $\mathrm{M}_{30}$ and $\mathrm{M}_{50}$ are shown in Figures 41 and 42.

Those maps can be used for preliminary practical purposes, e.g. to keep the designers aware of the types of structural systems that should be avoided for a given location (Paskaleva et al., 2002). The high seismic risk requires, however, the development of appropriate earthquakes scenarios and the use of advanced ground motion modeling techniques to define the seismic input for the city of Sofia. For this purpose, we have used the available information to define the four shallow earthquake scenarios, as shown in Figure 43 (e.g.

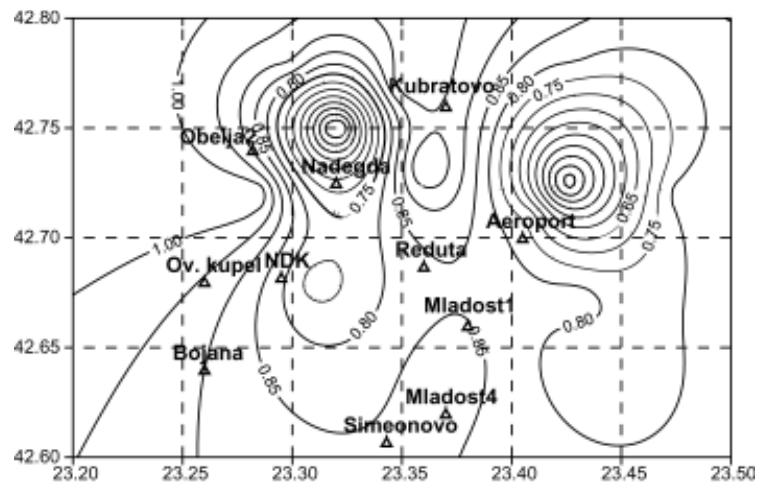

Figure 41. Site response estimation at Sofia: Distribution of the fundamental free period, Model30 (30m depth).

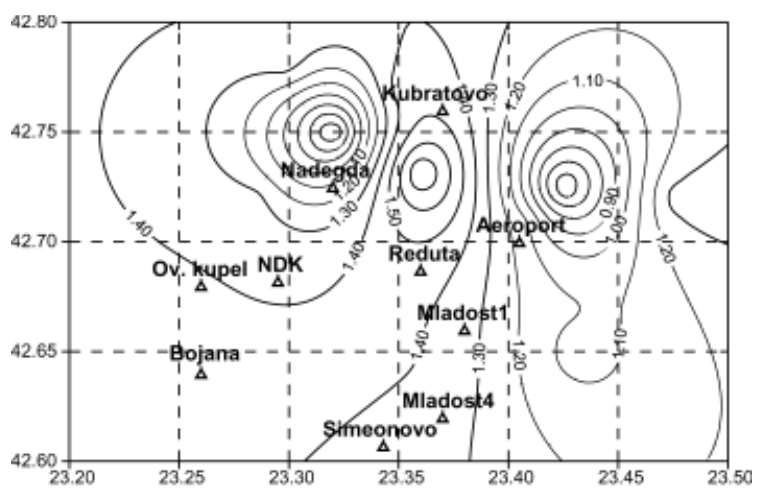

Figure 42. Site response estimation at Sofia: Distribution of the fundamental free period, Model50 (50m depth).

Earthquake catalogues: NEIC, CSEE; Shanov et al., 1992; Glavcheva et al., 1996) and the geological cross sections used in the computations (Petrov and Iliev, 1970; Kamenov and Kojumdjieva, 1983; Frangov, 1995; Ivanov et al., 1998). Complete synthetic seismic signals have been generated for all sites of interest along the profiles investigated (Figure 43, 100 sites per profile). The results obtained 
through theoretical modeling were successfully compared with the available macroseismic field information (Slavov et al., 2002).

The site amplification has been defined as RSR, which has been mapped versus epicentral distance and frequency for all ground motion components, TRA, RAD and VER, for all profiles investigated. The site amplification along the CD profile exposed to a distant earthquake is shown in Figure 44. The RSR reaches $7-8.5$ (at $2.5-5 \mathrm{~Hz})$ for RAD, $3.5-5.0(3.5-5.0 \mathrm{~Hz})$ for VER and about 6

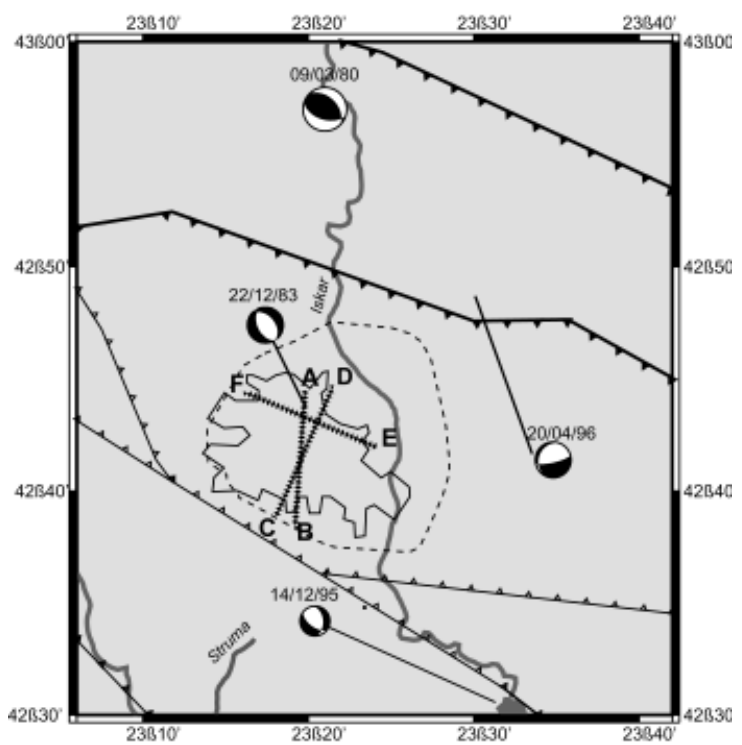

Figure 43. A generalized tectonic scheme of the Sofia region, investigated profiles $(A B, C D$ and $E F)$ and location and focal mechanisms of the considered earthquakes.

$(3.5-4.5 \mathrm{~Hz})$ for the TRA. For all scenarios the maximum amplifications along the profiles coincide with the zones of weak or intermediate soil conditions (e.g. Paskaleva et al., 2001) and the presence of thick sediments leads to an increase of the ground motion amplitudes and of the amplification, due to multiple reflections. A comparative study of the spectral amplification of the different ground motion components show that TRA, RAD and VER give a significant contribution to the seismic input. The RAD component exerts the largest influence on the site amplification $(\mathrm{RSR}=6$ ), compared to the TRA (RSR $\sim 5$ and less) and VER (RSR < 4). This result differs from the widely accepted idea, that the transverse component has a predominant role in the seismic input definition. Therefore, in the engineering practice, the contribution of the $\mathrm{P}-\mathrm{SV}$ waves to the seismic input must be considered with care.

13. The seismicity record and the recent deterministic hazard assessment show that the earthquake hazard at Russe (NE Bulgaria) is controlled by both Shabla and Vrancea seismic sources, more significantly by the intermediate-depth Vrancea sources, even if they

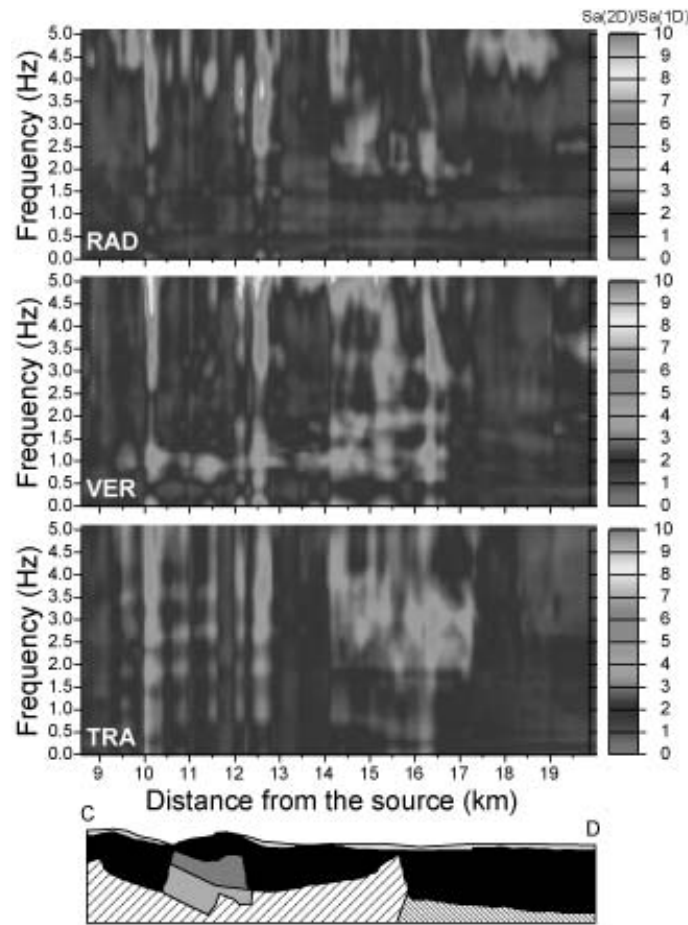

Figure 44. Profile CD: RSR versus frequency and epicentral distance

are located about $220 \mathrm{~km}$ far from the city. Macroseismic intensity I $=$ VII - VIII (MSK-64) were reported at Russe due to the Vrancea quake in 1940 and 1977 (Brankov, 1983). A schematic representation of the reported macroseismic intensity versus the magnitude and focal depth of Vrancea earthquakes is shown in Figure 45, where one can see that the maximum reported correspond to the intermediate depth events. The recent deterministic modeling of the Vrancea earthquake hazard (Panza and Vaccari, 2000) points out that the Vrancea earthquakes can produce at Russe ground displacements up to $30-60 \mathrm{~cm}$ and peak accelerations over $0.5 \mathrm{~g}$. The moving windows technique, applied to the available strong motion accelerograms recorded in NE Bulgaria from Vrancea seismic events, shows control periods of the response spectra Tc in the range of $0.4-1.6$ sec (Paskaleva et al., 2001). The wavefield radiated by the Vrancea intermediate-depth earthquakes, mainly at long periods, attenuates with distance less rapidly than the wavefield of the earthquakes in other seismically active zones in Bulgaria (Todorovska et al., 1995).

To define the seismic input at Russe from Vrancea events, an analytical deterministic technique, based on the simultaneous account of the fault mechanism and seismic wave propagation, has been applied. This approach differs significantly from the todayís engineering design practice that relays upon rock-site hazard maps
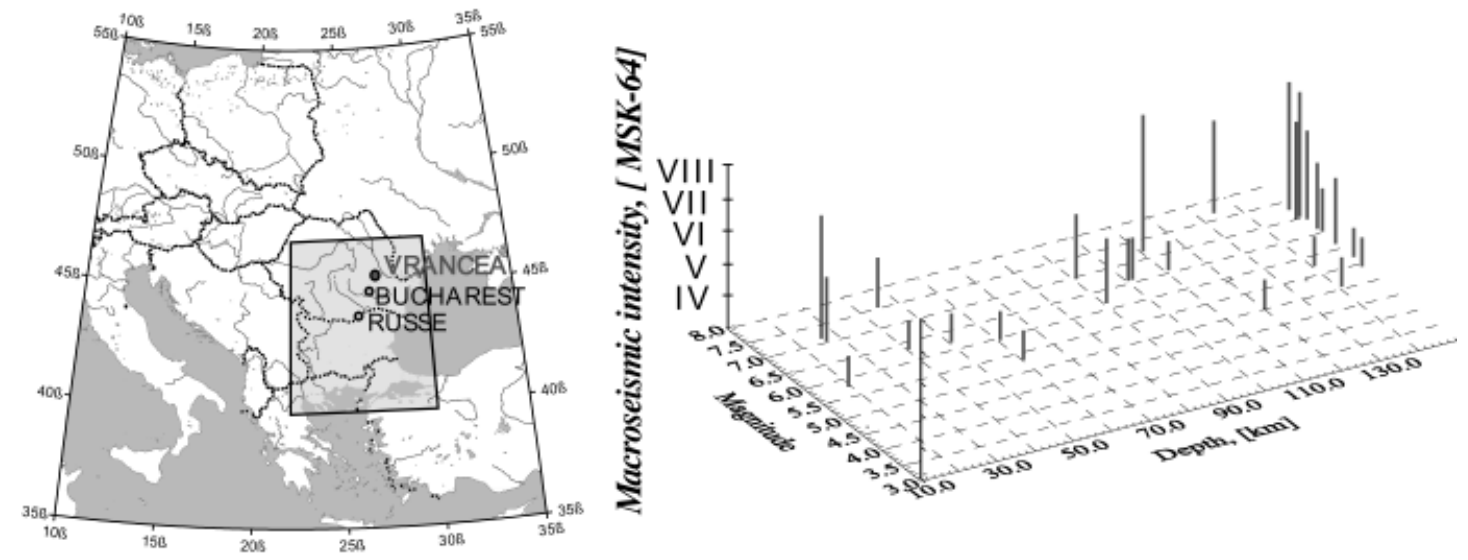

Figure 45. Schematic view of the location of Russe site with respect to the Vrancea intermediate-depth sources (left) and macroseismic intensity [MSK] reported at Russe due the Vrancea sources versus earthquake magnitude and focal depth (right). 
and applies, by convolution, the site correction at a later stage. The innovative method combines the modal-summation technique (Panza, 1985; Panza and Suhadolc, 1987; Florsch et al., 1991; Panza et al., 2000), used for the anelastic bedrock, and the mode coupling approach (Vaccari et al., 1989; Romanelli et al., 1996, 1997), used for the anelastic, laterally inhomogeneous, sedimentary media. The engineering aspect of the study has been focused on the built environment characterised by long free periods and a frequency range up to $1 \mathrm{~Hz}$ is considered in all computations. The seismic source has been modelled as a buried double couple, and the seismic source moment tensors provided by Dziewonsky et al. (1991) and Radulian et al. (2000) have been considered in the computations. The model is formed by two different quarter-spaces in welded contact: (1) the bedrock model that contains the source and the path from the Vrancea seismic sources to the target sites and (2) a NE $42^{\circ} \mathrm{SW}$ oriented profile crossing the town of Russe. The regional structural model, representative of the path Vrancea-Russe, passes through the Carpathians and the Moesian Platform, where Pliocene and significant Quaternary deposits are present (Brankov, 1983; Radulian et al., 2000). The detailed geological and geotechnical data available for the uppermost 100 m in Russe (Evlogiev, 1993; Evlogiev et al., 2000) have been used to define the uppermost part of the local model (Paskaleva et al., 2001). The overview of the engineering geological conditions at Russe shows a rock basement covered by incoherent sediments, where complicated ground conditions are combined with a shallow water table (Evlogiev et al., 2000; Paskaleva et al., 2001). Maps representing zoning of the town based on the soil classifications, as provided in different seismic codes, have been constructed. The results show that for Russe site, the EC8 (Eurocode, 1994) soil classification, Figure 46, is the most suitable in comparison with the Bulgarian and Romanian (MLPAT, 1997) Codes (Paskaleva et al., 2001).

Synthetic seismic signals along the representative geological cross section at Russe have been computed for five recent, strong and intermediate-depth, Vrancea earthquakes that occurred during the last century $(1940,1977,1986$ and 1990). Fourier amplitude spectra, response spectra and absolute energetic input have been derived both from the synthetic signals and the few existing records. Synthetic signals have been constructed and compared with the available observations (Nenov et al., 1990). The validation of the theoretical results against the available data (Kouteva et al., 2000; Paskaleva et al., 2001) has been performed on the base of the comparisons of different quantities used in the engineering practice (e.g. acceleration time histories, a(t), peak ground accelerations, PGA, Fourier amplitude spectra, FS, and response spectra, SA (e.g. see Figure 47). A further validation of the obtained results (Panza et al., 2002) was drawn out comparing the synthetic and the observed Absolute Energy Input, EI, (Uang and Bertero, 1990; Decanini and Mollaioli, 1998), Figure 48. Synthetic SA for four representative points, P.1, P.2, P.3 and P.4, that are located at the terraces crossed by the profile "a-a" (Figure 46) have been derived for Vrancea 1986 (VR86) and Vrancea 1990 (VR90) earthquakes (Paskaleva et al., 2001). The synthetic response spectra for VR86 are shown in Figure 49. The site amplification at Russe, defined by RSR, has been mapped versus epicentral distance and frequency (Panza et al., 2002; Kouteva et al.,

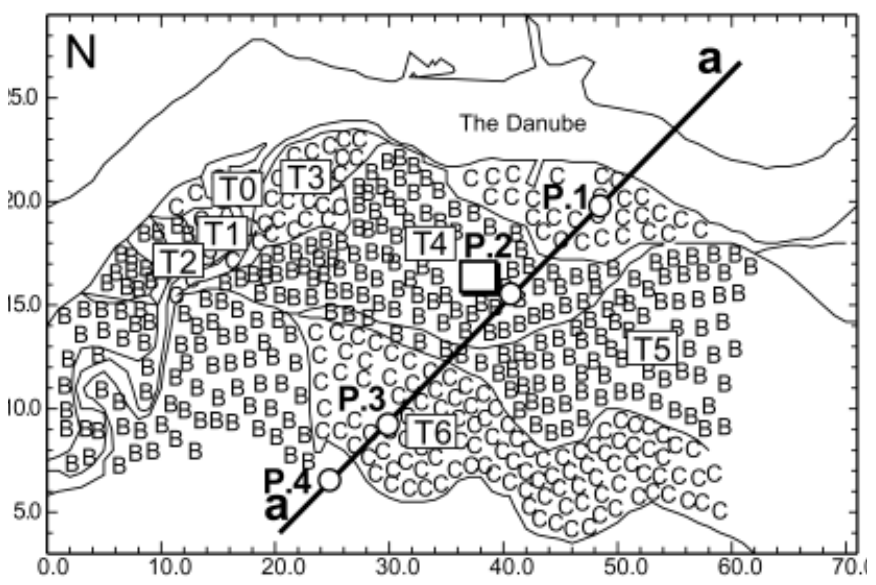

Figure 46. Scheme of the soil conditions at the site of Russe according to EUROCODE 8 crossed by the investigated profile a-a.

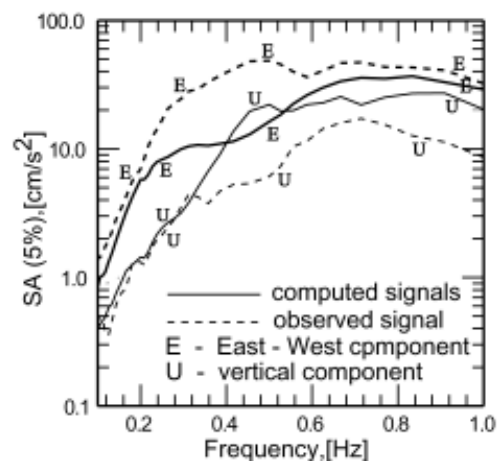

Figure 47. Validation of the theoretical results considering the recorded accelerations at Russe due to the Vrancea 1986 earthquake. Response spectra amplitude for $5 \%$ damping for East-West $(E)$ and for the vertical $(U)$ components for both theoretical (solid line) and observed (dashed line) signals are shown.

2001). The example for VR86 is shown in Figure 50. For the same event, the site amplification along the profile investigated is shown in Figure 51. The results of the analysis of the influence of some reasonable variations of the seismic source moment tensor on the ground motion at the site show that, contrary to the common engineering practice, the contribution of the P-SV waves to the seismic input must be considered with care (Kouteva et al., 2001). The comparison between the site responses due to the considered earthquakes (Panza et al., 2002; Kouteva et al., 2001) shows significantly different amplification pattern for all the components. This result indicates that the ground motion at the site depends not only on the elastic and non-elastic characteristics of the propagation media, but on the seismic source moment tensor and its location as well.
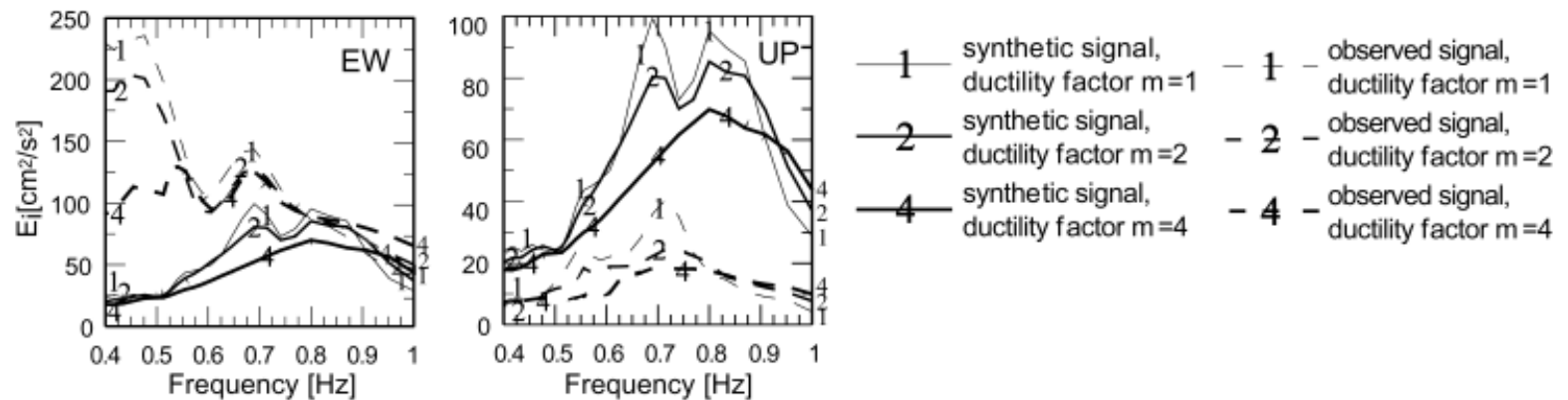

Figure 48. Validation of the theoretical results considering the recorded accelerations at Russe due to the Vrancea 1986 earthquake. Absolute energy input (Uang and Bertero, 1990; Decanini and Mollaioli, 1998) for three ductility factors for East-West (EW) and for the vertical (UP) components for both theoretical (solid line) and observed (dashed line) signals are shown. 

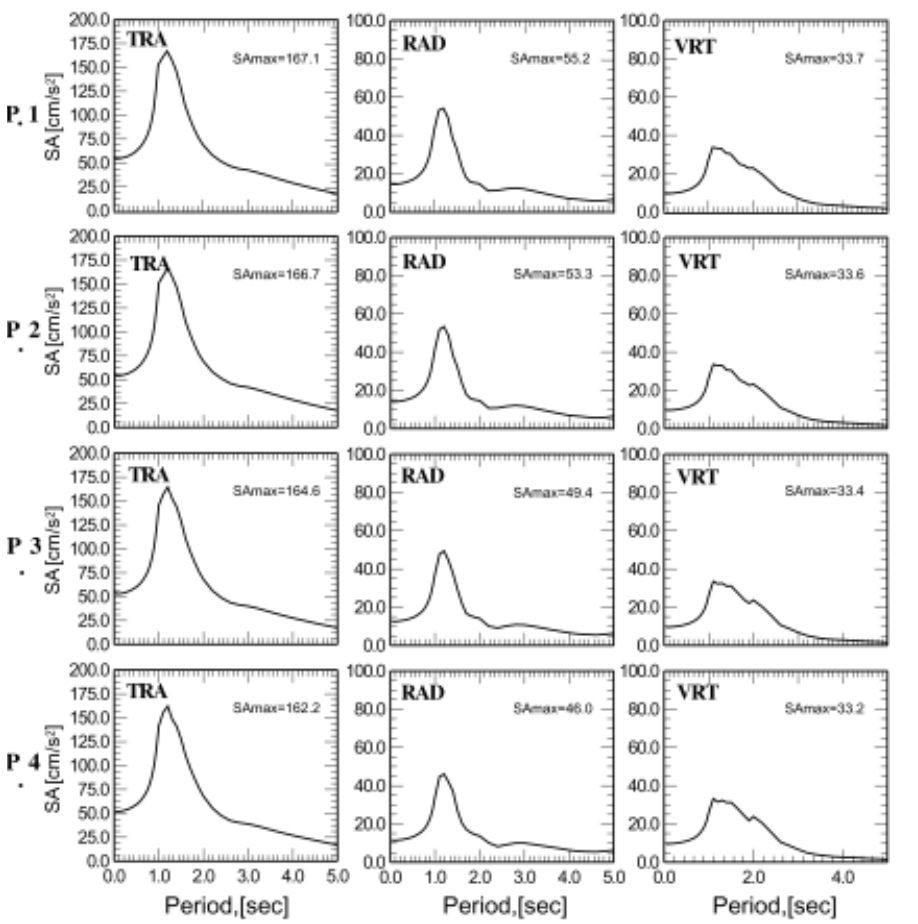

Figure 49. Russe site, Vrancea 1986 earthquake. Response spectra for 5\% damping, $S A\left(\mathrm{~cm} / \mathrm{s}^{2}\right)$, at receivers $P .1, P .2, P .3$ and P.4 located along the profile a-a, shown in Figure 46. Transverse (TRA), radial (RAD) and vertical (VRT) component are shown.

14. Within the framework of the project large tectonic domains of central Europe, Alps, Apennines, Carpathians, Dinarides and Balkanides have been studied with the goal to identify large cities exposed to the seismic hazard of $M \geq 6.5$ events. This has been done by means of the identification of seismogenic nodes that are specific structures formed around the intersections of the fault zones (Gorshkov et al., 2000; 2002). The nodes have been delineated with the morphostructural zoning method, based on the idea that the lithosphere is made-up by different-scale blocks, separated by mobile boundaries (Alexeevskaya et al., 1977; Rantsman, 1979). The crustal earthquakes with $M \geq 6.0$ recorded in the region are nucleated at some of the mapped nodes. With the assumption that the future strong events will occur at the nodes, the seismic potential of each node has been evaluated for two magnitude thresholds, $M \geq 6.0$ and $M \geq 6.5$. The pattern recognition algorithm "CORA-3" has been used in order to identify the nodes capable of earthquakes with $M$ $\geq 6.0$. Due to the insufficient number of the recorded quakes with $M$ $\geq 6.5$ in the studied regions, pattern recognition is not applicable to define the nodes prone to such events. Instead these nodes have been identified by the criteria of high seismicity nodes, previously derived from pattern recognition in the Pamirs and Tien Shan (Kossobokov,
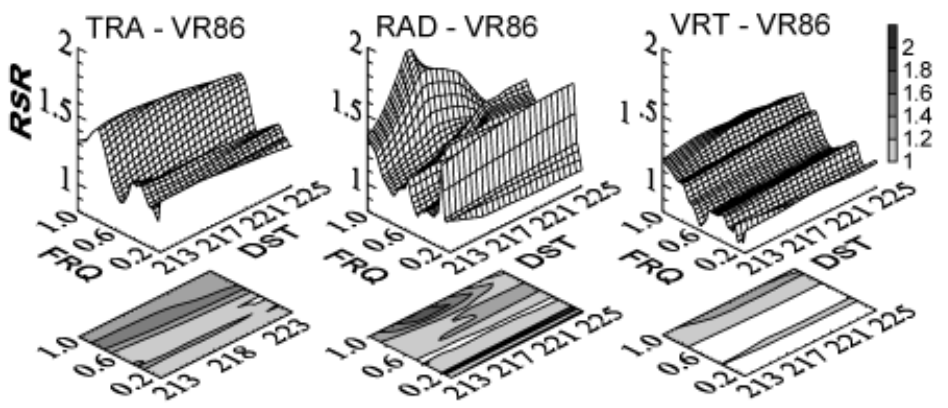

Figure 50. Russe site, Vrancea 1986 earthquake. Site amplification defined as RSR along the considered profile, mapped versus epicentral distance and frequency. Transverse (TRA), radial (RAD) and vertical (VRT) component are shown.
1983). The applicability of these criteria was discussed by (Gorshkov et al., 2000). Here we illustrate the seismogenic nodes delineated in Sicily, peninsular Italy (Gorshkov et al., 2002) and the Alps. The seismogenic nodes capable of $M \geq 6.5$ defined in these regions are shown in Figure 52.

The information on seismogenic nodes can be directly used for seismic hazard evaluation for different objects, including cities, roads, nuclear power plants and others. Table 1 illustrates that many large cities located within the studied regions are exposed to seismic hazard of $M \geq 6$. 5 .

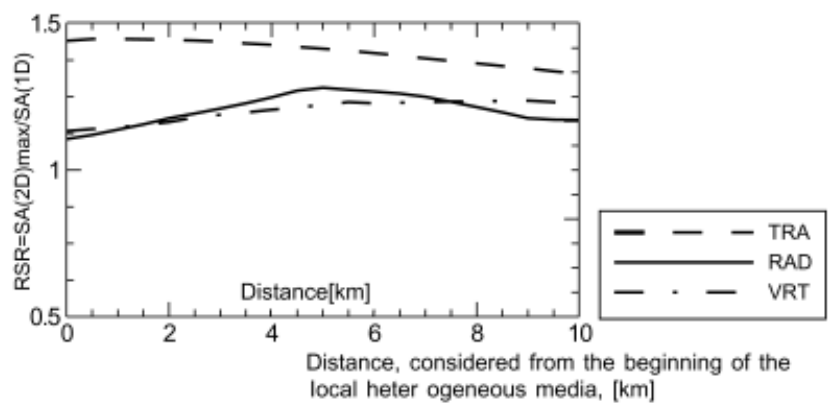

Figure 51. Russe site, Vrancea 1986 earthquake. Amplification along the investigated defined as the ratio between the maximum $S A$ amplitude, obtained considering the local heterogeneity and the corresponding value for the bedrock model. Transverse (TRA), radial (RAD) and vertical (VRT) component are shown.

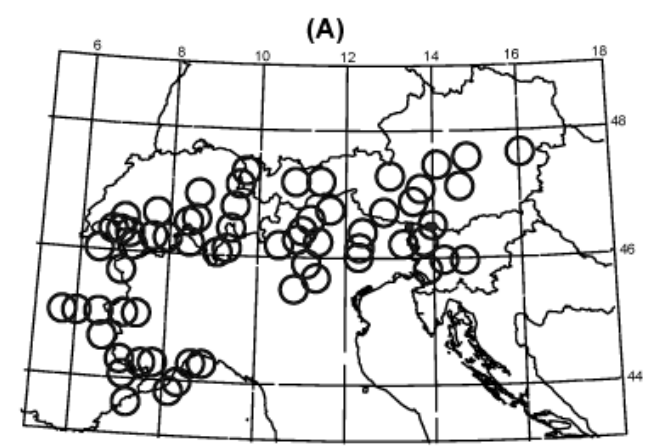

(B)

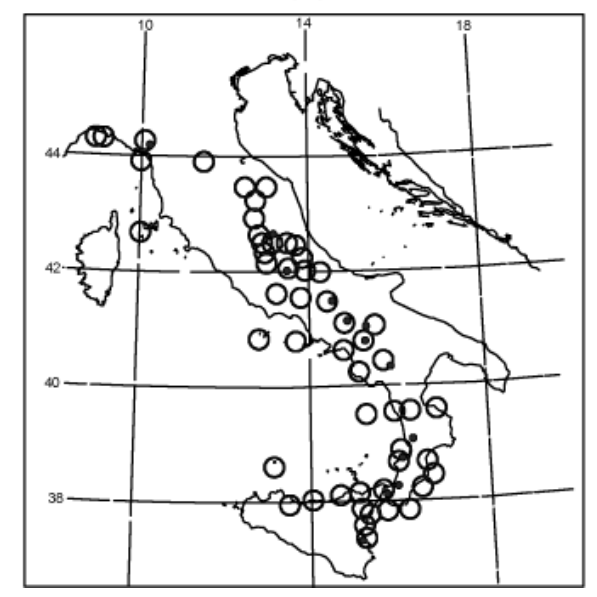

Figure 52. Seismogenic nodes capable of earthquake with $\mathrm{M} \geq$ 6.5 in the Alps (A) and in Sicily and peninsular Italy (B). Circles are the nodes with radius of $25 \mathrm{~km}$. Black dots are epicenters of recorded earthquales with $\mathrm{M} \geq 6.5$ (after Camassi and Stucchi., 1997). 
Table 1. Large cities situated within a distance of $50 \mathrm{~km}$ and 100 $\mathrm{km}$ from the center of the seismogenic nodes prone to $\mathrm{M} \geq 6.5$

\author{
Large cities in the studied region (see Figure 52 )
}

\begin{tabular}{l|l|l}
\hline Located in & \multicolumn{1}{|c|}{ within 50km from a node } & \multicolumn{1}{c}{ within 100km from a node } \\
\hline Italy & Benevento, Bolzano, Catania, & Ancona, Ascoli Piceno, Avellino, \\
& Catanzaro, Cosenza, Cuneo, Florence, & Brescia, Campobasso, Caserta, \\
& Como, Foggia, Latina, Mantova, \\
& Menoa, L'aquila, La Spezia, Mantova, & Naples, Perugia, Pesaro, \\
& Calabria, Salerno, Savona, Terni, & Pescara, Pordenone, Rome, \\
& Turin, Trento, Trieste, Udine, & Syracuse, Treviso, \\
France & Verona,Vicenza. & Ansy, Grenoble, Nice \\
Swiss & Geneva, Lausanne, Luzern & Bern, Zurich \\
Austria & Innsbruck, Klagenfurt & Salzburg, Sopron \\
Slovenia & Ljubljana & \\
\hline
\end{tabular}

\section{Conclusion}

The results obtained in the identification of large cities exposed to seismic hazard of $\boldsymbol{M} \geq \mathbf{6 . 5}$ events indicate that the seismic potential is generally higher than the one consistent with historical and instrumental records. A number of nodes where strong events have not been recorded to date, have been recognized to be prone to large earthquakes and they may warrant a detailed interdisciplinary investigation. The existence of such a large seismic hazard makes preventive actions mandatory, among which seismic microzonation and construction of earthquake scenarios play a key role.

For detailed microzonation studies the ground response at a given location must be, therefore, examined for various earthquake scenarios, i.e. earthquakes with different focal mechanisms, epicentral distances, azimuths and magnitudes, compatible with the characteristics of the active faults and nodes in the neighboring areas. In this way, the expected site amplification, estimated theoretically, should be reliable.

As a matter of fact, local site effects can be strongly dependent upon the characteristics of the seismic source (Romanelli and Vaccari, 1999; Field et al., 2000; Panza et al., 2001; Moldoveanu and Panza 1999, Moldoveanu et al., 2000; Panza et al., 2002, Triantafyllidis et al., 2002c, Herak et al., 2002). Therefore convolutive methods, currently used for hazard assessment, can be severely in error, and the use of synthetic seismograms is fundamental, even when relevant observational data are available, in order to explore the local responses that may correspond to sources that are different from the known ones.

Our results show that a preventive definition of the seismic hazard in any large town or megacity can be obtained immediately, without having to wait for another strong event to occur, from the computation of time histories corresponding to possible seismotectonic scenarios for different sources and structural models. The approach used to model the ground motion provides acceleration, velocity, and displacement time histories and related quantities of earthquake engineering interest. Then, the formulation of reliable building codes, based on the evaluation of the main potential earthquakes, will have a great impact on the effective reduction of their seismic vulnerability. Once a statistically significant amount of observation is available, it will be worth reaching a reasonable compromise between the probabilistic and the scenario approaches making use of the advantages of each method.

The comparative analysis of the spectral amplification of the different ground motion components show that TRA, RAD and VER give a significant contribution to the seismic input and that RAD can exert the biggest influence on the site amplification. This fact contradicts the widely accepted idea, that the transverse component has a predominant role on the seismic input definition.
In particular, the site responses for Bucharest, in frequency and space domains, are strongly dependent on Vrancea source properties. Therefore, to estimate in a reliable way the site effects, it is recommended to incorporate in the direct modeling of the wave field all factors controlling the ground motion at the site avoiding convolutive methods. Five zones are defined accordingly with their geological setting in the area of Bucharest, each characterized by different spectral responses. The response spectra indicate that peak spectral values as high as $0.2 \mathrm{~g}$ for frequencies lower than $1 \mathrm{~Hz}$ are compatible with the past seismicity.

The preliminary results obtained in Zagreb suggest that the largest amplification of ground motion (exceeding a factor of 3 ) may be expected beneath the very center of the city. This indicative finding should stimulate similar studies along other and possibly more detailed profiles, using realistic source models as well as all possible earthquake scenarios in the area.

The realistic evaluation of the local effects, in the frequency range of interest for civil engineering, in Delhi City has been made along two profiles: the RSR are as large as about 7 on the horizontal component and as large as 6 on the vertical. Such important result is a further evidence of the danger of applying the method, originally applied by Langston (1979) for crustal and upper mantle studies, based on the measurement of the spectral ratio between the horizontal and vertical components of motion. The method is based on the assumption, not always fulfilled, that the propagation of the vertical component of motion (in general only S-waves are considered) is not perturbed by the uppermost surface layers, and can therefore be used to remove source and path effects from the horizontal components.

Three-dimensional geological and geophysical models have been built up for Beijing City. With this database, realistic three component broadband synthetic seismograms have been calculated along five selected profiles and the results have been compared with macroseismic data and digital records. Along all the profiles the thick Quaternary sediments cause large amplitude and long duration of the ground motion, due to resonance effects and to the excitation of local surface waves. Four zones are defined according to the thickness of the Quaternary sediments in the area of Beijing City, each characterized by different spectral responses. The response spectra indicate that peak spectral values as high as $0.1 \mathrm{~g}$ for frequencies up to $4 \mathrm{~Hz}$ are compatible with the past seismicity and can be well exceeded if an event similar to the 1697 Sanhe-Pinggu occurs.

The validation of the synthetic seismograms with the instrumental recording at Torre del Greco station, together with the detailed study of stratigraphies, Vs profiles on one side, and the use of Rayleigh group velocities for Vs measurements in highly noisy areas, without any drilling, on the other, has allowed us to model the ground motion in Naples. Response spectra have been readily computed based on average or maximum spectral amplification. They show significant spectral accelerations which explain, in particular in the historical center, the damage to masonry buildings with resonant period of $0.3-0.5 \mathrm{~s}$ caused by the 1980 Irpinia event.

Cairo area is very vulnerable to both local and distant earthquake. This is mainly due to presence of soft sediments in the Nile valley that amplify the seismic waves by factors of up to 13 . Both modeling and observations indicate that the maximum amplification is concentrated mainly at the edges of the Nile and in the areas where the sediments are thick and the underground water table is shallow. The amplification becomes stronger at low frequencies and this may explain the severe effects caused by distant earthquakes in the Nile valley and its delta.

The results obtained in Thessaloniki show that the source plays an important role in the site response. Different source characteristics, e.g. epicentral distance and azimuth, produce variances of the expected mean site response, which are reflected in the standard deviation of that mean.

The city of Sofia is exposed to a high seismic risk that requires reliable definition of the seismic input for earthquake engineering purposes and the regular seismic monitoring in the region. Lacking both instrumental data and the possibility of accurately quantifying the magnitude scaling and the attenuation characteristics of the large 
magnitude earthquakes, the use of realistic synthetic seismograms, combined with the macroseismic data available, represent the only possibility for the assessment of the seismic input.

The results obtained in Russe, confirm that: (1) urban areas located at large epicentral distances with respect to the seismic source may be prone to severe earthquake hazard; (2) all ground motion components give a significant contribution to the design seismic input; (3) to define the seismic load different earthquake scenarios must be considered. These scenarios must be constructed taking into account the various factors influencing the ground motion like the seismic source, the path to the site and the geological properties of the site.

This study deals with a two-dimensional problem of wave propagation and ground motion modeling. The approach used is capable to provide, in a reasonable amount of time, large sets of seismic signals and related quantities of earthquake engineering interest. Thus it makes it possible to obtain the definition of the seismic input at low cost and exploiting large quantities of existing data (e.g. geotechnical, geological, seismological). Considering the relevance of the problem, it is advisable to extent the investigations to handle threedimensional geometry, for the theoretical assessment of possible 3-D effects.

The activity in each city will continue with the twofold purpose of refining the obtained results about the seismic microzonation and of putting them in a form more and more suitable for End Users. Examples are the UNESCO-IUGS-IGCP project 457 "Seismic Hazard and Risk Assessment in North Africa (SHRANA)" and other regional projects, presently shaping up, in Latin America, Asia and Europe.

\section{Acknowledgements}

This paper is the result of the assemblage of the local Centers contributions, made by the project Leader. Special thanks go to M. Herak, I. Paskaleva and F. Vaccari for their help in revising the final text and figures that represent a compilation of the contributions of the different local Centers that participated in the project.

\section{References}

Aki, K., 1987, Strong motion seismology, In: Strong ground motion seismology (eds. M. Erdik and M. Toksöz), NATO ASI Series, Series C: Mathematical and Physical Sciences, D. Reidel Publishing Company, Dordrecht, 204, 3-39.

Alekseevskaya, M.A., Gabrielov, A.M., Gvishiani, A.D., Gelfand, I.M. and Ranzman, E.Ya., 1977, Formal morphostructural zoning of mountain territories, J. Geophys, 43, 227-233

Alterman, Z.S. and Karal, F.C., 1968, Propagation of elastic waves in layered media by finite difference methods, Bull. Seism. Soc. Am., 58, 367-398.

Alvarez, L., Panza, G.F., Vaccari, F. and Gonzalez, B., 2001, Modeling of seismic ground motion in Santiago de Cuba city from earthquakes in Oriente Fault seismic zone. Pure and Appl. Geophys, 158, 1763-1782.

Ambraseys, N.N., Melville, C.P. and Adam, R. D., 1994, The seismicity of Egypt, Arabia and the Red Sea a historical review. Cambridge University Press, UK.

Anastasiadis, A., 1994, Contribution to the study and the determination of dynamic properties of typical Greek soils, PhD Thesis (in Greek), Dept. of Civil Eng., Aristotle Univ. of Thessaloniki, pp. 1-389.

Arango, E., 1996, Geodinámica de la región de Santiago de Cuba en el límite de las Placas de Norteamérica y el Caribe, Tesis en opción al Grado de Master en Ciencias. Instituto Politécnico Nacional, México, D.F. 111pp.

Arriaza, G., 1998, Nuevos enfoques en la interpretación y procesamiento de las ondas refractadas para el estudio del basamento de Cuba, Tesis presentada en opción al grado científico de Doctor en Ciencias Geológicas, La Habana, 179 pp.

Barazangi, M., Fielding, E.J., Isacks, B., and Seber, D., 1996, Geophysical and geological databases and CTBT monitoring: A case study of the Middle East. In: E.S. Husebye and A.M. Dainty eds., Monitoring a Comprehensive Test Ban Treaty; Kluwer Academic Publishers, The Netherlands, 197-224.
Ben-Menahem, A. and Harkrider, D.G., 1964, Radiation patterns of seismic waves from buried dipolar point sources in a flat stratified Earth, J. Geophys. Res., 69, 2605-2620.

Benouar, D., 1993, The seismicity of Algeria and Adjacent Regions During the Twentieth Century, Ph.D. thesis, Imperial College of Science, Technology and Medicine, University of London, 1993, $712 \mathrm{pp}$.

Berge-Thierry, C., Lussou, P., Hernández, B., Cotton E and Gariel, J.C., 1999, Computation of the strong motions during the 1995 HyogokenNambu earthquake, combining the k-square spectral source model and the discrete wavenumber technique. In: Proceedings of the Second International Symposium on the Effects of Surface Geology on Seismic Motion, Yokohama, Japan, 1-3 December, 1998; Volume 3, The Effects of Surface Geology on Seismic Motion, Recent Progress and New Horizon on ESG Study, 1414-1424.

Bobenko, V.G., Shcherbakova, B.Ye. and Hernández, G., 1980, New geophysical data on the deep structure of eastern Cuba (in Russian), Sov. Geol., 9, 101-109.

Bonchev, E., Bune, V., Christoskov, L., Karagyuleva, J., Kostadinov, V., Reisner, G., Rizikova, S., Shebalin, N., Sholpo, V. and Sokerova, D., 1982, A method for compilation of seismic zoning prognostic maps for the territory of Bulgaria, Geologica Balkanica, 12, 3-48.

Boore, D. M., 1972, Finite difference methods for seismic waves propagation in heterogeneous materials, In: B.A. Bolt, ed., Methods in Computational Physics, Vol.11, New York, Academic Press, 1-37.

Brankov G., (Editor), 1983, Vrancea Earthquake in 1977. Its after-effects in the People's Republic of Bulgaria, Publ. House of the Bulg. Ac. of Sciences, 1983, pp. 428; Sofia (in Bulgarian).

Bulgarian Code, 1987, Code for design of structures in seismic regions, 1987, Sofia, Bulgaria.

Christoskov, L., Georgiev, Tzv., Deneva, D. and Babachkova, B., 1989, On the seismicity and seismic hazard of Sofia valley, Proc. Of the 4th Int. Symposium on the Analysis of Seismicity and seismic risk, Bechyne castle, CSSR, IX, 1989, 448-454.

CSEE: Shebalin, N., Leydecker, G., Mokrushina, N. Tatevossian, R., Erteleva, O., Vassiliev, V., 1999, Earthquake Catalogue for Central and Southeastern Europe 342 BC - 1990 AD, European Commission, Report No. ETNU CT 93 - 0087.

Decanini, L., Gavarini, C. and Mollaioli, F., 1995, Proposta di definizione delle relazioni tra intensita' macrosismica e parametri del moto del suolo, Atti $70^{\circ}$ Convegno L'ingegneria sismica in Italia, 1, 63-72.

Decanini L. and Mollaioli, F., 1998, Formulation of Elastic Input Energy Spectra, Earthquake Engineering and Structural Dynamics, 27, 1503 1522.

Ding, Z., Chen, Y. and Panza, G.F., 2002b, Estimation of Site Effects in Beijing City, submitted to PAGEOPH.

Ding, Z., Romanelli, F., Chen, Y. and Panza, G.F., 2002a, Realistic modeling of seismic strong ground motion in Beijing area, submitted to PAGEOPH.

Dziewonsky A. M., Ekstrom, G., Woodhouse, J. H. and Zwart, G., 1991, Centroid moment tensor solutions for April-June 1990, Physics of the Earth and Planetary Interiors, 66, 133 - 143.

Elgamal, A.W., Amer, M., Adalier, K. and Abdul-Fadl, A., 1993, Engineering aspect of the October 12, 1992 Egyptian Earthquake, Technical report NCEER 91-7000B, National center for earthquake engineering research, State University of New at Buffalo, USA.

El-Sayed, A., Arvidsson, R. and Kulhanek, O., 1999, The 1992 Cairo earthquake - A case study of small destructive event, Journal of Seismology, 2, 1-10.

El-Sayed, A., Romanelli, F. and Panza, G., 2000, Recent seismicity and realistic waveforms modeling to reduce the ambiguities about the 1303 seismic activity in Egypt. Tectonophysics, 328, 341-357.

Eurocode 8, 1994, Basis of design and actions on structures, CEN 1994.

Evlogiev J., 1993, Paleogeography and stratigraphy of the Early Pleistocene in Peridanube Northeast Bulgaria, PhD thesis, pp. 200; Sofia (in Bulgarian).

Evlogiev J., Karachorov, P., Boikova, A. and Shanov, S., 2000, Seismogeological Settings of the Town of Rousse, 5th I. S. on Environmental Geotechnology and Global Sustainable Development, Belo Horizonte - Minas Gerais, 2000, Brazil - August 17-23, 2000, COD 173, ID 099.

Fäh, D., 1991, Stima del moto sismico del suolo in bacini sedimentari, Tesi di dottorato, tutor: G. F. Panza, Trieste University.

Fäh, D., 1992, A hybrid technique for the estimation of strong ground motion in sedimentary basins. Ph.D. Thesis n. 9767, Swiss Federal Institute of Technology, Zurich.

Fäh, D., Iodice, C., Suhadolc, P. and Panza G.F., 1993b, A New Method for the Realistic Estimation of Seismic Ground Motion in Megacities: the Case of Rome, Earthquake Spectra, 9, 643-668. 
Fäh, D., Suhadolc, P., Mueller, St. and Panza, G.F., 1994, A hybrid method for the estimation of ground motion in sedimentary basins: quantitative modeling for Mexico City, Bull. Seism. Soc. Am., 84, 383-399.

Fäh, D., Suhadolc, P. and Panza, G.F., 1990, Estimation of Strong Ground Motion in Laterally Heterogeneous Media: Modal Summation-Finite Difference, Proc. of the 9th European Conference of Earthquake Engineering, Moscow, 11-16 Sept, 1990, 4A, 100-109.

Fäh, D., Suhadolc, P. and Panza, G.F., 1993a, Variability of seismic ground motion in complex media: the Friuli area (Italy), In: R. Cassinis, K. Helbig and Panza, G.F. eds., Geophysical Exploration in Areas of Complex Geology, II, J. Appl. Geophys., 30, 131-148.

Field, E.H., the SCEC Phase III Working Group, 2000, Accounting for site effects in probabilistic seismic hazard analyses of Southern California: overview of the SCEC Phase III report, Bull. Seism. Soc. Am., 90, S1S31.

Florsch, N., Fäh, D., Suhadolc, P. and Panza, G.F., 1991, Complete synthetic seismograms for high-frequency multimode $\mathrm{SH}$-waves, PAGEOPH, 136, $529-560$.

Frangov, G., 1995, Assessment of the conditions and factors, determining the geological hazards at the Sofia kettle, Rep. To CGMR, 164p (in Bulgarian)

G.S.I., 1997, Contribution of Geological Survey of India in Delhi area - a resume, $1-41$.

Gao, W. and Ma, J., 1993, Seismo-geological surroundings and seismic hazards in Capital area, Seismological Press, Beijing.

Girardin, N., Hatzfeld, D. and Guiraud, R., 1977, La sismicité du Nord de l'Algerie, C. R. somm. Soc. géol. France, 2, ,95-100.

Glavcheva, R., Georgiev, Tz., Botev, E., Babachkova, Bl. and Toteva, T., 1996, Sofia graben and the earthquake of December 14 1995, Bulgarian Geophysical Journal, 22, 44-50.

Gorshkov, A., Kuznetsov, I., Panza, G.F. and Soloviev, A.A., 2000, Identification of future earthquake sources in the Carpatho-Balkan orogenic belt using morphostructural criteria. PAGEOPH, 157, 79-95.

Gorshkov, A.I., Panza, G.F., Soloviev, A.A. and Aoudia A., 2002, Morphostructural zonation and preliminary recognition of seismogenic nodes around the Adria margin in peninsular Italy and Sicily, JSEE, 3, 1-24.

Grandjean, A., 1954, Séismes d'Algérie de 1940 á 1950 inclus, Ann. Inst. phys. Globe, Strasbourg, 3 éme partie, Géophysique, VII, 83 (Le Puy).

Group of results of deep geophysical prospecting, 1986, State Seismological Bureau, Results of Deep Exploration of the Crust and Upper Mantle of China, Seismological Press, Beijing.

Gusev, A.A., 1983, Descriptive statistical model of earthquake source radiation and its application to an estimation of short-period strong motion, Geophys. J. R. Astr. Soc., 74, 787-808.

Harkrider, D.G., 1970, Surface waves in multilayered elastic media. Part II. Higher mode spectra and spectral ratios from point sources in plane layered Earth models, Bull. Seism. Soc. Am., 60, 6, 1937-1987.

Haskell, N.A., 1953, The dispersion of surface-waves on multilayered media, Bull. Seism. Soc. Am., 43, 17-34.

Hée, A., 1950, Catalogue des séismes algériens de 1850 á 1911, Ann. Inst. Phys. Globe, Strasbourg, 6, 41-49.

Herak, M., Lokmer, I., Vaccari, F. and Panza, G. F., 2002, Amplification of horizontal strong ground motion in Zagreb (Croatia) for realistic earthquake scenarios, PAGEOPH, (submitted for publication).

Ishihara, K., chairman, 1993, The Technical Committee for earthquake Geotechnical Engineering (TC-4) of the International Society for Soil Mechanics and Foundation Engineering, Manual for Zonation on Seismic Geotechnical Hazards, The Japanese Society of Soil Mechanics and Foundation Engineering, 145 pp.

Ivanov, Pl., Frangov, G. and Yaneva, M., 1998, Engineering geological characteristics of Quaternary sediments in the Sofia graben, Proc. 3rd WG Meeting, Dec. 2-5, 1998, Sofia, 33-37.

Iyengar, R.N., 2000, Seismic status of Delhi megacity, Current Science, 78, 568-574.

JICA, Japan International Cooperation Agency (JICA), 1993, Report of Japan Disaster relief team on the earthquake in Arab Republic of Egypt of October 12, 1992, 88pp.

Kamenov, B. and Kojumdjieva, N., 1983, Stratigraphy of the Neogene in Sofia Basin. Paleontology, stratigraphy and lithology, 18, 69-85.

Kelly, K.R., Ward, R.W., Treitel, S. and Alford, R.M., 1976, Synthetic seismograms: A finite difference approach, Geophysics, 41, 2-27.

Kossobokov V.G., 1983, Recognition of the sites of strong earthquakes by Hamming's method in East Central Asia and Anatolia, In: Computational Seismology (eds. V.I. Keilis-Borok and A.L. Levshin) Iss.14. Allerton Press Inc., New York., 78-82.

Kouteva, M., Panza, G. F. and Paskaleva, I., 2000, An example for ground motions in connection with Vrancea earthquakes (case study in EN Bul- garia, Russe site), 12 WCEE 2000, Auckland, New Zealand, 30 Jan.-4 Feb, 2000, Ref.2185, on CD.

Kouteva M., Panza, G.F., Paskaleva, I. and Romanelli, F., 2001, Modeling of the Ground Motion at Russe site (NE Bulgaria) due to Vrancea Earthquakes, IC/2001/145 (submitted to JEE).

Langston, C.A., 1979, Structure under Mount Rainier, Washington, inferred from teleseismic body waves, J. Geophys. Res., 84, 4749-4762.

Levander, A.R., 1988, Fourth-order finite-difference P-SV seismograms, Geophysics, 53, 1425-1436.

Levshin, A., Ratnikova, L. and Berger, J. 1992, Peculiarities of surface wave propagation across Central Eurasia. Bull. Seism. Soc. Am., 82, 2464-2493.

Maouche, S., 2001, Etude sismotectonique dans l'Algérois et les zones limitrophes de Cherchell-Gouraya, Magister Thesis, FSTGAT/USTHB, Alger.

Maouche, S., Benouar, D., Harbi, A. and Benhallou, H., 1998, The Algiers (Algeria) earthquake of 4 September 1996, Europ. Earth. Engi., 1, 51-55.

Maouche, S. and Haddoum, A., 2001, La sismicité de l'Algérois: aspect tectonique, Procceding du 11Ëme Séminaire National des Sciences de la Terre, Tlemcen, 28-30 Octobre, 2001.

Markusiic, S., Suhadolc, P., Herak, M. and Vaccari, F., 2000, Contribution to Seismic Hazard Assessment in Croatia from Deterministic Modeling, PAGEOPH, 157, 185-204.

Matova, M., 2001, Recent manifestations of seismotectonic activity in Sofia region and their land subsidence potential. Proc. Final Conf. of UNESCO -BAS Project on land subsidence, June 27-30, 2001, Sofia, pp.93-98.

Medina, A., Escobar, E., Ortíz, G. Ramírez, M., Díaz, L., Móndelo, F., Montejo, N., Diéguez, H., Guevara, T. and Acosta, J., 1999, Reconocimiento geólogo-geofísico de la cuenca de Santiago de Cuba, con fines de riesgo sİsmico. Empresa Geominera de Oriente, Santiago de Cuba, 32 pp., graphic annexes.

Medvedev, S.V., 1977, Seismic Intensity Scale MSK - 76, Publ. Inst. Geophys. Pol. Acad. Sc. 117, 95-102.

Meghraoui, M., 1988, Géologie des zones sismiques du nord de l'Algérie: Paléosismologie, Tectonique Active et Synthèse Sismotectonique, Thèse de Doctorat es Sciences, Université de Paris sud, Centre d'Orsay, 356 pp.

MLPAT, 1997, Cod de projetare pentru struturi in cadre de beton armat, NP 007-97, Bul. Constr. No 10, Bucharest: MLPAT.

Mokrane, A., Ait Messaoud, A., Sebai, A., Ayadi, A., Bezzeghoud, M. and Benhallou, H., 1994, Les séismes en Algérie de 1365 - 1992, Publication du Centre de Recherche en Astronomie, Astrophysique et Géophysique, Département: Etudes et Surveillance Sismique, ESS, C.R.A.A.G, AlgerBouzaréah, 277 pp.

Moldoveanu, C.L., Marmureanu, G., Panza, G.F. and Vaccari, F., 2000, Estimation of site effects in Bucharest, caused by the May 30-31, 1990, Vrancrea seismic events, PAGEOPH, 157, 249-267.

Moldoveanu, C.L. and Panza, G.F., 1999, Modeling for microzanation purposes, of the seismic ground motion in Bucharest, due to Vrancrea earthquake of May 30, 1990, In: F. Wenzel, D. Lungu and O. Novak eds. Vrancea Earthquakes: Tectonics, Hazard and Risk Mitigation 85-97, Kluwer Academy Publishers.

NEIC: National Earthquake Information Center, http://wwwneic.cr.usgs.gov/neis/epic/epic_global.html

Nenov D., Georgiev G., Paskaleva I., V. W. Lee and Trifunac, M. D., 1990 Strong ground motion data in EQINFOS: accelerograms recorded in Bulgaria between 1981-1987, Bulgarian Academy of Sciences, Central Lab. For Seismic Mechanics and Earthquake Engineering \& Dept. of Civil engineering, Dpt. No 90-02, University of South. California, Los Angeles, California.

Norma Cubana, 1999, Propuesta de nueva norma cubana sismorresistente, 110 pp., (Draft).

Nunziata, C., Costa, G., Marrara, F. and Panza, G.F., 2000, Validated estimation of the response spectra for the 1980 Irpinia earthquake in the eastern area of Naples, Earthquake Spectra, 16, 643-660.

Nunziata, C., Costa G., Natale M. and Panza, G.F., 1999b, FTAN and SASW methods to evaluate Vs of neapolitan pyroclastic soils, Earthquake Geotechnical Engineering, Balkema, I, 15-19.

Nunziata, C., Mele, R. and Natale, M., 1999a, Shear wave velocities of the Campi Flegrei- Neapolitan deposits and the primary influencing factors Engineering Geology, 54, 299-312.

Nunziata, C. and Panza, G.F., 2002, A contribution to the microzoning of Naples, Mem. Soc. Geol. It. (in press)

Orihuela, N. and Cuevas, J. L., 1993, Modelaje sismogravimétrico de perfiles regionales del Caribe central, Revista Ingeniería, Universidad Central de Venezuela, 8, 55-73.

Panza, G.F., 1981, The resolving power of seismic surface wave with respect to crust and upper mantle structural models. In: R. Cassinis ed., The solu- 
tion of the inverse problem in Geophysical Interpretation,Plenum press, $39-77$.

Panza, G.F., 1985, Synthetic seismograms: The Rayleigh waves modal summation, J. Geophysics, 58, 125-145.

Panza, G.F., 1993, Synthetic Seismograms from Multimode Summation Theory and Computational Aspects, Acad. Geod. Geoph. Mont. Hung., 28, 197-247.

Panza, G.F., Cioflan, C., Kouteva, M., Paskaleva, I., Romanelli, F. and Marmureanu, G., 2002, An Innovative Assessment of the seismic hazard from Vrancea Intermediate-Depth Earthquakes: Case Studies in Romania and Bulgaria, 12th European Conference on Earthquake Engineering, Paper Reference 230, Elsevier.

Panza, G.F., Romanelli, F. and Vaccari, F., 1999a, The IUGS-UNESCO IGCP Project 414: Realistic modeling of Seismic Input for Megacities and Large Urban Areas, Episodes, 22, 26-32.

Panza, G.F., Romanelli, F. and Vaccari, F., 2000, Seismic wave propagation in laterally heterogeneous anelastic media: theory and applications to the seismic zonation, Advances in Geophysics, Academic Press, 43, 1-95.

Panza, G.F. and Suhadolc, P., 1987, Complete strong motion synthetics, In: B. A. Bolt, ed., Seismic Strong Motion Synthetics, Computational Techniques, 4, , Academic Press, Orlando, 153-204.

Panza, G.F. and Vaccari F., 2000, Introduction, In: G. F. Panza, M. Radualian and C. Trifu, eds., Seismic Hazard of the Circum-pannonian Region, Pageoph Topical Volumes, 157, Birkhauser Verlag, 5-10.

Panza, G.F., Vaccari, F. and Cazzaro, R., 1999b, Deterministic seismic hazard assessment, In: F. Wenzel, D. Lungu and O. Novak, eds., Vrancea Earthquakes: Tectonics, Hazard and Risk Mitigation, 269-286, Kluwer Academy Publishers.

Panza, G.F., Vaccari, F. and Romanelli, F., 2001, Realistic Modeling of Seismic Input in Urban Areas: A UNESCO-IUGS-IGCP Project, PAGEOPH, 158, 12, 2389-2406.

Paskaleva, I., Kouteva, M., Panza, G. F., Evlogiev, J., Koleva, N. and Ranguelov, B., 2001, Deterministic approach of seismic hazard assessment in BG, Case study NE Bulgaria - the town of Russe. In Proc. of the Workshop on Deterministic Approach of Seismic Zonation of Some Balkan Countries, Tirana, Albania, April, 2001: 51-73.

Paskaleva, I., Matova, M., Frangov, G. and Panza, G.F., 2002, Expert assessment of displacements provoked by seismic events: case study for the city of Sofia, submitted to PAGEOPH.

Pavlov O.Y., 1984, Seismic microzoning (in Russian), Moscow, Nauka.

Pérez, C. and García, D., 1997, Tectónica de la Sierra Maestra (Sureste de Cuba), In: Furrazola, G. and Núnez, K, Centro, eds., Estudios sobre Geología de Cuba, Nacional de Información Geológica, Instituto de Geología y Paleontología, La Habana, pp. 462-473.

Petkov I, Christoskov L., 1964, On the seismicity in the region of the town of Sofia concerning the macroseismic zoning, Ann. Sofia Univ., 58,163-179

Petrov, P. and Iliev, I., 1970, The effect of engineering geological conditions on seismic microzoning in Sofia, Proc. Of the 3rd Eur. Symposium on EE, Sofia, Sept. 14-17, pp.79-86.

Pico, R., 1999, Determinación del umbral de semejanza (0 para los algoritmos de agrupamiento lógico-combinatorios, mediante el dendrograma de un algoritmo jerárquico, SIARP'99, IV Simposio Iberoamericano de Reconocimiento de Patrones, Memorias, pp. 259-265.

Pitilakis, K., B. Margaris, V. Lekidis, N. Theodoulidis and A. Anastasiadis 1992. The Griva, northern Greece, earthquake of December 21, 1990, seismological, structural and geotechnical aspects, J. of Eur. Earthq. Eng. 2, 20-35.

Rantsman E.Ya., 1979, Morphostructure of mountain regions and sites of earthquakes, Nauka, Moscow (In Russian).

Raptakis, D., 1995, Contribution to the determination of the geometry and the dynamic properties of soil formations and their seismic response, Ph.D Thesis (in Greek), Dept. of Civil Eng., Aristotle Univ. of Thessaloniki.

Radualian, M., Vaccari, F., Mandrescu, N., Panza, G.F. and Moldoveanu, C., 2000, Seismic Hazard of Romania: Deterministic Approach. In Panza G. F, Radulian M, Trifu C. I, (eds.): Seismic Hazard of the Circum-Pannonian Region. Pageoph Topical Volumes, Basel: Birkhauser Verlag, 2000: 221-248.

Romanelli, F., Bekkevold, J. and Panza, G. F., 1997, Analytical computation of coupling coefficients in non-poissonian media. Geophys. J. Int., 129, p. 205-208.

Romanelli, F., Bing, Z., Vaccari, F. and Panza, G.F., 1996, Analytical Computations of Reflection and Transmission Coupling Coefficients for Love Waves, Geophys. J. Int, 125, 132-138.

Romanelli, F., and Vaccari, F., 1999, Site response estimation and ground motion spectral scenario in the Catania Area, J. of Seism., 3, 311-326.

Ruiz, J., Pico, R., López, R., Alaminos, C., Lazo, M., Baggiano, M., Barreto, E., Santana, A.; Alvarez, L. and Chuy, T., 1992), PROGNOSIS y sus aplicaciones a las geociencias, In IBERAMIA-92, III Congreso Iberoamericano de Inteligencia Artificial, MEMORIAS. México, LIMUSA, pp. 561-586.

Said, R., 1981, The River Nile, Springer Verlag, New York, USA.

Schwab, F., 1970, Surface-wave dispersion computations: Knopoff's method, Bull. Seism. Soc. Am., 60, 1491-1520.

Schwab, F. and Knopoff, L., 1972, Fast surface wave and free mode computations, In Bolt B. A. ed Methods in Computational Physics, Vol.11, New York, Academic Press, 86-180.

Schwab, F., Nakanishi, K., Cuscito, M., Panza, G. F., Liang, G. and Frez, J., 1984, Surface-wave computations and the synthesis of theoretical seismograms at high frequencies, Bull. Seism. Soc. Am., 74, 1555-1578.

Sebaï, A., 1997, Analyse sismologique des séismes récents du Sahel d'Alger, Magister thesis, IST-USTHB, Alger, $178 \mathrm{pp}$.

Shanov, S., Spassov, E. and Georgiev, T., 1992, Evidence for the existence of a paleosubduction zone beneath the Rhodopean massif (Central Balkan), Tectonophysics, 206, 307-314.

Slavov, S1., Vaccari, F., Paskaleva, I. Kouteva, M. and Panza, G.F. (2002) Deterministic earthquake scenarios for the city of Sofia, submitted to PAGEOPH.

Sponheuer W., 1960, Methoden zur Herdtiefenbestimmung in der Makroseismik, Freiberger Forschungshefte, C88. Berlin: Akademie Verlag.

Sun, R., Vaccari, F., Marrara, F. and Panza, G.F., 1998, The main features of the local geological conditions can explain the macroseismic intensity caused in Xiji-Langfu (Beijing) by the MS=7.7 Tangshan 1976 earthquake, PAGEOPH, 152, 507-521.

Szeidovitz, Gy., 2000, Êrmelléki földrengések (Earthquakes in Êrmelléki area), Magyar Geofizika 41, Êvf. 2. Sz.

Szeidovitz, Gy. and Gribovszki, K., 2002, Az Êrmelléki földrengések epicentr-lis területének földtani szerkezete, geomorfológiai, geodéziai, geofizikai és egyéb sajátosságai (Geological structure and geomorphological, geodetic and geophysical features of the epicentral area of the Êrmelléki region), Magyar Geofizika, in press.

Thomson, W. T., 1950, Transmission of elastic waves through a stratified solid medium, J. Appl. Phys., 21, 89-93.

Todorovska M, Paskaleva I. and Glavcheva R., 1995, Earthquake source parameters for seismic hazard assessment: examples in Bulgaria, In Proc. of the X ECEE, Vienna, Austria.

Triantafyllidis, P., Hatzidimitriou, P. M., Suhadolc P., Theodulidis, N. and Anastasiadis, A., 2002b. PART II: Comparison of theoretical and experimental estimations of site effects. Submitted to PAGEOPH.

Triantafyllidis, P., Hatzidimitriou, P.M., Theodulidis, N., Suhadolc, P., Papazachos, C., Raptakis, D. and Lontzetidis, K., 1999, Site effects in the city of Thessaloniki (Greece) estimated from acceleration data and 1-D local soil profiles, Bull. Seism. Soc. Am. 89, 521-537.

Triantafyllidis, P., Suhadolc P. and Hatzidimitriou, D., 2002a. PART I: Theoretical site response estimation for microzoning purposes, Submitted to PAGEOPH.

Triantafyllidis, P., Suhadolc P. and Hatzidimitriou, D., 2002c. Influence of source on 2-D site effects, Geophys. Res. Lett., in press.

Uang, C. M. and Bertero, V. V., 1990, Evaluation of seismic energy in structures. Earthquake Engineering and Structural Dynamics, 19, 77-90.

Vaccari, F., Gregersen, S., Furlan, M. and Panza, G.F., 1989, Synthetic Seismograms in Laterally Heterogeneous, Anelastic Media by Modal Summation of the P-SV Waves, Geophys. J. Int., 99, 285-295.

Vaccari, F., Nunziata, C., Fäh, D. and Panza, G.F., 1995. Reduction of seismic vulnerability of megacities: the cases of Rome and Naples. Proc. Fifth Int. Conf. Seismic Zonation, 1392-1399, AFPS-EERI, Ouest Editions Presses Académiques.

Valyus, V.P., Keilis-Borok, V.I. and Levshin, A.L., 1968, Determination of the velocity profile of the upper mantle in Europe. Nauk SSR, 1, 185 (8): 564-567.

Van der Hilst, R. D., 1990, Tomography with P, PP and pP delay-time data and the three-dimensional mantle structure below the Caribbean region, $\mathrm{Ph} . \mathrm{D}$. Thesis, University of Utrecht.

Virieux, J., 1984, SH-wave propagation in heterogeneous media: velocitystress finite-difference method, Geophysics, 49, 1933-1957.

Virieux, J., 1986, P-SV wave propagation in heterogeneous media: velocitystress finite-difference method, Geophysics, 51, 889-901.

Xie, Y., 1957, A new scale of seismic intensity adapted to the conditions in Chinese territories, Acta Geophysica Sinica, 6, 35-48 
The corresponding address of authors is as follows:

${ }^{1}$ The Abdus Salam International Center for Theoretical Physics, SAND Group, Mirarmar, Trieste, Italy.

${ }^{2}$ Department of Earth Sciences, University of Trieste, Via E. Weiss 1, 34127 Trieste, Italy.

${ }^{3}$ Centro Nacional de Investigaciones Sismologicas, Cuba.

${ }^{4}$ Centre de Recherche en Astronomie, Astrophysique et Geophysique, BP. 63, Bouzaréah, Alger, Algérie.

${ }^{5}$ Faculté des Sciences de la Terre de l'Aménagment du Territoire et de la Geographie, USTHB, Alger, Algérie.

${ }^{6}$ University of Algiers (USTHB), Civil Engineering Dpt., Alger, Algeria.

${ }^{7}$ Hungarian Academy of Sciences, Seismological Observatory of GGRI, H-1112 Budapest, Meredek u. 18, Hungary.

${ }^{8}$ Institute of Geophysics, China Seismological Bureau, Beijing, 100081, China.

${ }^{9}$ National Institute for Earth Physics, Calugareni 12, P.O.Box: MG 2, 76900 Bucharest-Magurele, Romania.

${ }^{10}$ Department of Geology, Mansoura University, Mansoura, Egypt.

${ }^{11}$ Dipartimento Geofisica e Vulcanologia, Universitaí Federico II, Largo San Marcellino, 10-80138 Naples, Italy.

${ }^{12}$ International Institute of Earthquake Prediction Theory and Mathematical Geophysics, Russian Academy of Sciences, Moscow, Russia.

${ }^{13}$ Hungarian Academy of Sciences, Geodetic and Geophysical Research Institute H-9400, Sopron, Csatkai E. str. 6-8., Hungary.

${ }^{14}$ Aristotle University, Geophysical Laboratory, P.O.Box 111, GR54006 Thessaloniki, Greece.

${ }^{15}$ Department of Geophysics, Faculty of Science, University of Zagreb, Horvatovac bb, 10000 Zagreb, Croatia.

${ }^{16}$ Central Laboratory for Seismic Mechanics and Earthquake Engineering, BAS, Sofia.

${ }^{17}$ CSIR Centre for Mathematical Modeling and Computer Simulation (C-MMACS), NAL Belur Campus, Bangalore - 560 037, India.

${ }^{18}$ Instituto de Cibernetica, Matematica y Fisica, Cuba.

${ }^{19}$ INGV - Oss. Vesuviano, via Diocleziano 328, 80124 Naples, Italy.
Giuliano F. Panza is Professor of seismology in the Department of Earth Sciences at the University of Trieste, and is head of the SAND Group of the ICTP at Trieste. He received his Laurea in physics from the University of Bologna in 1967 and performed PoctDoc research at the UCLA University. He is fellow of Academia Nazionale dei Lincei, of Academia Europea, and of Third World Academy of Sciences. He is leader of several projects funded by EC related to seismic hazard assessment.

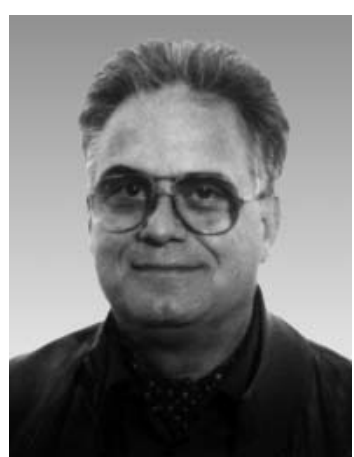

More effective prevention strategies would save not only tens of billions of dollars, but save tens of thousands of lives. Funds currently spent on intervention and relief could be devoted to enhancing equitable and sustainable development instead, which would further reduce the risk for war and disaster.

Building a culture of prevention is not easy. While the costs of prevention have to be paid in the present, its benefits lie in a distant future. Moreover, the benefits are not tangible; they are the disasters that did NOT happen.

\section{— from Kofi Annan, 1999 (document A/54/1)}

